

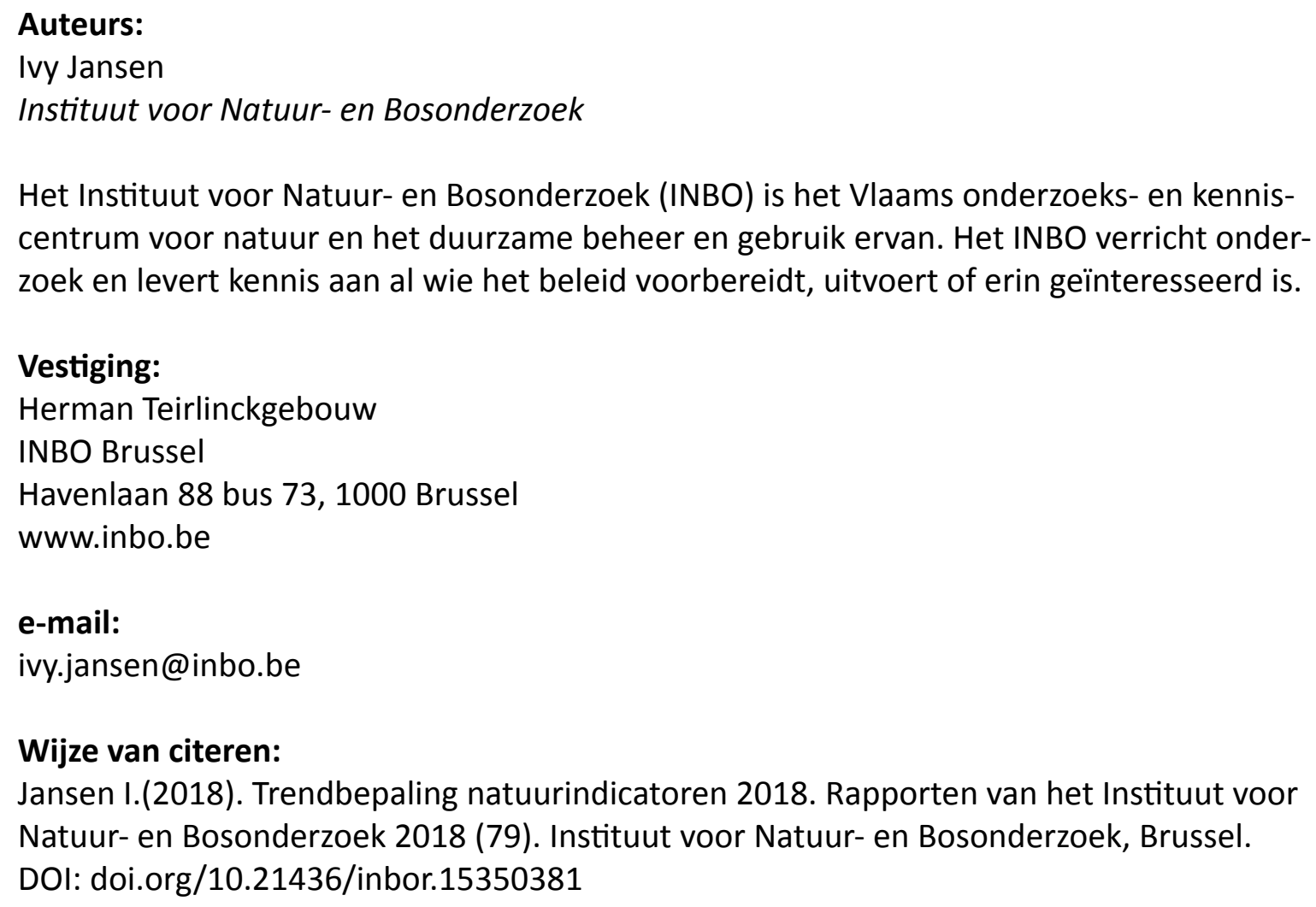

(C) 2018, Instituut voor Natuur- en Bosonderzoek 
INSTITUUT

NATUUR- EN

BOSONDERZOEK

\section{TRENDBEPALING NATUURINDICATOREN 2018}

Ivy Jansen

Rapporten van het Instituut voor Natuur- en Bosonderzoek 2018 (79)

doi.org/10.21436/inbor.15350381 D/2018/3241/281 


\section{Dankwoord}

Met medewerking van: Raf Bayens, Niko Boone, Lode De Beck, Geert De Knijf, Heidi Demolder, Lieven De Smet, Koen Devos, Caroline Geeraerts, Dirk Maes, Marijke Thoonen, Beatrijs Van der Aa, Wouter Van Landuyt en Jan Van Uytvanck. 


\section{Inhoudsopgave}

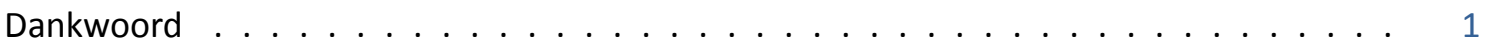

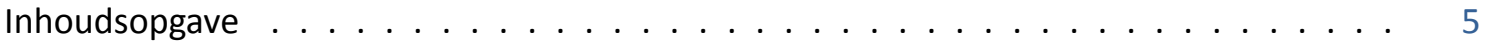

1 Introductie ......................... 6

2 Trendberekeningen ....................... 8

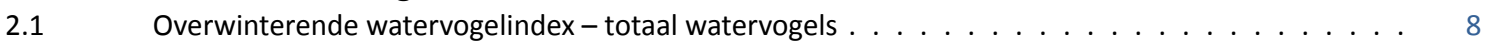

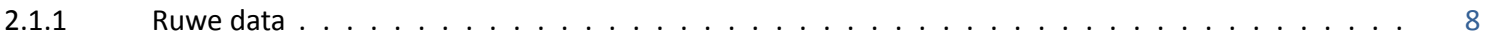

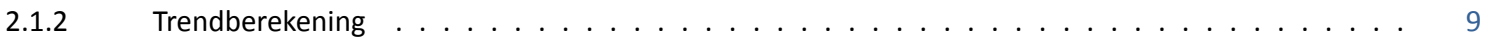

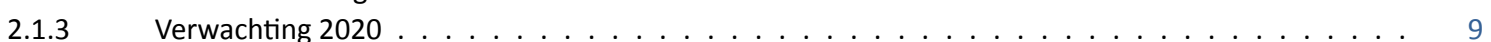

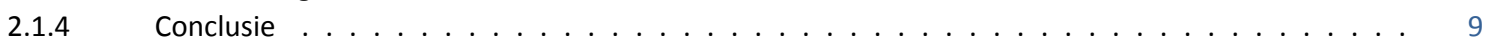

$2.2 \quad$ Soortbeschermingsplannen - aantal soortbeschermingsplannen . . . . . . . . . . . . . . 11

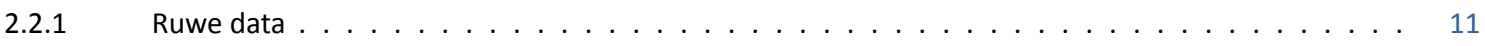

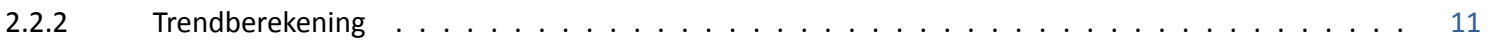

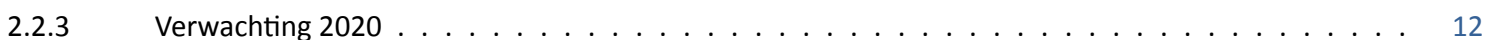

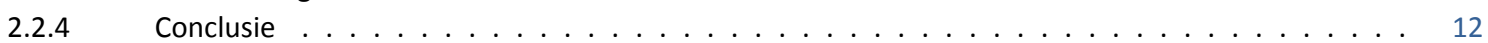

2.3 Gesaneerde vismigratieknelpunten (prioriteitsklasse 1) - aantal opgeloste knelpunten . . . . . 13

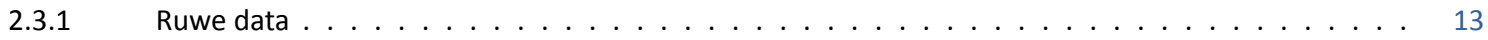

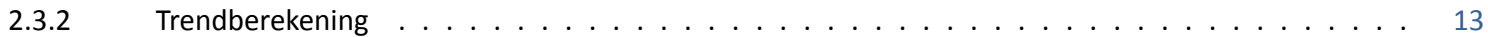

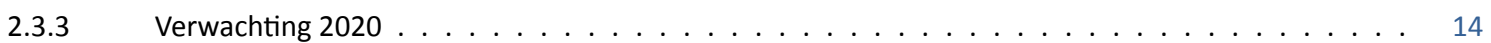

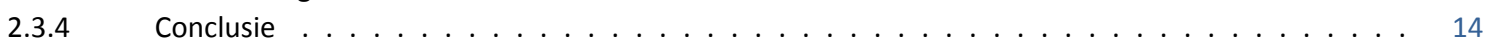

$2.4 \quad$ Oppervlakte met effectief natuurbeheer - totale oppervlakte effectief natuurbeheer . . . . . . . 15

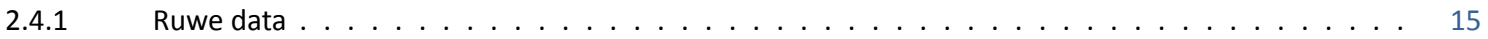

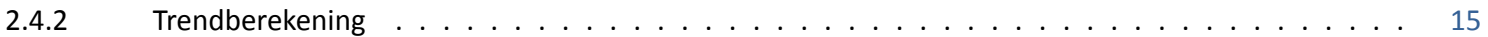

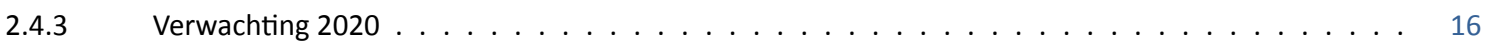

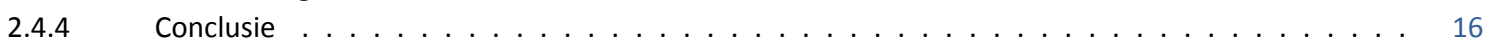

$2.5 \quad$ Verwerving natuurgebieden - oppervlakte Vlaamse overheid . . . . . . . . . . . . 17

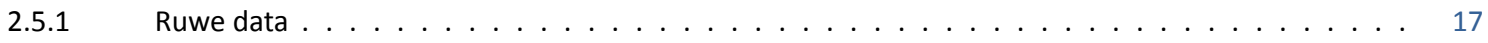

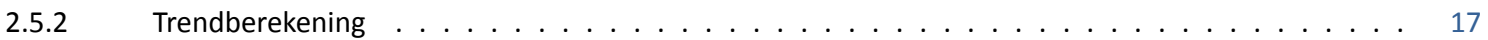

$2.5 .3 \quad$ verwachting $2020 \ldots \ldots \ldots \ldots \ldots \ldots \ldots \ldots$

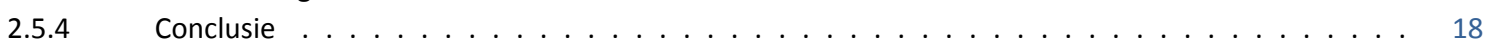

$2.6 \quad$ Verwerving natuurgebieden - oppervlakte terreinbeherende verenigingen . . . . . . . . . 19

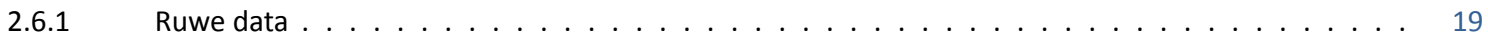

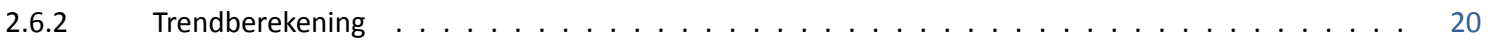

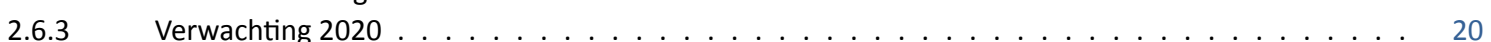

$2.6 .4 \quad$ Conclusie . . . . . . . . . . . . . . . . . . . . . . . . . . . 20

$2.7 \quad$ Verwerving natuurgebieden - eigen uitgaven Vlaamse overheid . . . . . . . . . . . . . . 21

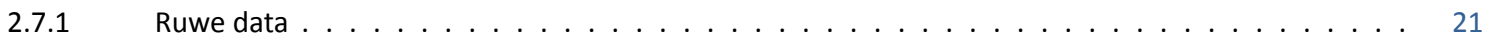

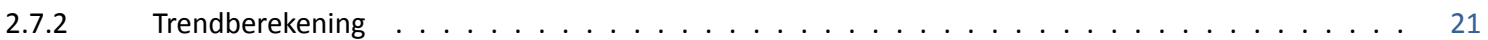

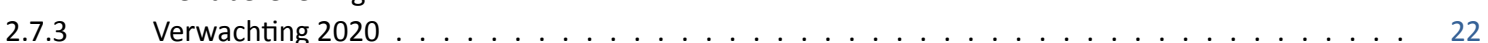

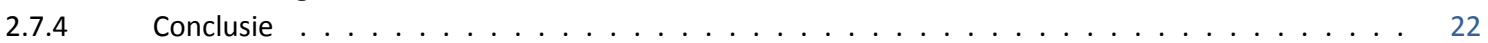

$2.8 \quad$ Verwerving natuurgebieden - subsidies aan verenigingen $\ldots \ldots \ldots \ldots \ldots$

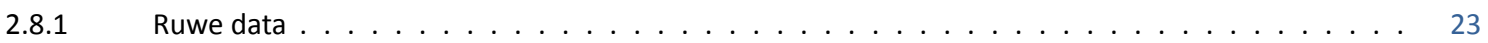

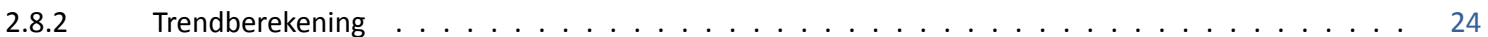

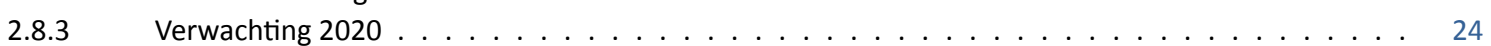

$2.8 .4 \quad$ Conclusie . . . . . . . . . . . . . . . . . . . . . . . . . . . . . . . . . . 24

$2.9 \quad$ Oppervlakte afgebakend VEN - totale oppervlakte afgebakend VEN . . . . . . . . . . . . . 25

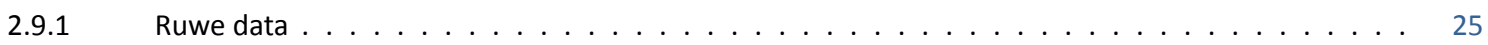

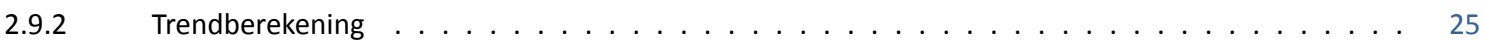


Oppervlakte afgebakend natuurverwevingsgebied - totale oppervlakte afgebakend natuurverwev-

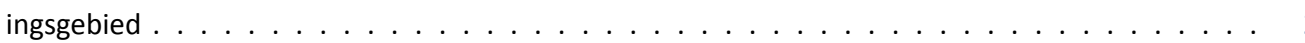

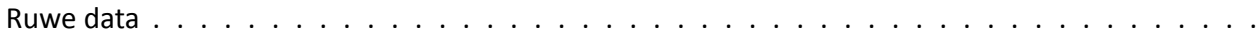

Trendberekening

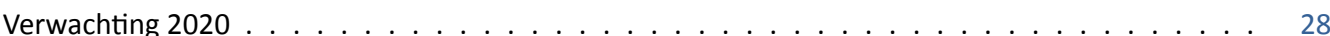

2.10 .3

Oppervlakte aandeel toegankelijke bossen - totale oppervlakte toegankelijke bossen . . . . . . . 29

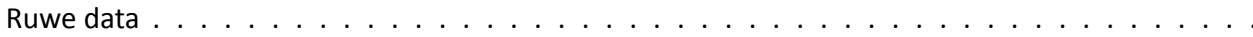

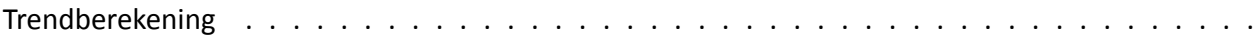

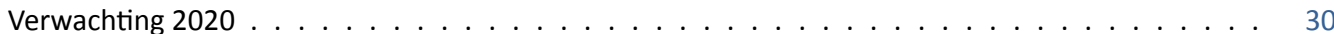

2.11 .3

2.11.4

forve speelzones in bossen en natuurreservaten - totale oppervlakte speelzones . . . . .

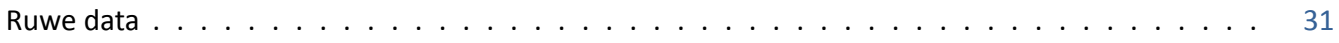

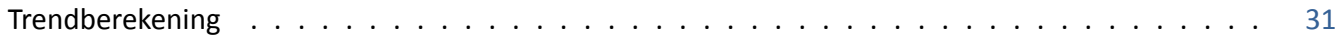

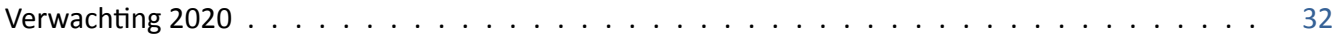

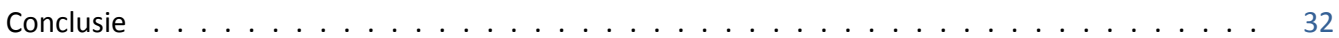

Trend Zuid-Europese libellensoorten - aantal soorten $\ldots \ldots \ldots 33$

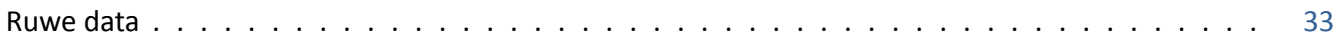

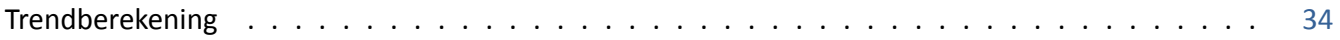

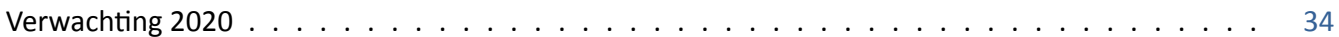

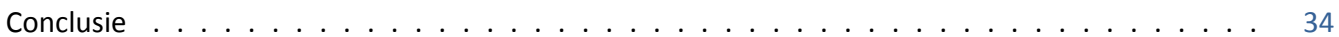

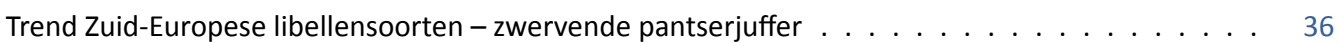

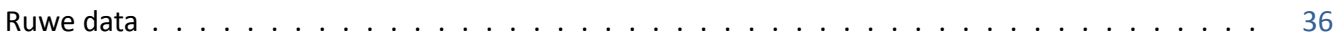

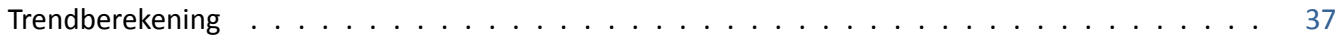

Verwachting $2020 \ldots \ldots \ldots \ldots \ldots$

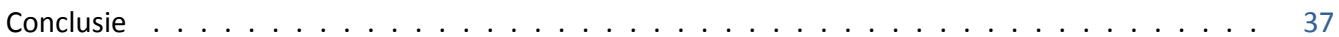

Trend Zuid-Europese libellensoorten - gaffelwaterjuffer . . . . . . . . . . . . . . . . . 39

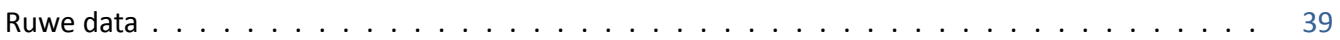

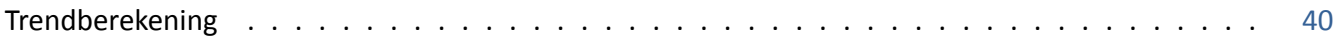

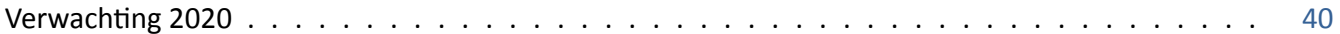

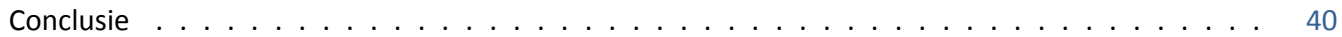

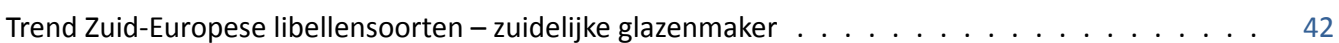

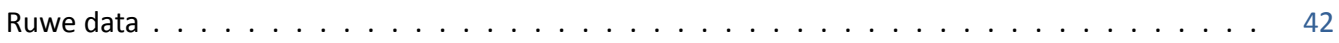

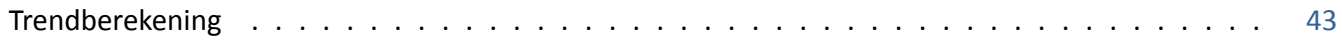

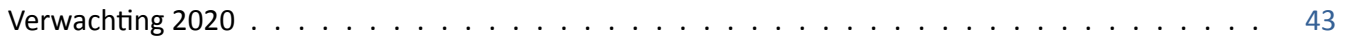

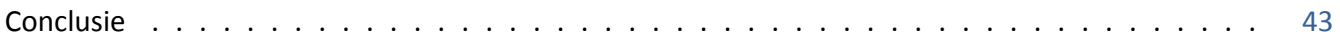

Trend Zuid-Europese libellensoorten -zadellibel $\ldots \ldots \ldots \ldots \ldots$

Ruwe data . . . . . . . . . . . . . . . . . . . . . . . . . . 45

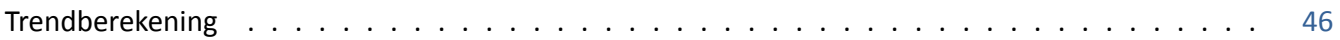

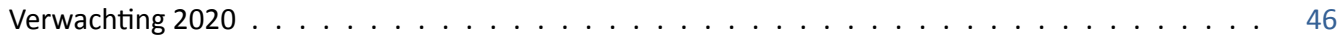

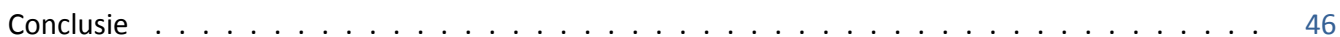

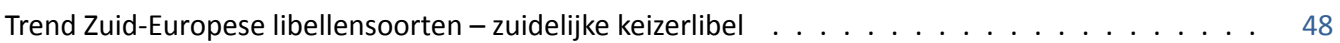

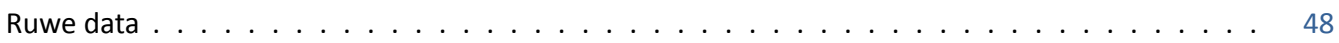

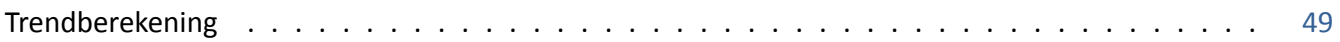

Verwachting $2020 \ldots \ldots \ldots$. . . . . . . . . . . . . . . . . . . 49

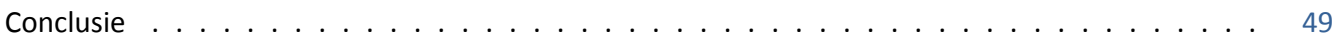

Trend Zuid-Europese libellensoorten - vuurlibel $\ldots \ldots \ldots \ldots$

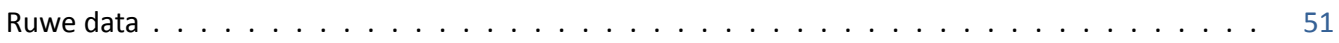

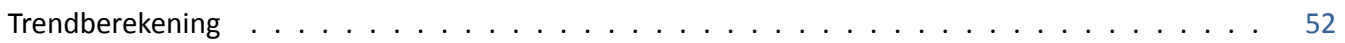

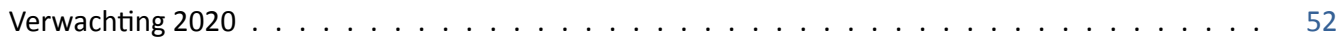

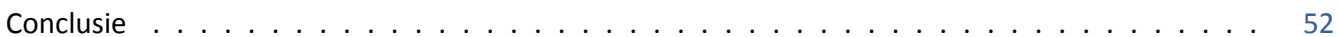

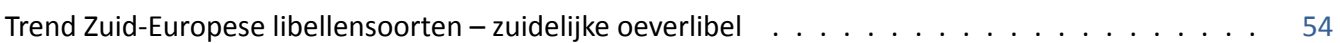

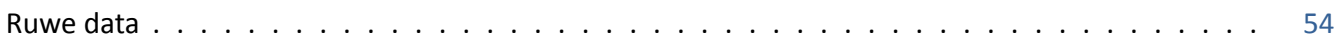

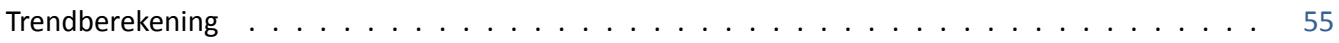

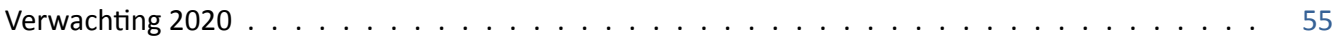

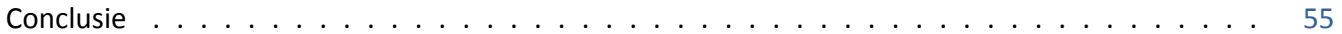

Trend Zuid-Europese libellensoorten -zuidelijke heidelibel $\ldots \ldots \ldots \ldots$

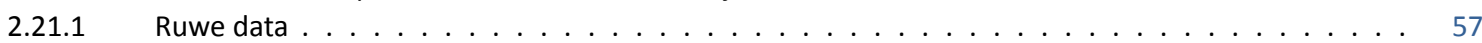


Trend Zuid-Europese libellensoorten - zwervende heidelibel . . . . . . . . . . . . . . . . . 60

Trendberekening

Verwachting 2020 
Oppervlakte gerealiseerde natuurinrichtingsprojecten - totale oppervlakte uitgevoerde projecten .

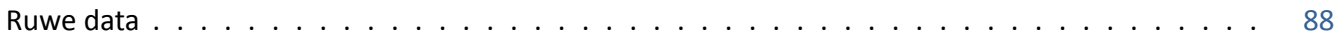

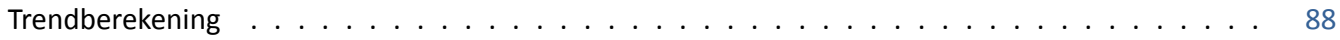

Verwachting $2020 \ldots \ldots \ldots \ldots$

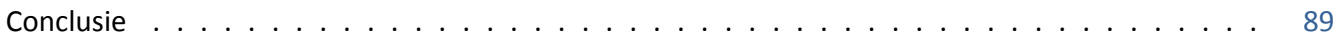

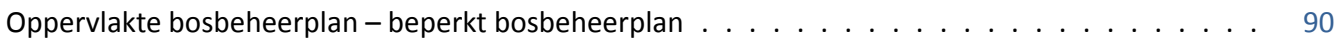

Ruwe data . . . . . . . . . . . . . . . . . . . . . . . . . . . 90

2.35 .2

2.35 .3

2.35 .4

Trendberekening

Verwachting 2020

Conclusie

Oppervlakte bosbeheerplan - uitgebreid bosbeheerplan . . . . . . . . . . . . . . . 92

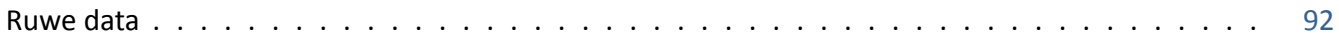

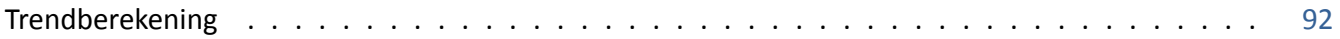

Verwachting $2020 \ldots \ldots \ldots \ldots$

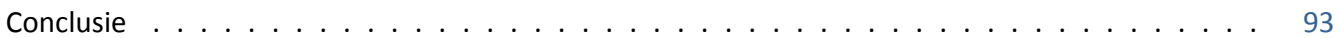

Oppervlakte beheerovereenkomsten - botanisch beheer $\ldots \ldots \ldots$. . . . . . . . . . . 94

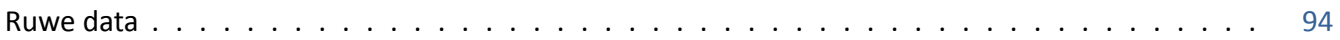

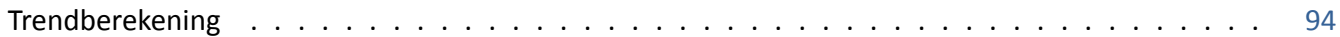

Verwachting $2020 \ldots \ldots \ldots \ldots$

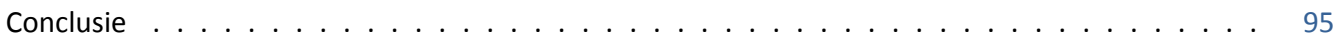

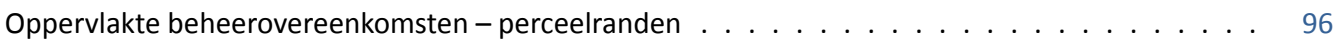

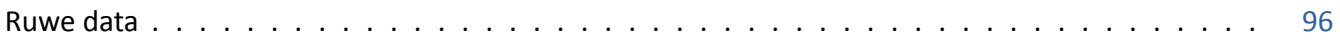

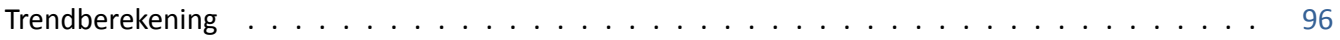

Verwachting $2020 \ldots \ldots \ldots \ldots$

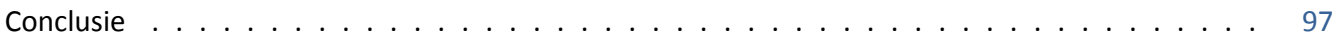

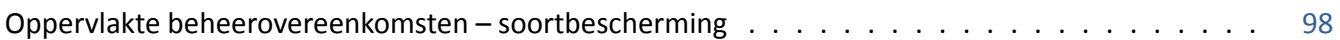

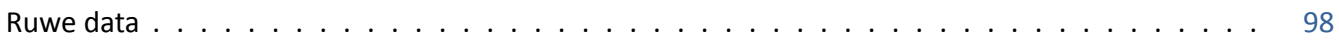

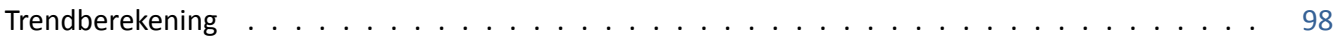

Verwachting $2020 \ldots \ldots \ldots$

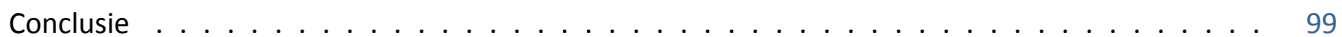

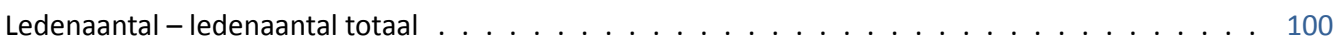

Ruwe data . . . . . . . . . . . . . . . . . . . . . . . 100

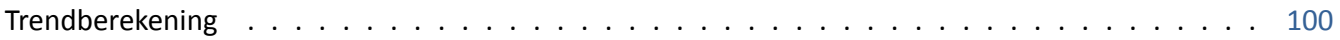

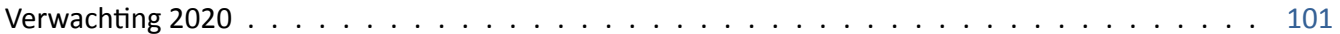

2.40 .4 Conclusie . . . . . . . . . . . . . . . . . . . . . . . . . . . . . . . 101 


\section{INTRODUCTIE}

De NARA natuurindicatoren kunnen in 3 grote groepen onderverdeeld worden op basis van de gemeten eenheid:

1. aantallen (Poisson verdeelde gegevens)

2. percentages (binomiaal verdeelde gegevens)

3. oppervlakte, lengte, index (normaal verdeelde gegevens)

Voor elk type indicator is een andere aanpak van de trendberekening noodzakelijk:

1. $Y=$ aantal

Poisson regressie

$$
\log (Y)=a+b X
$$

2. $Y=1$ (succes) of $Y=0$ (faling), met $\pi=P(Y=1)=$ kans op succes Logistische regressie

$$
\operatorname{logit}(\pi)=\log \left(\frac{\pi}{1-\pi}\right)=a+b X
$$

3. $Y=$ continue variabele (normaal verdeeld)

lineaire regressie

$$
Y=a+b X+\epsilon
$$

of kwadratische regressie

$$
Y=a+b X+c X^{2}+\epsilon
$$

of kubische regressie

$$
Y=a+b X+c X^{2}+d X^{3}+\epsilon
$$

of exponentiële regressie

$$
\log (Y+1)=a+b X+\epsilon
$$

waarbij telkens $X=$ Jaartal. In het derde geval wordt op basis van statistische testen het beste model geselecteerd.

Voor grote aantallen (zoals Ledenaantal) is het niet noodzakelijk om een Poisson regressie uit te voeren, maar kan in vele gevallen een normale benadering gebruikt worden, en kunnen we overschakelen naar de derde methode.

Omdat voor bepaalde indicatoren het gekozen model een te sterke vereenvoudiging lijkt van de werkelijke trend, bekijken we ook het model met een smoother doorheen de tijd.

$$
f(Y)=a+s(\text { Jaartal }, k)+\epsilon
$$

waarbij het aantal knopen $k$ wel beperkt wordt tot het minimum van 4 en het aantal observaties gedeeld door 2, om te vermijden dat er oversmoothing optreedt. Een optimalisatiemethode bepaalt uiteindelijk het aantal vrijheidsgraden (edf) voor deze smoother. Ook voor de smoother kiezen we de gepaste verdeling voor de respons via de link-functie $f$ (log-link voor Poisson, logit-link voor binomiaal, identity-link voor de normale verdeling). Deze smoother geeft voor continue variabelen ook een indicatie welke macht van Jaartal opgenomen moet worden in het model. 
Voor elke indicator worden de schattingen van de modelparameters weergegeven, samen met hun significantie. Voor de "gewone" modellen werd voor de eenvoud van interpretatie van de parameterschattingen jaar steeds herschaald zodat de start van de metingen als referentie genomen wordt, dwz. dat voor de start van de studie jaar $=0$, het volgende jaar jaar $=1, \ldots$. Dit geeft als voordeel dat het intercept $(a)$ van het model altijd de startwaarde van de indicator is, en de helling van de rechte $(b)$ de jaarlijkse wijziging t.o.v. de start weergeeft. Voor de modellen met smoother gebeurde deze herschaling niet, aangezien daar het intercept steeds de gemiddelde respons is. Voor de smoothers s(Jaartal) zijn de waarden onder Estimate en Std..Error respectievelijk edf (estimated degrees of freedom) en res.df (estimated residual degrees of freedom).

Tevens worden per indicator 2 figuren getoond:

- scatterplot van de gegevens

- berekende trend met een $95 \%$ betrouwbaarheidsinterval voor de trendlijn

Uiteindelijk wordt er ook nog een verwachting voor 2020 gegeven. Dit is niets anders dan een predictie interval voor het jaar 2020, bekomen uit het gekozen model. 


\section{TRENDBEREKENINGEN}

\subsection{OVERWINTERENDE WATERVOGELINDEX - TOTAAL WATERVOGELS}

\subsubsection{Ruwe data}

\begin{tabular}{rr}
\hline Jaartal & index \\
\hline 1991 & 100.00 \\
1992 & 156.70 \\
1993 & 177.00 \\
1994 & 244.60 \\
1995 & 297.70 \\
1996 & 259.00 \\
1997 & 229.90 \\
1998 & 322.30 \\
1999 & 316.30 \\
2000 & 397.00 \\
2001 & 478.80 \\
2002 & 531.00 \\
2003 & 425.00 \\
2004 & 452.00 \\
2005 & 485.00 \\
2006 & 396.00 \\
2007 & 403.00 \\
2008 & 376.00 \\
2009 & 422.00 \\
2010 & 384.00 \\
2011 & 349.00 \\
2013 & 408.00 \\
2014 & 359.00 \\
2015 & 385.00 \\
2016 & 387.00 \\
2017 & 367.00 \\
\hline \hline
\end{tabular}


Overwinterende watervogelindex totaal watervogels

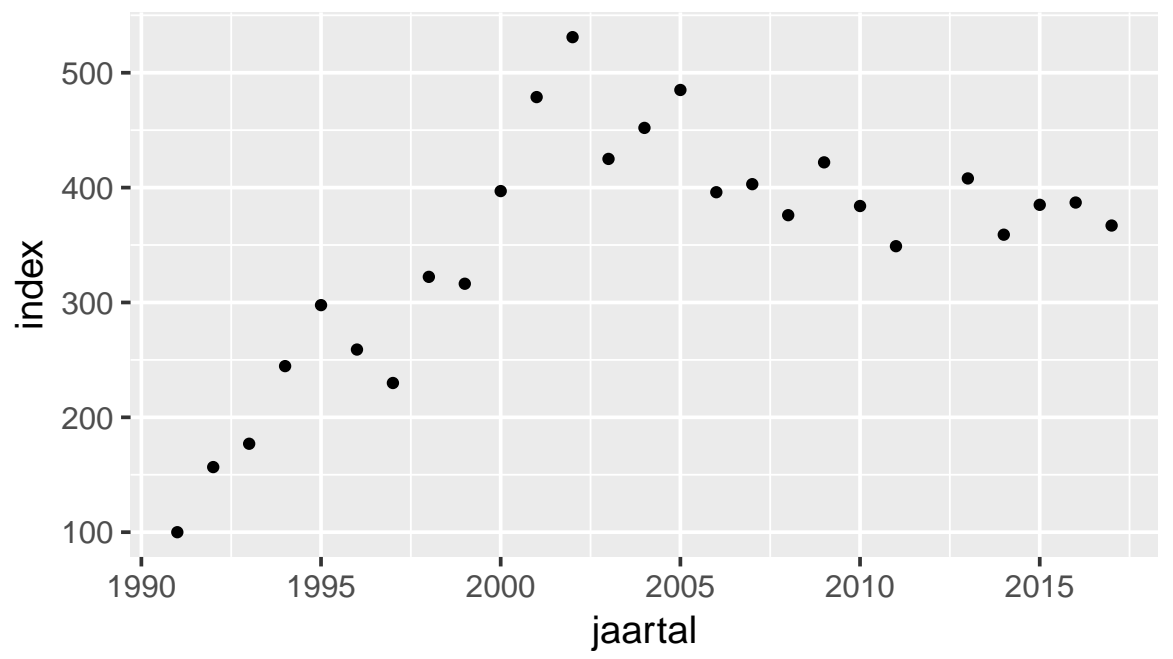

\subsubsection{Trendberekening}

Methode: Derdemacht

Parameterschattingen

params Estimate Std..Error statistic p.value 1 Intercept $81.85001257 \quad 32.19741136 \quad 2.5421301 .857157 \mathrm{e}-02$

cJaar 58.23060509 $11.03491102 \quad 5.276944 \quad 2.701339 \mathrm{e}-05$

cJaar2 -3.07867886 $1.00331850-3.068496 \quad 5.623913 \mathrm{e}-03$

cJaar3 $0.04824724 \quad 0.02534732 \quad 1.903446 \quad 7.014726 \mathrm{e}-02$

Overwinterende watervogelindex totaal watervogels

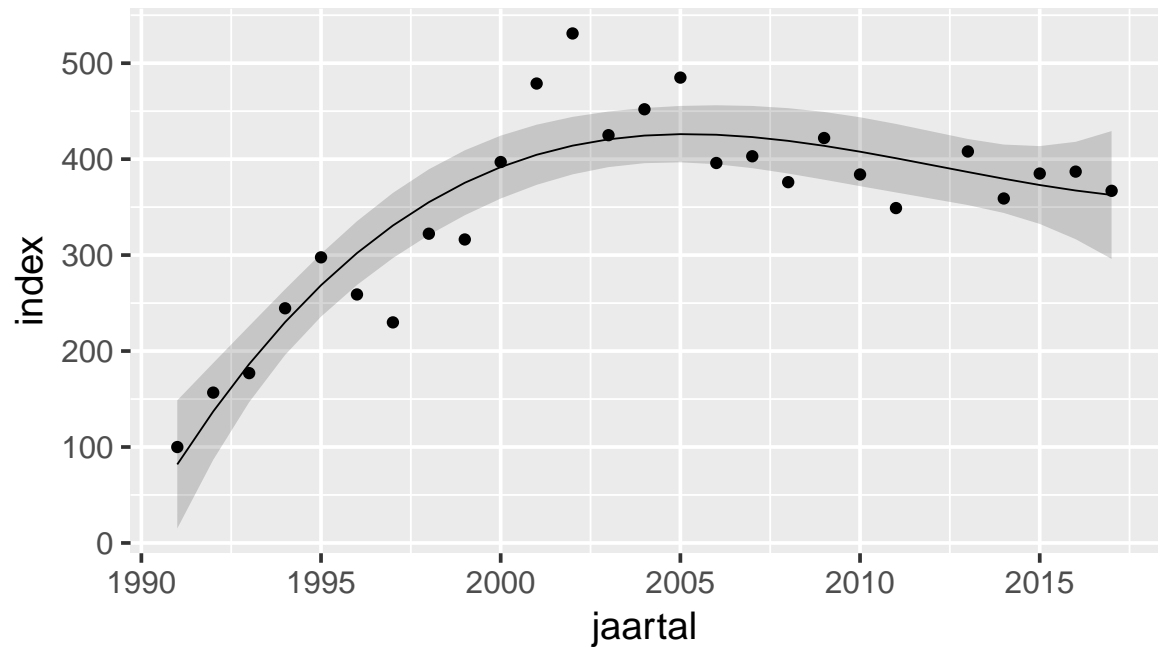

\subsubsection{Verwachting 2020}

$[182,535]$ 


\subsubsection{Conclusie}

Significante trend. Stijging tot 2005, sindsdien lichte afname. 


\subsubsection{Ruwe data}

\begin{tabular}{rr}
\hline Jaartal & aantal \\
\hline 1992 & 0.00 \\
1994 & 1.00 \\
1995 & 2.00 \\
1996 & 5.00 \\
1998 & 5.00 \\
1999 & 6.00 \\
2000 & 9.00 \\
2001 & 10.00 \\
2002 & 11.00 \\
2004 & 11.00 \\
2006 & 11.00 \\
2007 & 12.00 \\
2008 & 13.00 \\
2009 & 13.00 \\
2010 & 18.00 \\
2011 & 18.00 \\
2012 & 18.00 \\
2013 & 18.00 \\
2014 & 19.00 \\
2015 & 23.00 \\
2016 & 27.00 \\
2017 & 31.00 \\
\hline \hline & \\
\hline
\end{tabular}

Soortbeschermingsplannen aantal soortbeschermingsplannen

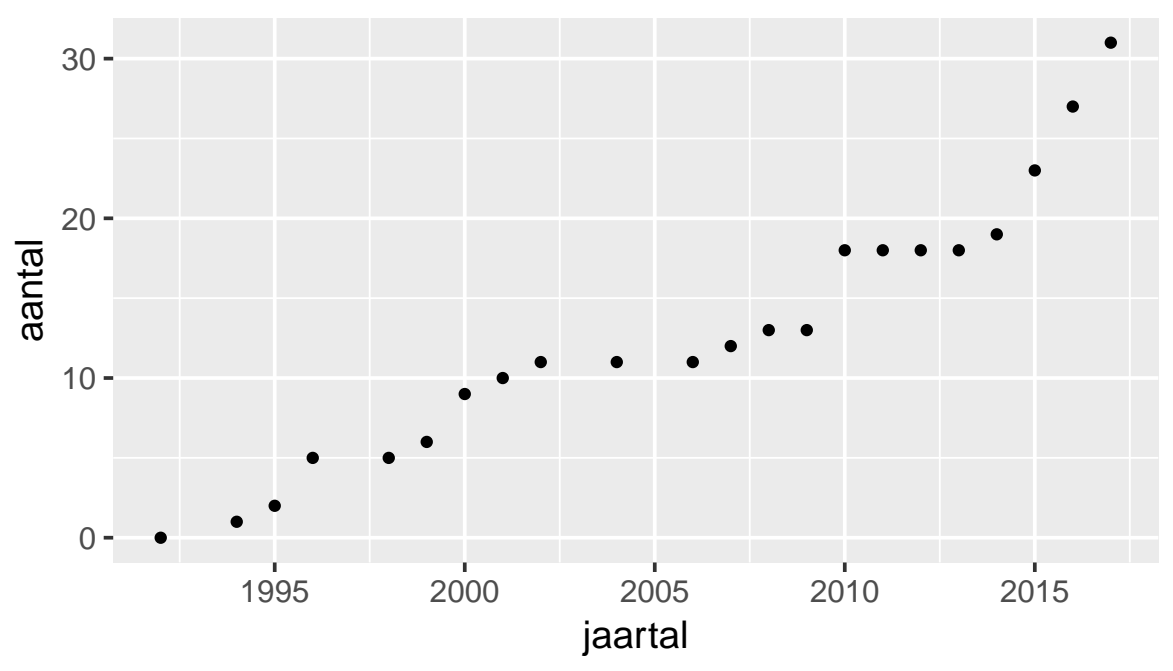




\subsubsection{Trendberekening}

Methode: Poisson smoother

Parameterschattingen

params Estimate Std..Error statistic p.value 1 Intercept $2.247625 \quad 0.08700978 \quad 25.83186 \quad 3.890405 \mathrm{e}-147$

$\begin{array}{llllll}2 \mathrm{~s} \text { (Jaartal) } & 2.847374 & 2.98152091 & 83.36319 & 1.142564 \mathrm{e}-17\end{array}$

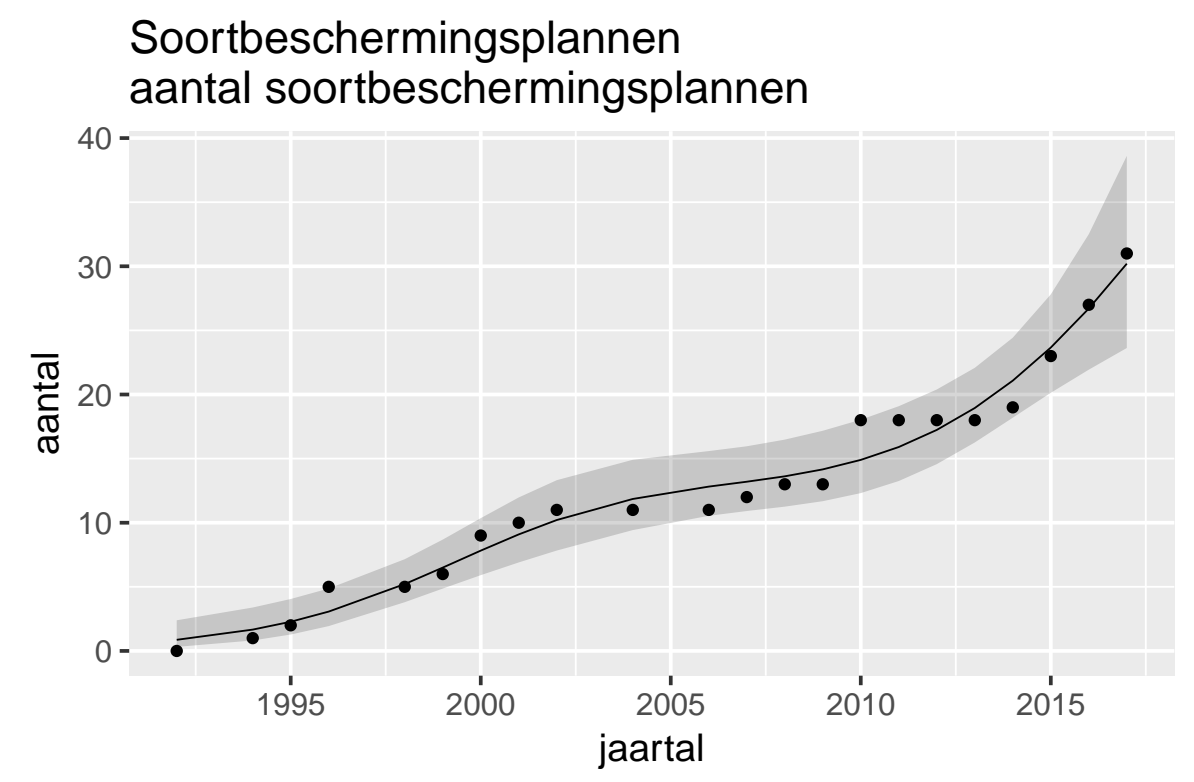

\subsubsection{Verwachting $\mathbf{2 0 2 0}$}

$[28.6,66.9]$

\subsubsection{Conclusie}

Significante toename. 


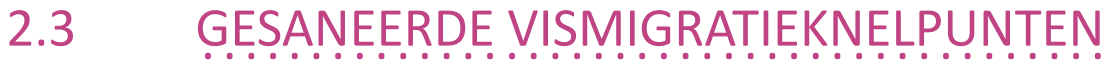

(PR!ORITE!TSSLLASSTE 1)...AANTAL OPGGELOSTTE

KṆELPUNT!EN

\subsubsection{Ruwe data}

\begin{tabular}{rr}
\hline Jaartal & aantal \\
\hline 2001 & 2.00 \\
2002 & 2.00 \\
2003 & 3.00 \\
2004 & 5.00 \\
2005 & 6.00 \\
2006 & 6.00 \\
2007 & 6.00 \\
2008 & 7.00 \\
2009 & 9.00 \\
2010 & 10.00 \\
2011 & 10.00 \\
2012 & 15.00 \\
2013 & 18.00 \\
2014 & 18.00 \\
2015 & 19.00 \\
2016 & 22.00 \\
2017 & 27.00 \\
\hline \hline
\end{tabular}

Gesaneerde vismigratieknelpunten (prioriteitsklasse 1 aantal opgeloste knelpunten

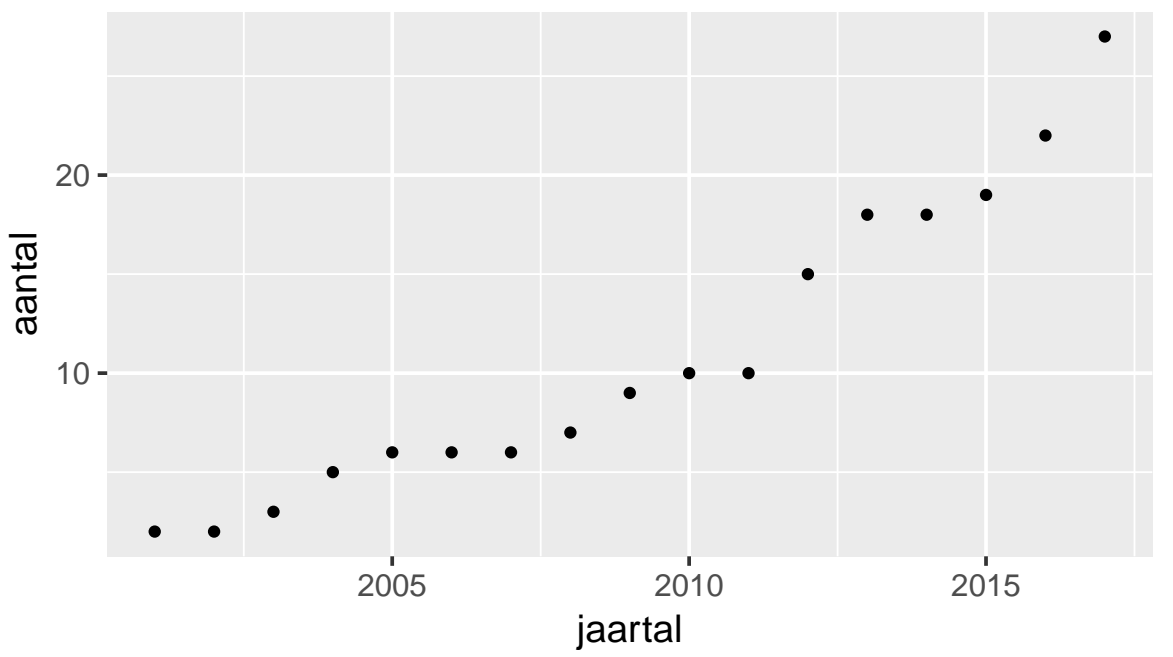




\subsubsection{Trendberekening}

Methode: Poisson

Parameterschattingen

params Estimate Std..Error statistic p.value 1 Intercept $0.9852021 \quad 0.20647339 \quad 4.771569 \quad 1.827963 \mathrm{e}-06$

2 cJaar $0.1451207 \quad 0.01726846 \quad 8.403804 \quad 4.322444 \mathrm{e}-17$

Gesaneerde vismigratieknelpunten (prioriteitsklasse 1 aantal opgeloste knelpunten

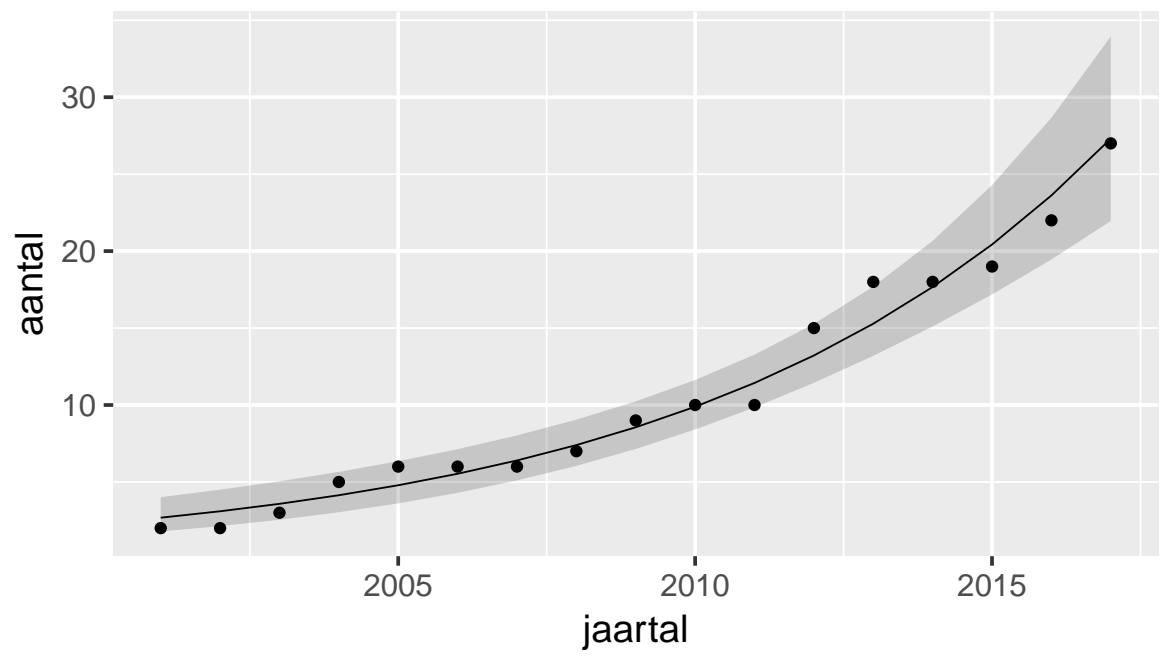

2.3.3 Verwachting 2020

$[31.2,57.1]$

2.3.4 Conclusie

Significante toename. 


\subsubsection{Ruwe data}

\begin{tabular}{rr}
\hline Jaartal & opp in ha \\
\hline 2011 & 63329.00 \\
2012 & 67450.60 \\
2013 & 69897.00 \\
2014 & 76206.00 \\
2015 & 79521.00 \\
2016 & 81699.00 \\
2017 & 82368.00 \\
\hline \hline
\end{tabular}

\section{Oppervlakte met effectief natuurbeheer} totale oppervlakte effectief natuurbeheer

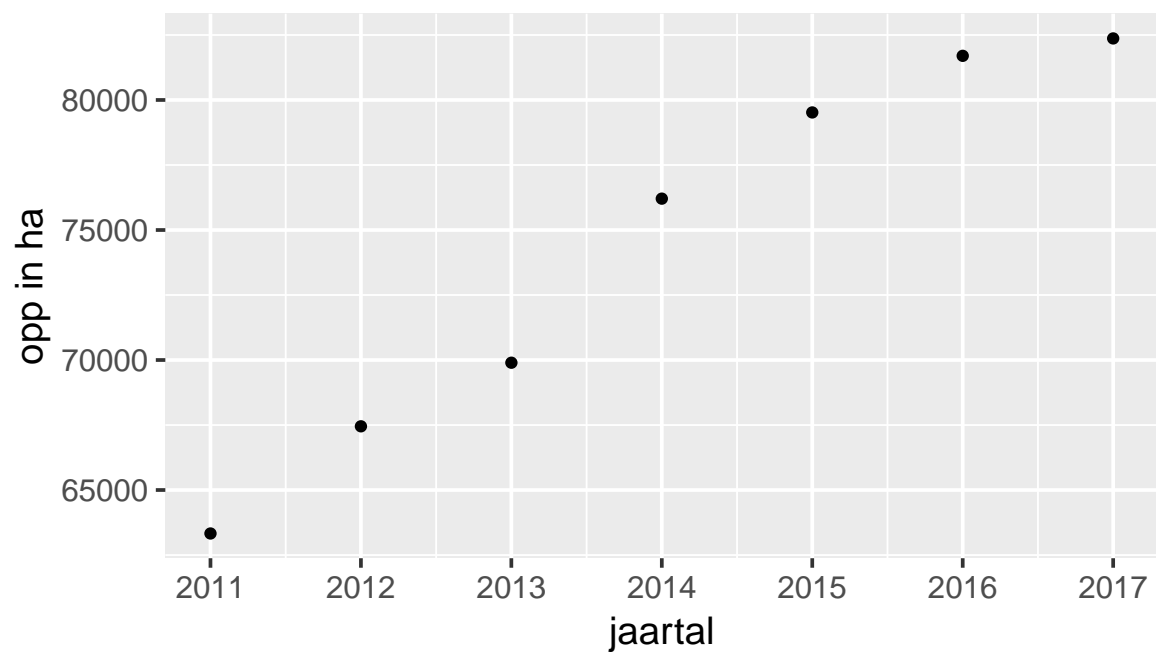

\subsubsection{Trendberekening}

Methode: Lineair

Parameterschattingen

params Estimate Std..Error statistic p.value

1 Intercept $64148.89 \quad 1116.9863 \quad 57.43033 \quad 3.02822 \mathrm{e}-08$

2 cJaar $3401.35 \quad 309.7963 \quad 10.97931 \quad 1.09039 \mathrm{e}-04$ 


\section{Oppervlakte met effectief natuurbeheer totale oppervlakte effectief natuurbeheer}

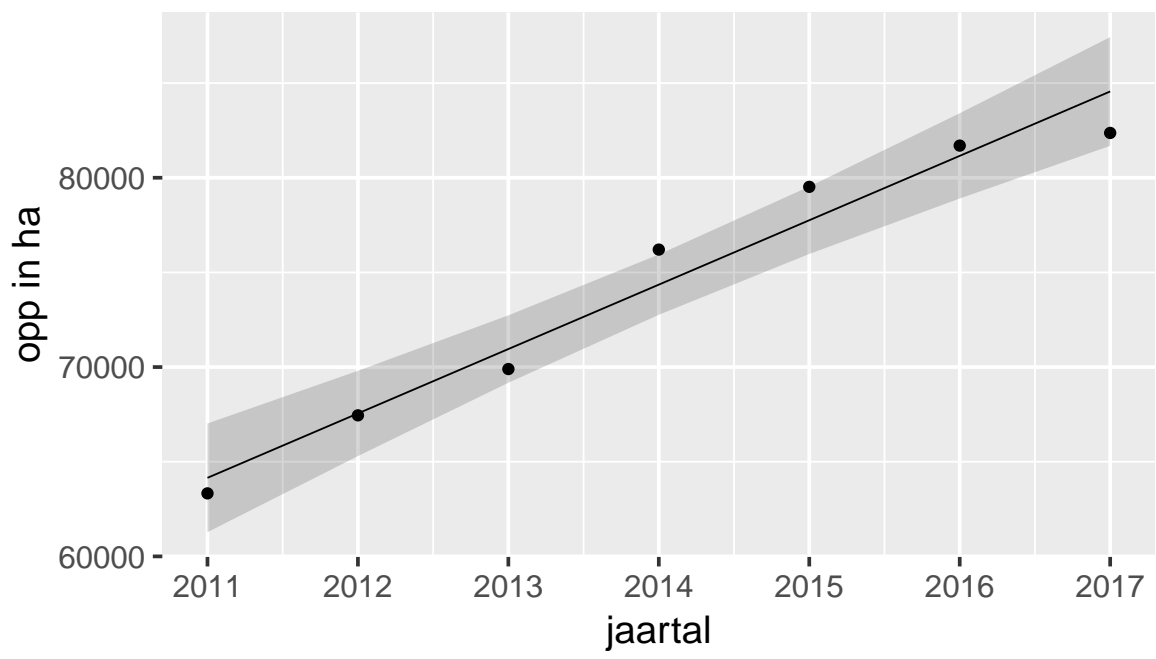

\subsubsection{Verwachting 2020}

$[88200,101000]$

\subsubsection{Conclusie}

Significante toename. 


\subsubsection{Ruwe data}

\begin{tabular}{rr}
\hline Jaartal & opp in ha \\
\hline 1996 & 792.00 \\
1997 & 910.00 \\
1998 & 1050.00 \\
1999 & 950.00 \\
2000 & 1145.00 \\
2001 & 1209.00 \\
2002 & 2063.00 \\
2003 & 1412.00 \\
2004 & 1233.00 \\
2005 & 1394.00 \\
2006 & 1182.00 \\
2007 & 925.00 \\
2008 & 1108.00 \\
2009 & 777.00 \\
2010 & 881.00 \\
2011 & 1007.00 \\
2012 & 896.00 \\
2013 & 802.00 \\
2014 & 697.00 \\
2015 & 351.00 \\
2016 & 599.00 \\
2017 & 718.00 \\
\hline \hline
\end{tabular}

Verwerving natuurgebieden oppervlakte Vlaamse overheid

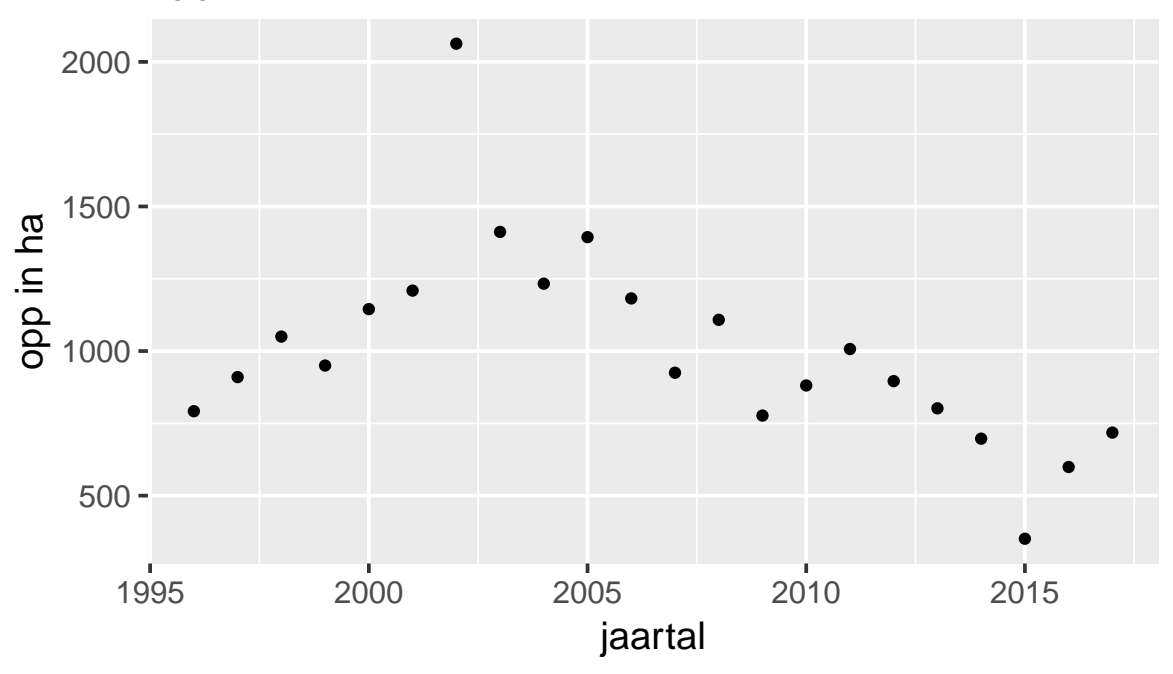




\subsubsection{Trendberekening}

Methode: Derdemacht

\section{Parameterschattingen}

params Estimate Std..Error statistic p.value 1 Intercept $687.7197628 \quad 159.6357768 \quad 4.308055 \quad 0.0004234672$

$2 \quad$ cJaar $242.7477998 \quad 67.3993316 \quad 3.601635 \quad 0.0020397662$

$3 \quad$ cJaar2 $-25.2605337 \quad 7.5612645 \quad-3.340782 \quad 0.0036383284$

$\begin{array}{llllll}4 & \text { cJaar3 } & 0.6471777 & 0.2364297 & 2.737294 & 0.0135341026\end{array}$

Verwerving natuurgebieden

oppervlakte Vlaamse overheid

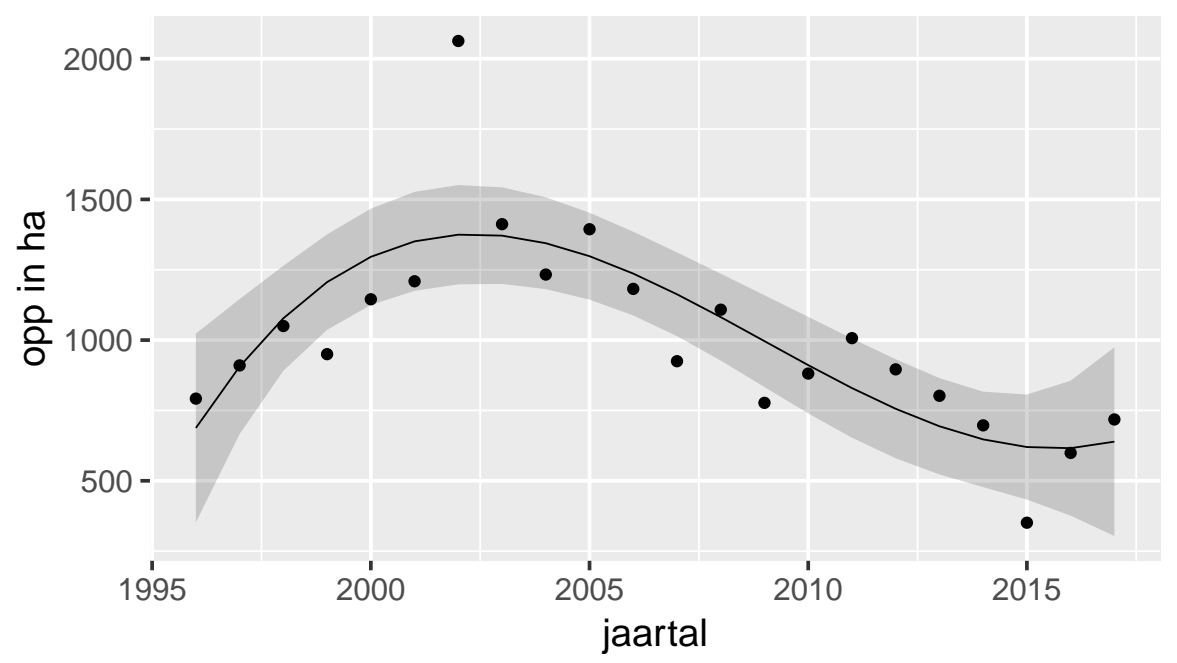

\subsubsection{Verwachting 2020}

$[-71.2,1890]$

\subsubsection{Conclusie}

Significante trend. Stijging tot 2002, afname tot 2015, sindsdien terug een stijging. 


\subsubsection{Ruwe data}

\begin{tabular}{rr}
\hline Jaartal & opp in ha \\
\hline 1995 & 439.00 \\
1996 & 655.00 \\
1997 & 480.00 \\
1998 & 619.00 \\
1999 & 750.00 \\
2000 & 852.00 \\
2001 & 1026.00 \\
2002 & 814.00 \\
2003 & 878.00 \\
2004 & 890.00 \\
2005 & 690.00 \\
2006 & 1162.00 \\
2007 & 587.00 \\
2008 & 589.00 \\
2009 & 922.00 \\
2010 & 578.00 \\
2011 & 772.00 \\
2012 & 371.00 \\
2013 & 478.00 \\
2014 & 520.00 \\
2015 & 576.00 \\
2016 & 676.00 \\
2017 & 722.00 \\
\hline \hline
\end{tabular}

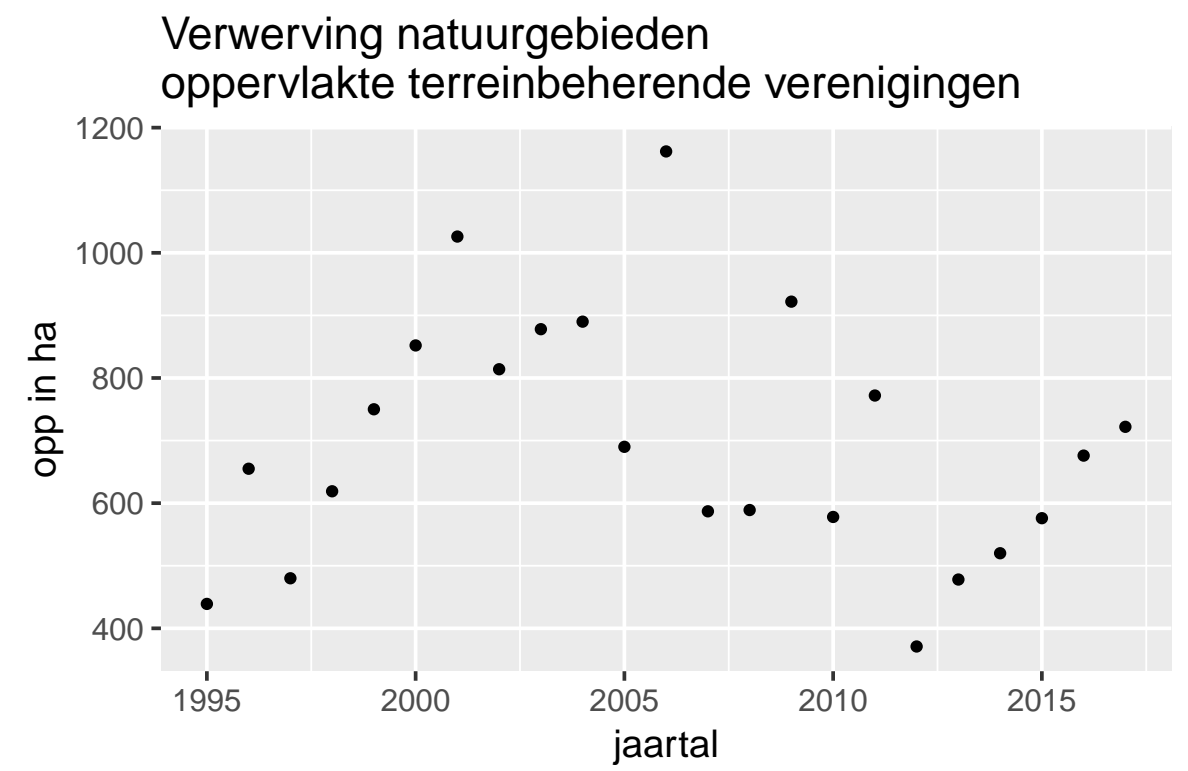




\subsubsection{Trendberekening}

Methode: Derdemacht

\section{Parameterschattingen}

params Estimate Std..Error statistic p.value 1 Intercept $375.0769231 \quad 109.3444513 \quad 3.430233 \quad 0.002805778$

$2 \quad$ cJaar $165.4604685 \quad 44.0204729 \quad 3.758716 \quad 0.001329282$

$3 \quad$ cJaar2 $-16.2263801 \quad 4.7109554-3.444393 \quad 0.002717226$

$4 \quad$ cJaar3 $0.4239536 \quad 0.1406143 \quad 3.015009 \quad 0.007120968$

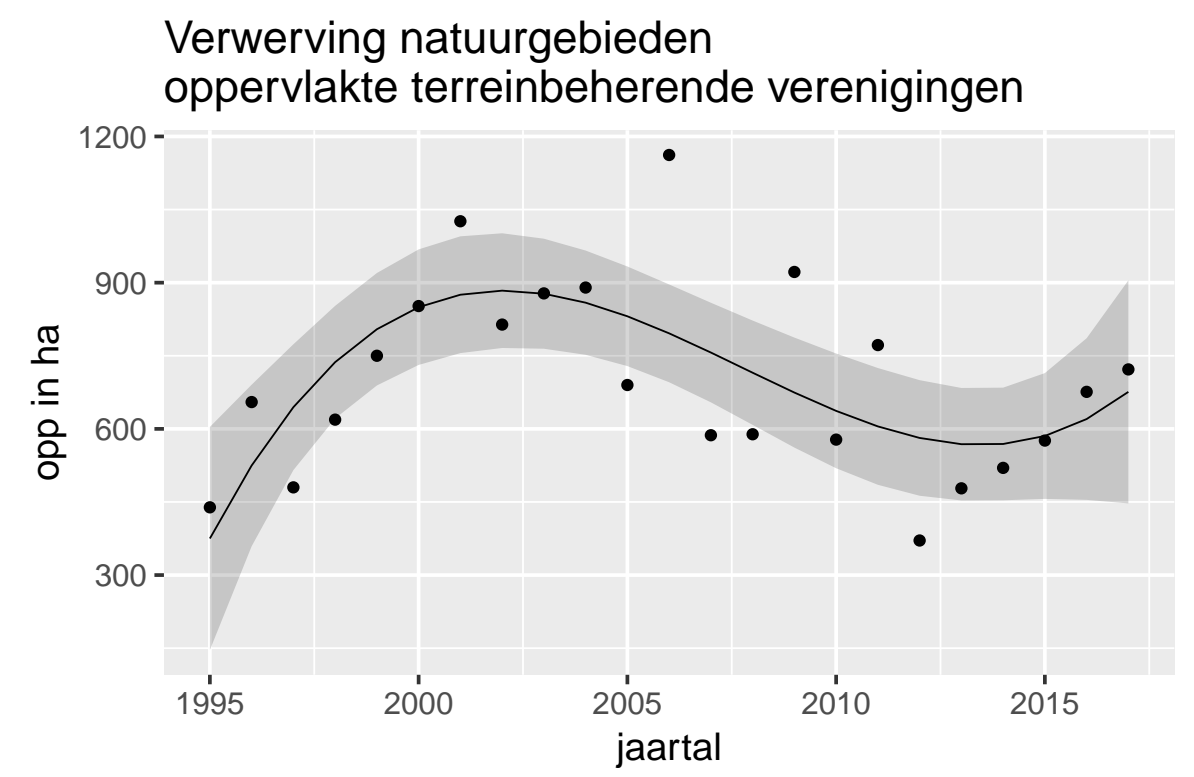

\subsubsection{Verwachting 2020}

$[342,1650]$

\subsubsection{Conclusie}

Significante trend. Stijging tot 2002, afname tot 2013, sindsdien terug een stijging. 


\subsubsection{Ruwe data}

\begin{tabular}{rr}
\hline Jaartal & uitgave in (1000) euro \\
\hline 2003 & 26207.75 \\
2004 & 18344.34 \\
2005 & 24571.11 \\
2006 & 22140.34 \\
2007 & 17099.30 \\
2008 & 26119.47 \\
2009 & 13876.51 \\
2010 & 16307.73 \\
2011 & 21535.12 \\
2012 & 18483.72 \\
2013 & 17838.07 \\
2014 & 14178.00 \\
2015 & 9555.10 \\
2016 & 17158.00 \\
2017 & 23051.00 \\
\hline \hline
\end{tabular}

Verwerving natuurgebieden eigen uitgaven Vlaamse overheid

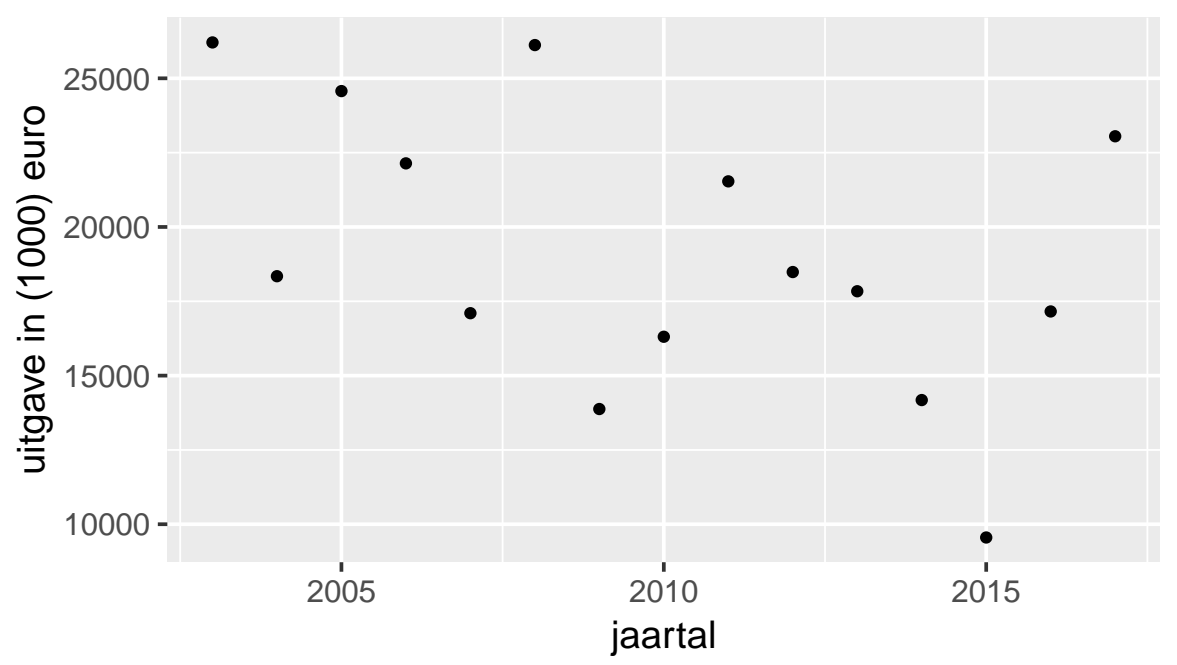

\subsubsection{Trendberekening}

Methode: Lineair

Parameterschattingen 
params Estimate Std..Error statistic p.value 1 Intercept 22636.2354 2154.4560 10.506706 $1.010969 \mathrm{e}-07$

2 cJaar $-505.5044 \quad 261.9089-1.930077 \quad 7.570707 \mathrm{e}-02$

Verwerving natuurgebieden eigen uitgaven Vlaamse overheid

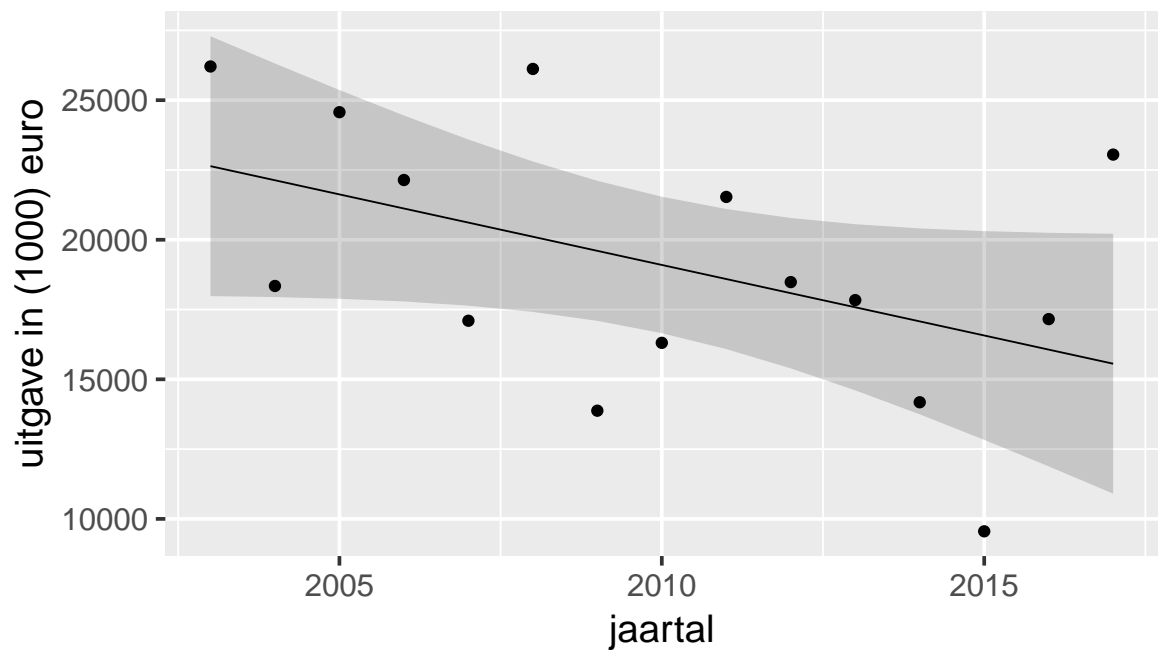

\subsubsection{Verwachting $\mathbf{2 0 2 0}$}

$[2750,25300]$

\subsubsection{Conclusie}

Geen significante afname. 


\subsubsection{Ruwe data}

\begin{tabular}{rr}
\hline Jaartal & uitgave in (1000) euro \\
\hline 1995 & 2511.16 \\
1996 & 4291.04 \\
1997 & 3696.09 \\
1998 & 3324.26 \\
1999 & 5538.37 \\
2000 & 8195.36 \\
2001 & 10203.30 \\
2002 & 10377.00 \\
2003 & 9370.13 \\
2004 & 9571.06 \\
2005 & 8306.29 \\
2006 & 8304.99 \\
2007 & 8305.00 \\
2008 & 9221.00 \\
2009 & 8527.00 \\
2010 & 7147.00 \\
2011 & 7155.00 \\
2012 & 6757.00 \\
2013 & 6766.00 \\
2014 & 6750.00 \\
2015 & 6780.00 \\
2016 & 6757.00 \\
2017 & 9266.00 \\
\hline \hline & \\
& \\
\hline
\end{tabular}

Verwerving natuurgebieden subsidies aan verenigingen

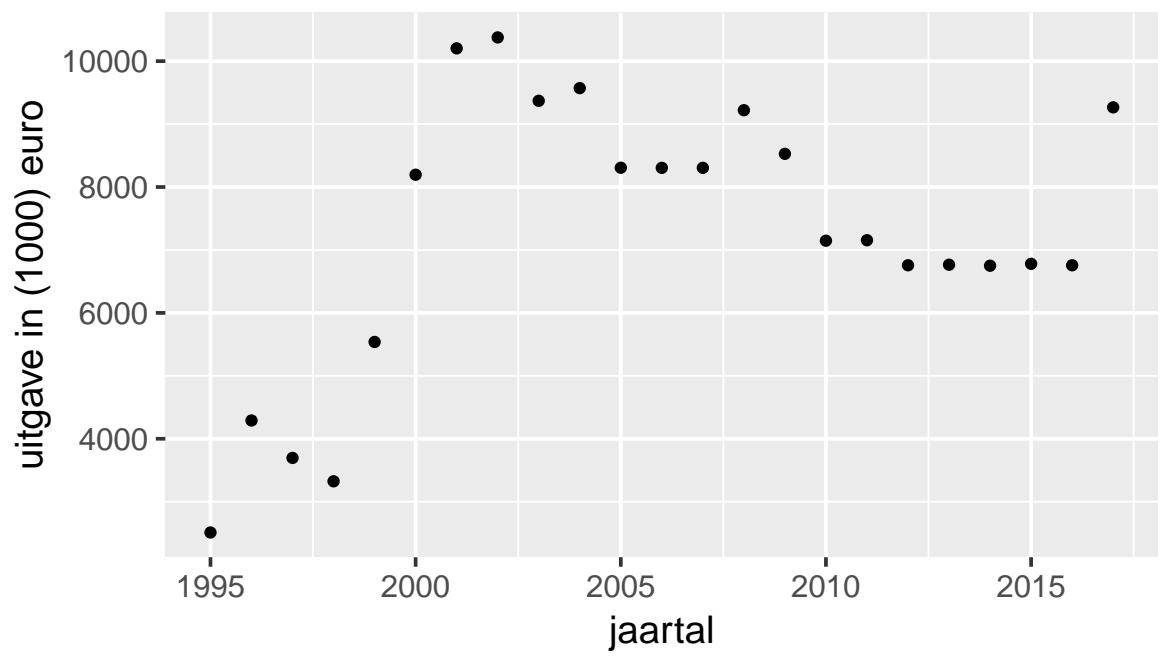




\subsubsection{Trendberekening}

Methode: Derdemacht

\section{Parameterschattingen}

params Estimate Std..Error statistic p.value 1 Intercept $1222.955198 \quad 822.625015 \quad 1.486650 \quad 1.535140 \mathrm{e}-01$

$2 \quad$ cJaar $2142.438047 \quad 331.176770 \quad 6.469168 \quad 3.363864 \mathrm{e}-06$

3 cJaar2 $-181.175219 \quad 35.441668 \quad-5.111927 \quad 6.195452 \mathrm{e}-05$

$4 \quad$ cJaar3 $4.444925 \quad 1.057876 \quad 4.201744 \quad 4.833890 \mathrm{e}-04$

\section{Verwerving natuurgebieden}

subsidies aan verenigingen

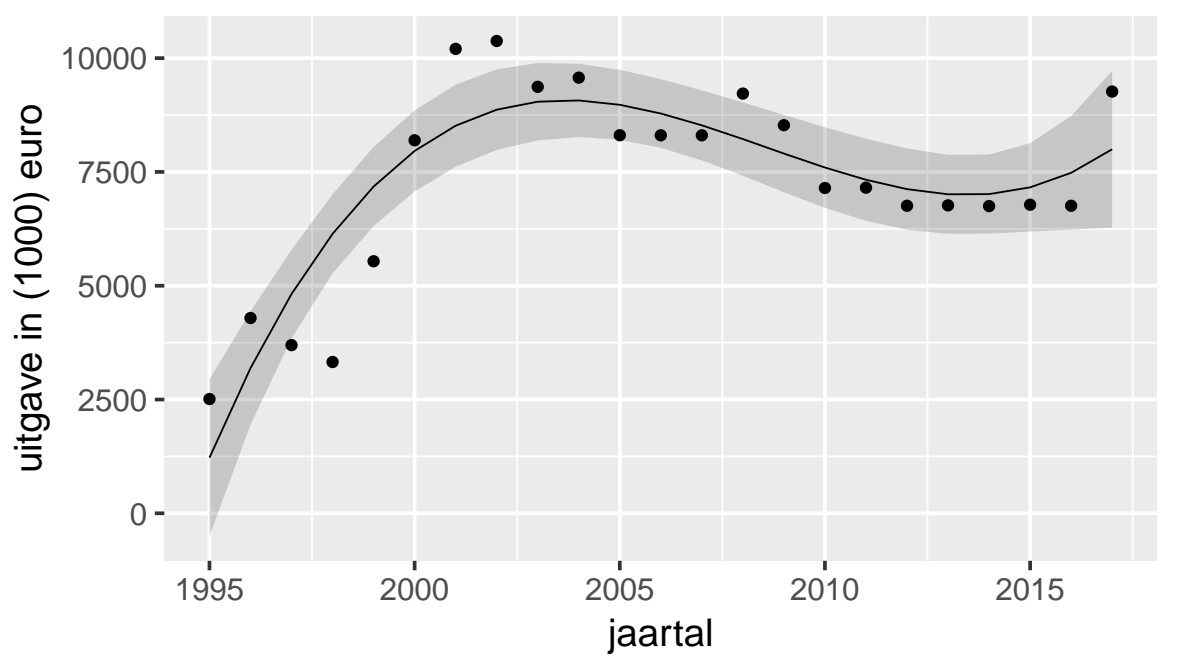

\subsubsection{Verwachting 2020}

$[6090,15900]$

\subsubsection{Conclusie}

Significante trend. Stijging tot 2004, afname tot 2014, sindsdien terug een stijging. 


\subsubsection{Ruwe data}

\begin{tabular}{rr}
\hline Jaartal & opp in ha \\
\hline 2003 & 84965.00 \\
2004 & 86772.00 \\
2005 & 86940.00 \\
2006 & 87022.00 \\
2007 & 87045.00 \\
2008 & 87491.00 \\
2009 & 89331.00 \\
2010 & 88972.00 \\
2011 & 89318.00 \\
2012 & 89719.00 \\
2013 & 90006.00 \\
2014 & 90522.00 \\
2015 & 91897.00 \\
2016 & 92220.00 \\
2017 & 92488.00 \\
\hline \hline
\end{tabular}

Oppervlakte afgebakend VEN totale oppervlakte afgebakend VEN

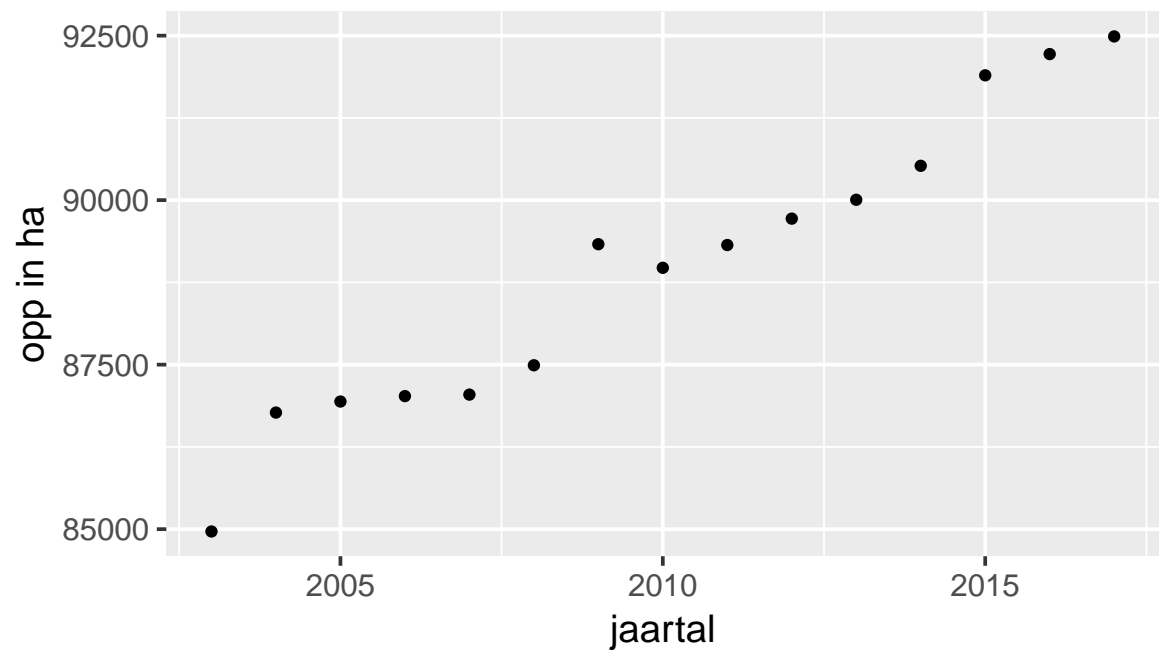

\subsubsection{Trendberekening}

Methode: Lineair

Parameterschattingen 
params Estimate Std..Error statistic p.value 1 Intercept $85544.0333 \quad 235.98880 \quad 362.49192 \quad 2.023567 \mathrm{e}-27$

2 cJaar $490.9286 \quad 28.68825 \quad 17.11253 \quad 2.689735 \mathrm{e}-10$

\section{Oppervlakte afgebakend VEN totale oppervlakte afgebakend VEN}

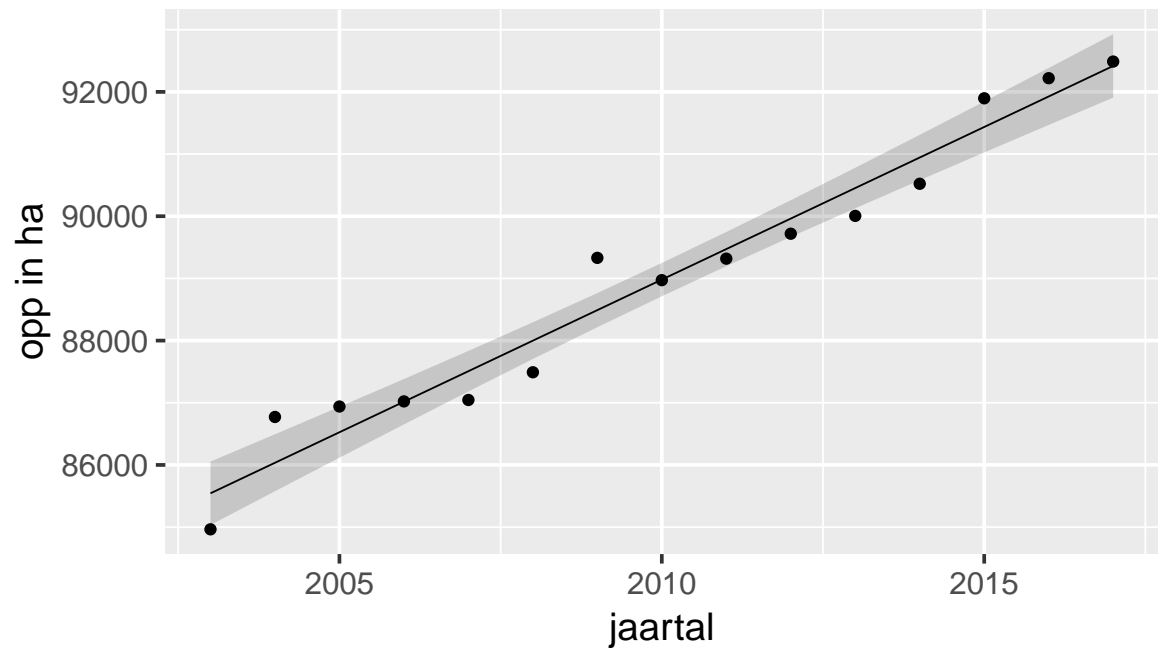

\subsubsection{Verwachting 2020}

$[92700,95100]$

\subsubsection{Conclusie}

Significante toename. 


\subsubsection{Ruwe data}

\begin{tabular}{rr}
\hline Jaartal & opp in ha \\
\hline 2003 & 0.00 \\
2004 & 768.00 \\
2005 & 768.00 \\
2006 & 934.00 \\
2007 & 934.00 \\
2008 & 1992.00 \\
2009 & 3094.00 \\
2010 & 3203.00 \\
2011 & 3974.00 \\
2012 & 3964.00 \\
2013 & 4089.39 \\
2014 & 4441.00 \\
2014 & 4337.77 \\
2015 & 5084.00 \\
2016 & 5084.00 \\
2017 & 5103.00 \\
\hline \hline
\end{tabular}

Oppervlakte afgebakend natuurverwevingsgebied totale oppervlakte afgebakend natuurverwevingsgek

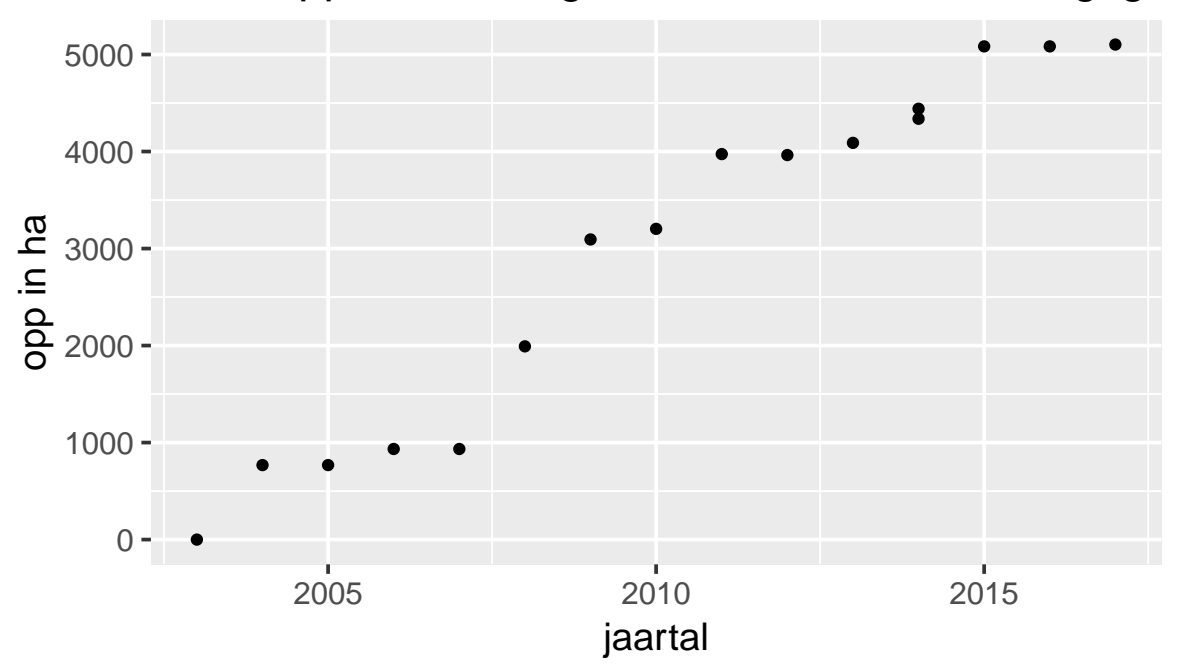

\subsubsection{Trendberekening}

Methode: Derdemacht 
Parameterschattingen

params Estimate Std..Error statistic p.value

1 Intercept $111.727728 \quad 279.537151 \quad 0.3996883 \quad 0.69640881$

$\begin{array}{lllll}\text { cJaar } 227.164055 & 176.280186 & 1.2886534 & 0.22180913\end{array}$

$\begin{array}{llllll}\text { cJaar2 } & 46.462853 & 29.489418 & 1.5755771 & 0.14110639\end{array}$

$\begin{array}{lllll}\text { cJaar3 } & -2.682932 & 1.378572 & -1.9461672 & 0.07542977\end{array}$

Oppervlakte afgebakend natuurverwevingsgebied totale oppervlakte afgebakend natuurverwevingsgek

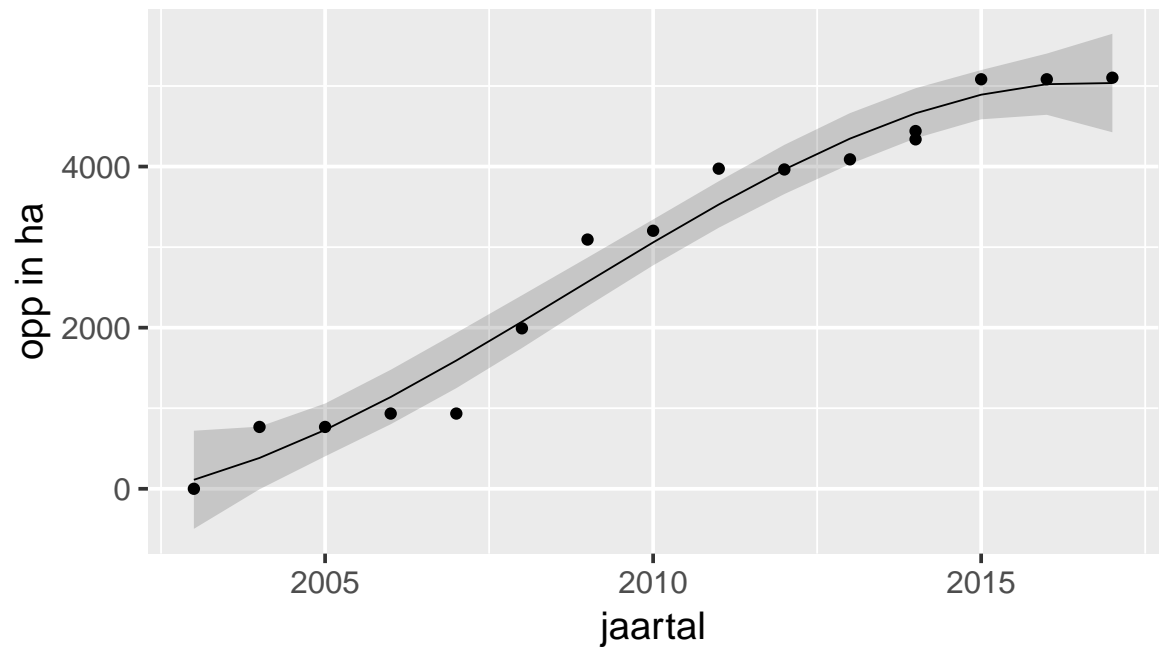

\subsubsection{Verwachting 2020}

$[1810,6630]$

\subsubsection{Conclusie}

Significante toename. 


\subsubsection{Ruwe data}

\begin{tabular}{rr}
\hline Jaartal & opp in ha \\
\hline 2009 & 433.21 \\
2010 & 1075.00 \\
2011 & 2422.00 \\
2012 & 6289.00 \\
2013 & 14630.00 \\
2014 & 25834.00 \\
2015 & 31106.00 \\
2016 & 34408.00 \\
2017 & 36116.00 \\
\hline \hline
\end{tabular}

Oppervlakte aandeel toegankelijke bossen totale oppervlakte toegankelijke bossen

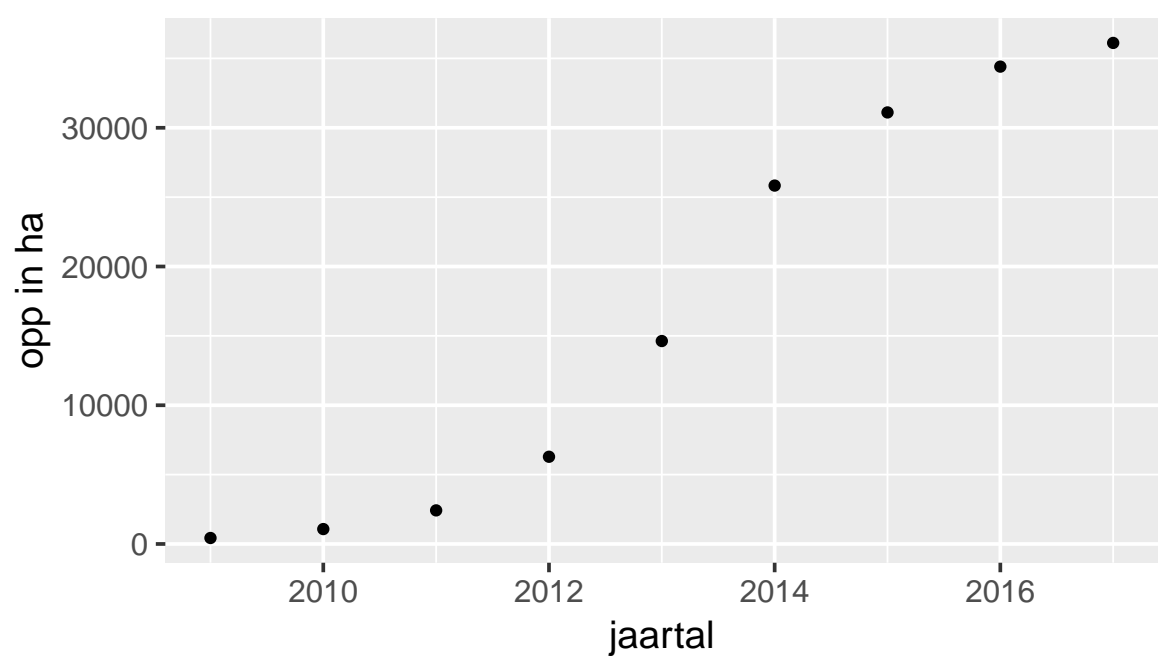

\subsubsection{Trendberekening}

Methode: Derdemacht

Parameterschattingen

params Estimate Std..Error statistic p.value 1 Intercept $1275.1601 \quad 1496.04256 \quad 0.8523555 \quad 0.432937117$

$2 \quad$ cJaar $-4710.0994 \quad 1726.64927 \quad-2.7278843 \quad 0.041384392$

$3 \quad$ cJaar2 $3032.6342 \quad 521.32001 \quad 5.8172219 \quad 0.002119314$

$4 \quad$ cJaar3 $\quad-237.8526 \quad 42.76153 \quad-5.5623042 \quad 0.002583942$ 
Oppervlakte aandeel toegankelijke bossen totale oppervlakte toegankelijke bossen

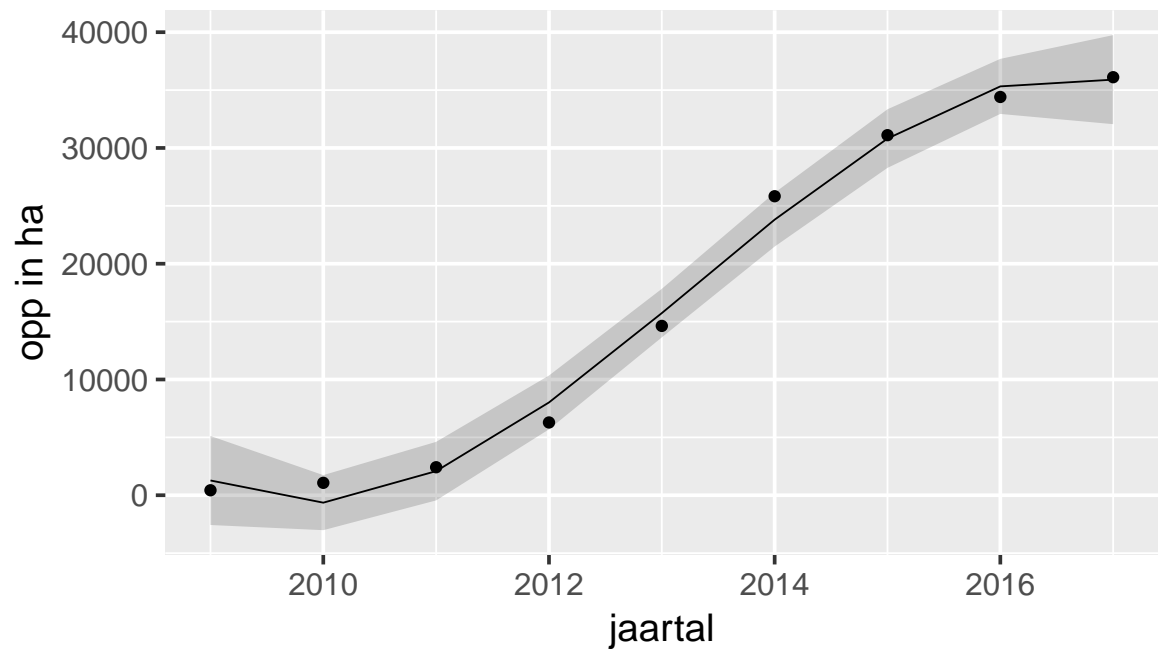

\subsubsection{Verwachting 2020}

$[-31000,30700]$

\subsubsection{Conclusie}

Significante toename. 
2.12 OPPERVLAKTE SPEEELZOYNES IN BOSSTSEN EN

NATUUURRESERVATEN - TOTALE OPPERVLAKTE

SPEELZOYNES

\subsubsection{Ruwe data}

\begin{tabular}{rr}
\hline Jaartal & opp in ha \\
\hline 2007 & 2048.50 \\
2008 & 2141.46 \\
2009 & 2362.29 \\
2010 & 2452.61 \\
2011 & 2433.69 \\
2012 & 2475.30 \\
2013 & 2388.65 \\
2014 & 2336.78 \\
2015 & 2318.99 \\
2016 & 2642.00 \\
2017 & 2720.00 \\
\hline \hline
\end{tabular}

Oppervlakte speelzones in bossen en natuurreserv: totale oppervlakte speelzones

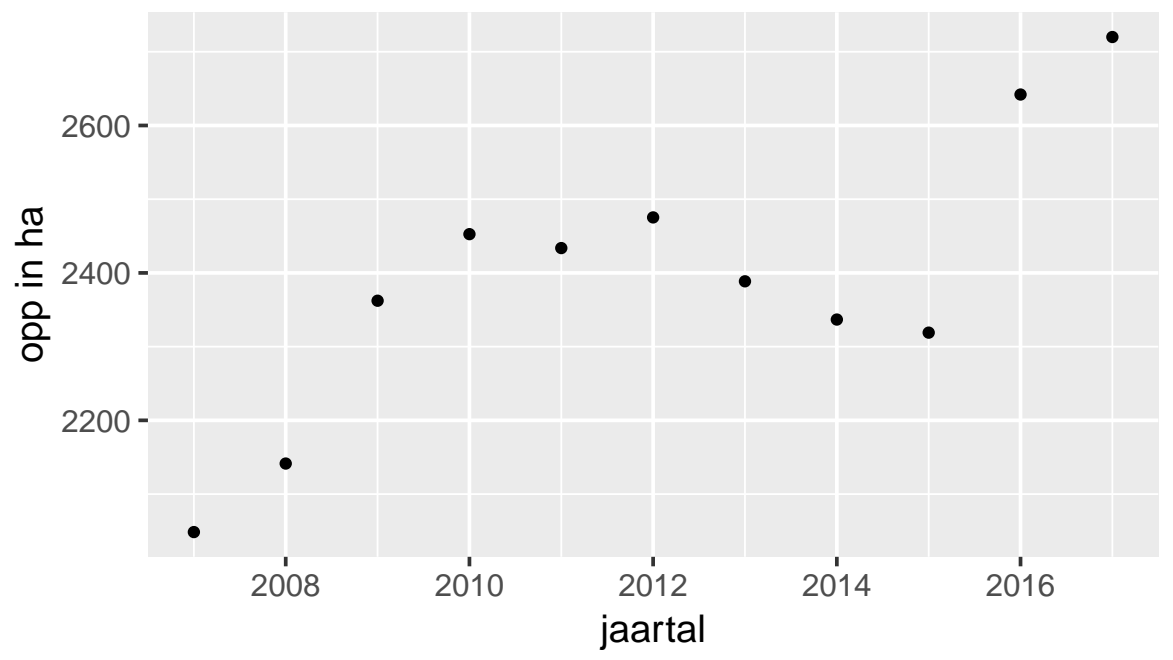

\subsubsection{Trendberekening}

Methode: Derdemacht

Parameterschattingen

params Estimate Std..Error statistic p.value

1 Intercept $1994.55285 \quad 67.7782448 \quad 29.427626 \quad 1.347752 \mathrm{e}-08$

2 cJaar $298.3411061 .7205056 \quad 4.833744 \quad 1.891308 \mathrm{e}-03$ 
Oppervlakte speelzones in bossen en natuurreserve totale oppervlakte speelzones

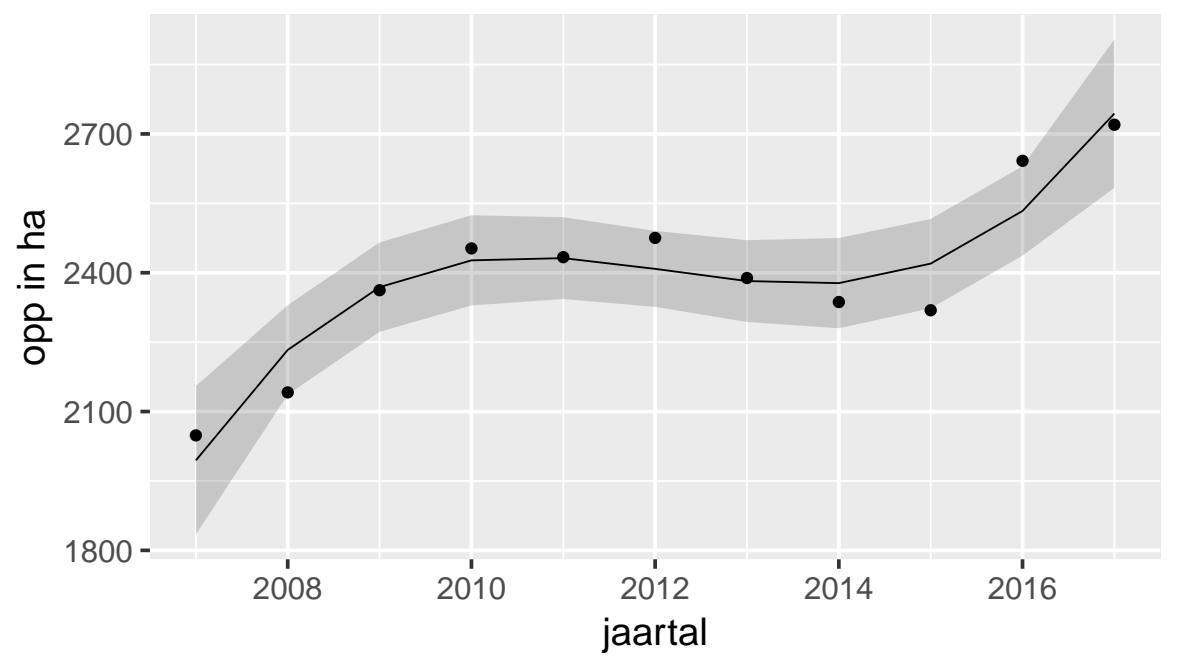

\subsubsection{Verwachting 2020}

$[3260,5140]$

\subsubsection{Conclusie}

Significante toename. 


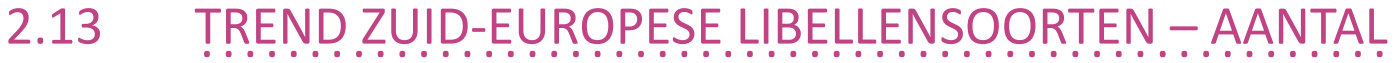 SOORTEN}

\subsubsection{Ruwe data}

\begin{tabular}{rr}
\hline Jaartal & aantal \\
\hline 1980 & 0.00 \\
1981 & 0.00 \\
1982 & 0.00 \\
1983 & 0.00 \\
1984 & 3.00 \\
1985 & 1.00 \\
1987 & 1.00 \\
1989 & 2.00 \\
1990 & 1.00 \\
1991 & 3.00 \\
1992 & 2.00 \\
1993 & 2.00 \\
1994 & 5.00 \\
1995 & 5.00 \\
1996 & 5.00 \\
1997 & 5.00 \\
1998 & 5.00 \\
1999 & 5.00 \\
2000 & 6.00 \\
2001 & 5.00 \\
2002 & 6.00 \\
2003 & 8.00 \\
2004 & 8.00 \\
2005 & 7.00 \\
2006 & 8.00 \\
2007 & 8.00 \\
2008 & 9.00 \\
2009 & 8.00 \\
2010 & 8.00 \\
2011 & 8.00 \\
2012 & 8.00 \\
2013 & 8.00 \\
2014 & 8.00 \\
2015 & 9.00 \\
2016 & 10.00 \\
2017 & 9.00 \\
\hline \hline & \\
\hline
\end{tabular}




\section{Trend Zuid-Europese libellensoorten}

aantal soorten

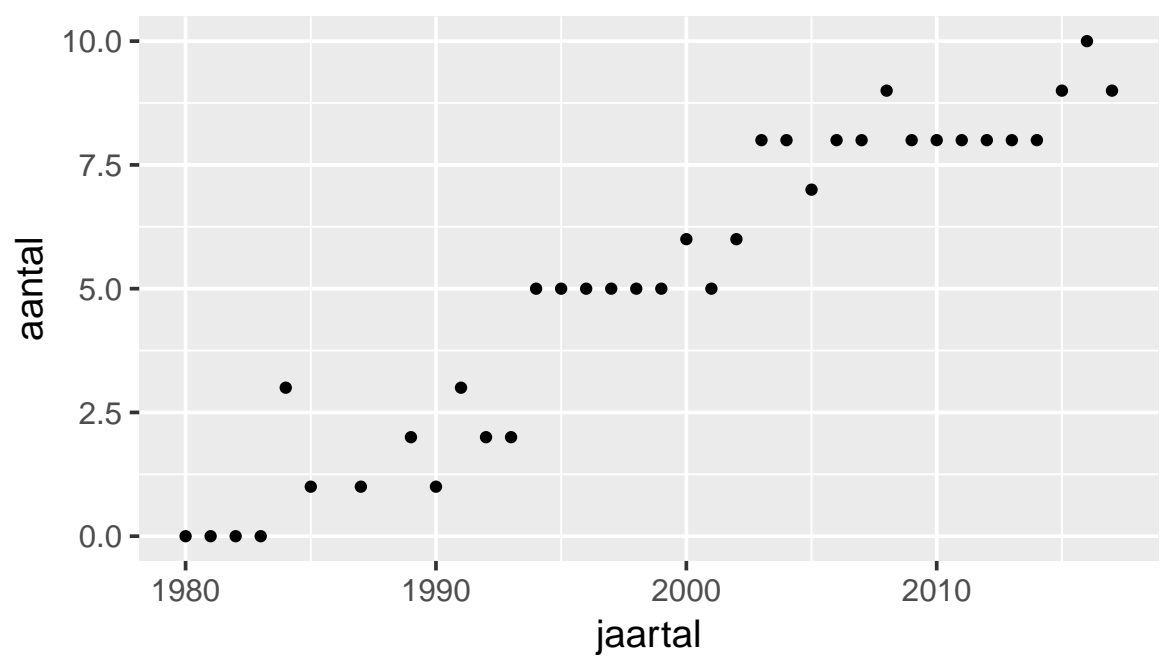

\subsubsection{Trendberekening}

Methode: Poisson smoother

\section{Parameterschattingen}

params Estimate Std..Error statistic p.value

1 Intercept $1.341571 \quad 0.1044828 \quad 12.84012 \quad 9.772725 \mathrm{e}-38$

$2 \mathrm{~s}$ (Jaartal) $2.313506 \quad 2.6824396 \quad 49.88556 \quad 1.807948 \mathrm{e}-10$

\section{Trend Zuid-Europese libellensoorten aantal soorten}

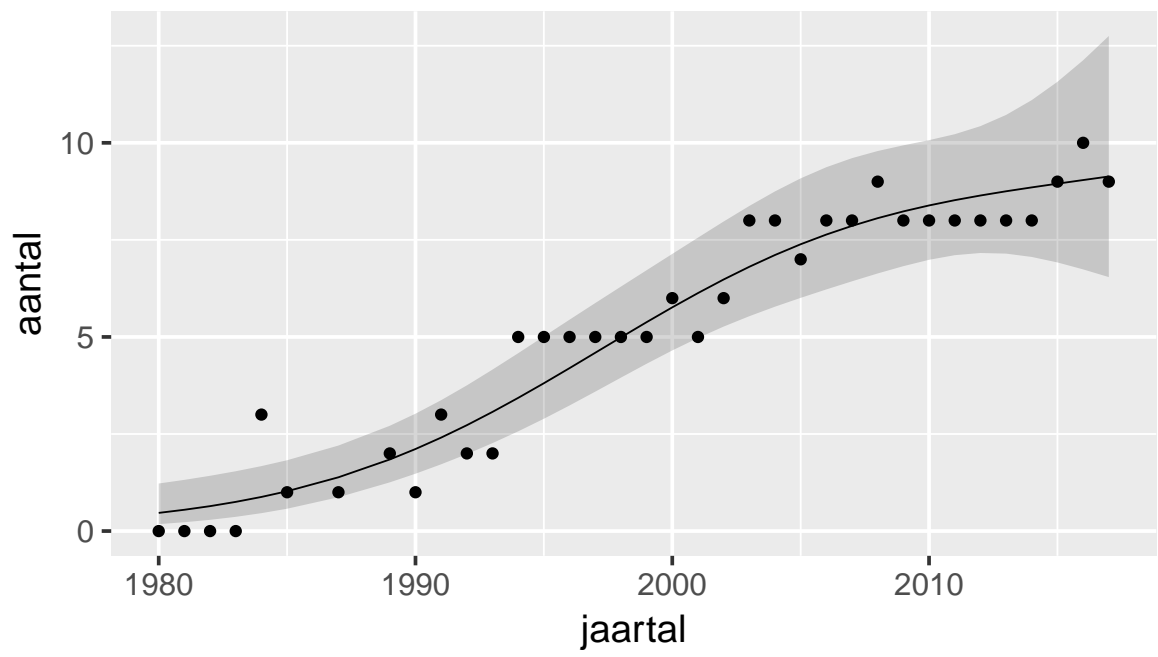

\subsubsection{Verwachting 2020}

$[5.91,15]$ 


\subsubsection{Conclusie}

Significante toename. 


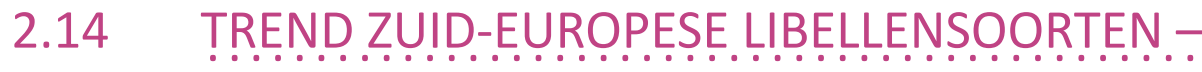
ZWERVENDE PANTSERUUTEFER

\subsubsection{Ruwe data}

\begin{tabular}{rr}
\hline Jaartal & aantal \\
\hline 1980 & 0.00 \\
1981 & 0.00 \\
1982 & 0.00 \\
1983 & 0.00 \\
1984 & 1.00 \\
1985 & 3.00 \\
1987 & 0.00 \\
1989 & 0.00 \\
1990 & 0.00 \\
1991 & 0.00 \\
1992 & 0.00 \\
1993 & 0.00 \\
1994 & 5.00 \\
1995 & 55.00 \\
1996 & 12.00 \\
1997 & 30.00 \\
1998 & 17.00 \\
1999 & 26.00 \\
2000 & 24.00 \\
2001 & 7.00 \\
2002 & 13.00 \\
2003 & 23.00 \\
2004 & 17.00 \\
2005 & 22.00 \\
2006 & 45.00 \\
2007 & 33.00 \\
2008 & 35.00 \\
2009 & 30.00 \\
2010 & 58.00 \\
2011 & 36.00 \\
2012 & 48.00 \\
2013 & 64.00 \\
2014 & 53.00 \\
2015 & 31.00 \\
2016 & 84.00 \\
2017 & 57.00 \\
\hline \hline &
\end{tabular}


Trend Zuid-Europese libellensoorten zwervende pantserjuffer

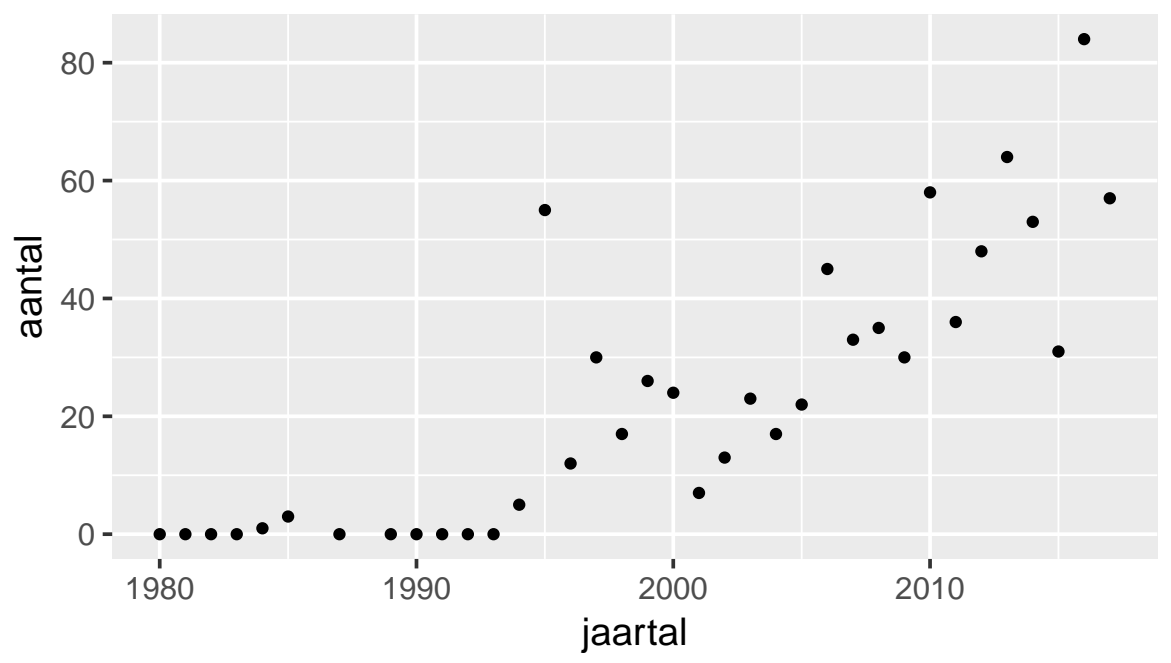

\subsubsection{Trendberekening}

Methode: Poisson smoother

Parameterschattingen

params Estimate Std..Error statistic p.value

1 Intercept $2.066529 \quad 0.1471233 \quad 14.04624 \quad 8.123409 \mathrm{e}-45$

$2 \mathrm{~s}$ (Jaartal) $2.960020 \quad 2.9985835 \quad 289.87068 \quad 4.938759 \mathrm{e}-61$

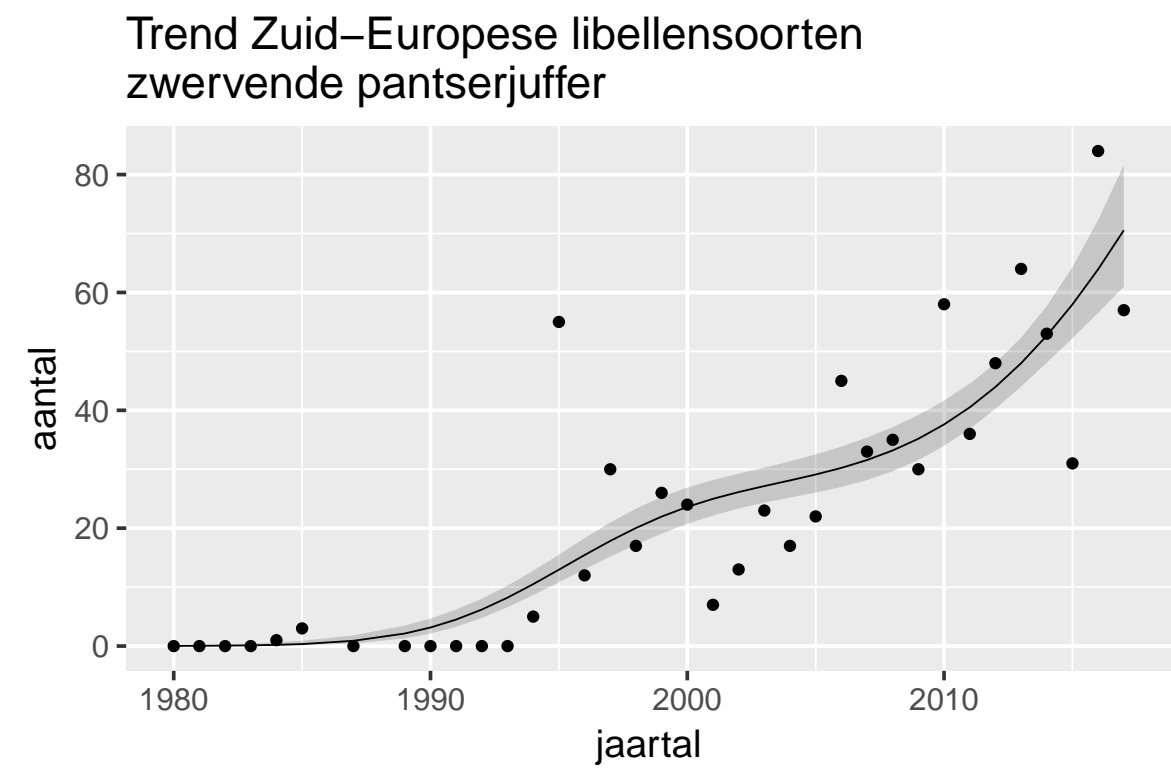

\subsubsection{Verwachting 2020}

$[75.7,119]$ 


\subsubsection{Conclusie}

Significante exponentiële toename. 


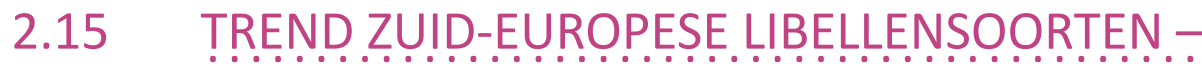
GAFFELWATERJUFFER

\subsubsection{Ruwe data}

\begin{tabular}{rr}
\hline Jaartal & aantal \\
\hline 1980 & 0.00 \\
1981 & 0.00 \\
1982 & 0.00 \\
1983 & 0.00 \\
1984 & 0.00 \\
1985 & 0.00 \\
1987 & 0.00 \\
1989 & 0.00 \\
1990 & 0.00 \\
1991 & 0.00 \\
1992 & 0.00 \\
1993 & 0.00 \\
1994 & 0.00 \\
1995 & 0.00 \\
1996 & 0.00 \\
1997 & 0.00 \\
1998 & 0.00 \\
1999 & 1.00 \\
2000 & 0.00 \\
2001 & 0.00 \\
2002 & 0.00 \\
2003 & 1.00 \\
2004 & 1.00 \\
2005 & 0.00 \\
2006 & 4.00 \\
2007 & 15.00 \\
2008 & 23.00 \\
2009 & 37.00 \\
2010 & 52.00 \\
2011 & 49.00 \\
2012 & 57.00 \\
2013 & 69.00 \\
2014 & 80.00 \\
2015 & 88.00 \\
2016 & 128.00 \\
2017 & 139.00 \\
\hline &
\end{tabular}


Trend Zuid-Europese libellensoorten gaffelwaterjuffer

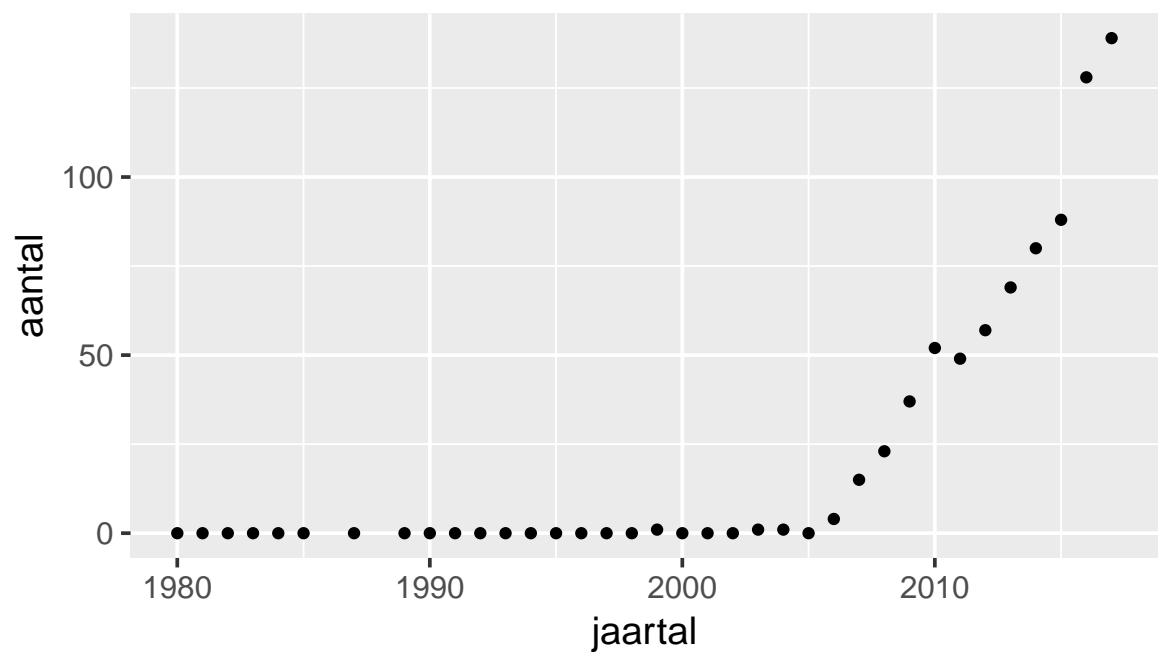

\subsubsection{Trendberekening}

Methode: Poisson smoother

Parameterschattingen

\begin{tabular}{|c|c|c|c|c|}
\hline params & Estimate & Std..Error & statistic & p. value \\
\hline Intercept & -4.674618 & 2.301825 & -2.030831 & $4.227210 \mathrm{e}-02$ \\
\hline s(Jaartal) & 2.000854 & 2.088734 & 351.596106 & $5.161338 \mathrm{e}-53$ \\
\hline
\end{tabular}

Trend Zuid-Europese libellensoorten gaffelwaterjuffer

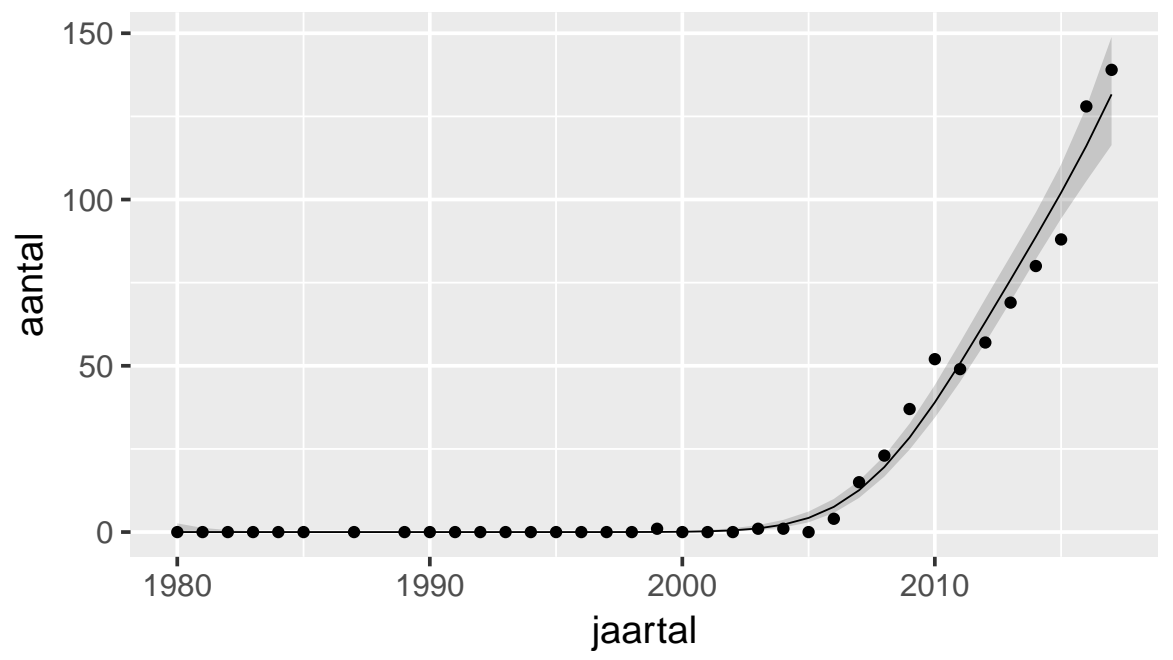

\subsubsection{Verwachting 2020}




\subsubsection{Conclusie}

Significante exponentiële toename. 


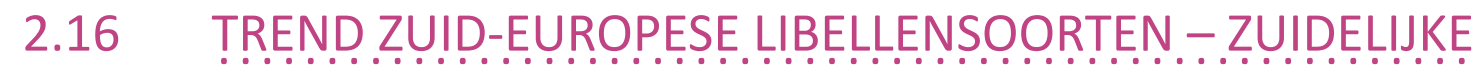
GLAZENMAKER

\subsubsection{Ruwe data}

\begin{tabular}{rr}
\hline Jaartal & aantal \\
\hline 1980 & 0.00 \\
1981 & 0.00 \\
1982 & 0.00 \\
1983 & 0.00 \\
1984 & 0.00 \\
1985 & 0.00 \\
1987 & 0.00 \\
1989 & 0.00 \\
1990 & 0.00 \\
1991 & 1.00 \\
1992 & 0.00 \\
1993 & 0.00 \\
1994 & 1.00 \\
1995 & 17.00 \\
1996 & 2.00 \\
1997 & 2.00 \\
1998 & 1.00 \\
1999 & 0.00 \\
2000 & 2.00 \\
2001 & 1.00 \\
2002 & 1.00 \\
2003 & 7.00 \\
2004 & 8.00 \\
2005 & 8.00 \\
2006 & 13.00 \\
2007 & 0.00 \\
2008 & 7.00 \\
2009 & 14.00 \\
2010 & 18.00 \\
2011 & 0.00 \\
2012 & 3.00 \\
2013 & 15.00 \\
2014 & 12.00 \\
2015 & 8.00 \\
2016 & 12.00 \\
2017 & 13.00 \\
\hline \hline &
\end{tabular}


Trend Zuid-Europese libellensoorten zuidelijke glazenmaker

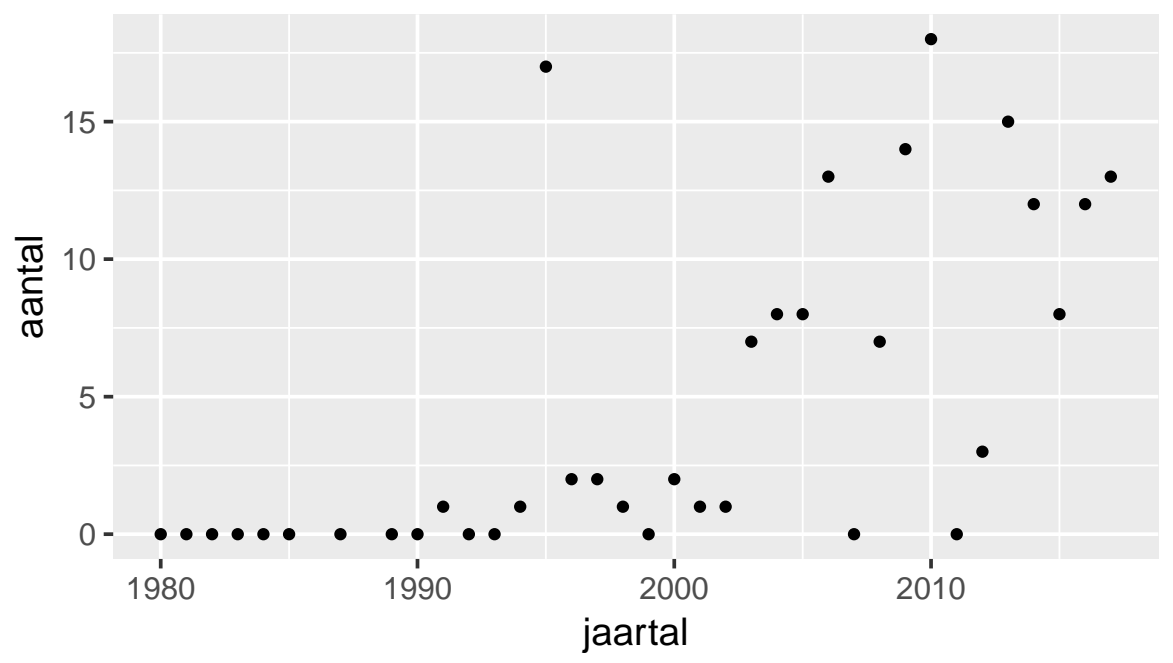

\subsubsection{Trendberekening}

Methode: Poisson smoother

Parameterschattingen

params Estimate Std..Error statistic p.value

1 Intercept $0.6592133 \quad 0.2376128 \quad 2.774317 \quad 5.531774 \mathrm{e}-03$

$2 \mathrm{~s}$ (Jaartal) $2.6838102 \quad 2.9186089 \quad 67.427910 \quad 2.164431 \mathrm{e}-12$

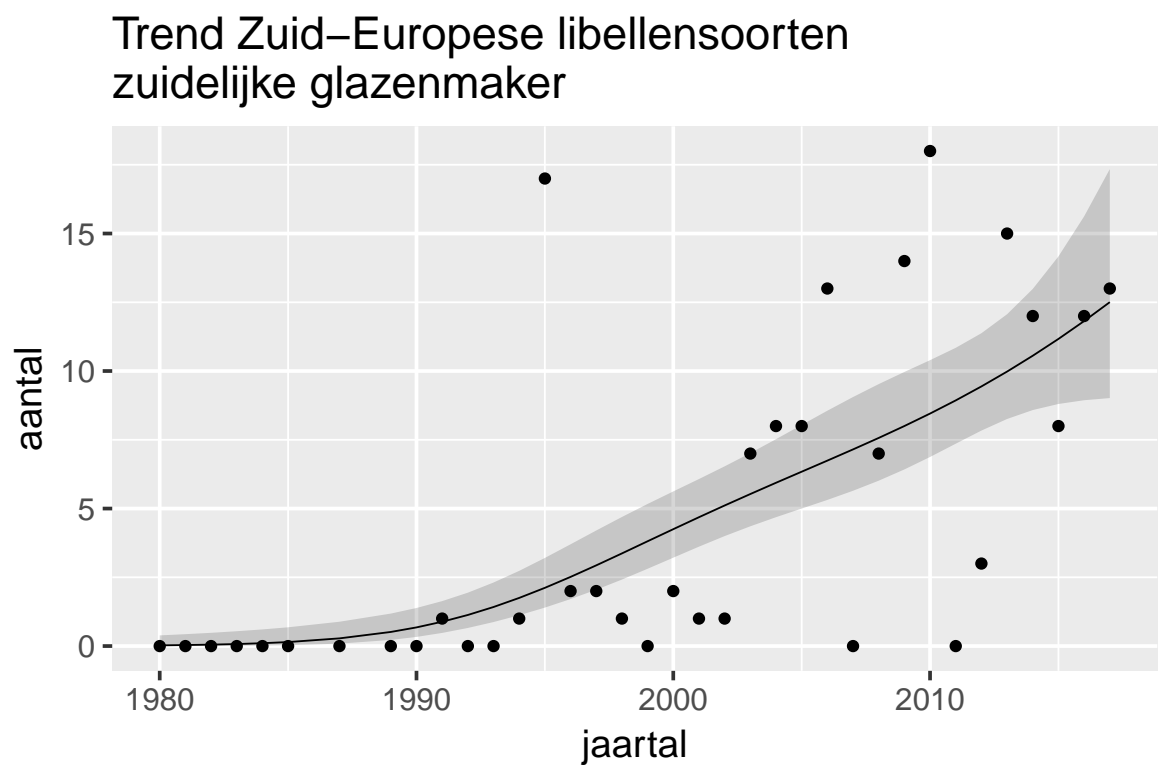

\subsubsection{Verwachting 2020}

$[9.08,24.2]$ 


\subsubsection{Conclusie}

Significante toename. 


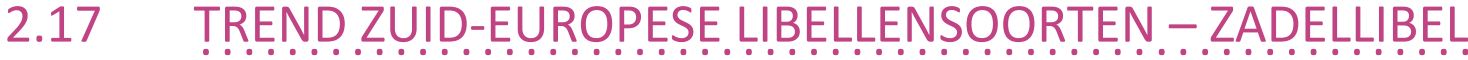

\subsubsection{Ruwe data}

\begin{tabular}{cc}
\hline Jaartal & aantal \\
\hline 1980 & 0.00 \\
1981 & 0.00 \\
1982 & 0.00 \\
1983 & 0.00 \\
1984 & 0.00 \\
1985 & 0.00 \\
1987 & 0.00 \\
1989 & 0.00 \\
1990 & 0.00 \\
1991 & 0.00 \\
1992 & 0.00 \\
1993 & 0.00 \\
1994 & 0.00 \\
1995 & 0.00 \\
1996 & 0.00 \\
1997 & 0.00 \\
1998 & 1.00 \\
1999 & 0.00 \\
2000 & 0.00 \\
2001 & 0.00 \\
2002 & 0.00 \\
2003 & 0.00 \\
2004 & 0.00 \\
2005 & 1.00 \\
2006 & 0.00 \\
2007 & 1.00 \\
2008 & 1.00 \\
2009 & 0.00 \\
2010 & 0.00 \\
2011 & 7.00 \\
2012 & 0.00 \\
2013 & 0.00 \\
2014 & 0.00 \\
2015 & 7.00 \\
2016 & 1.00 \\
\hline \hline & 3.00 \\
\hline
\end{tabular}




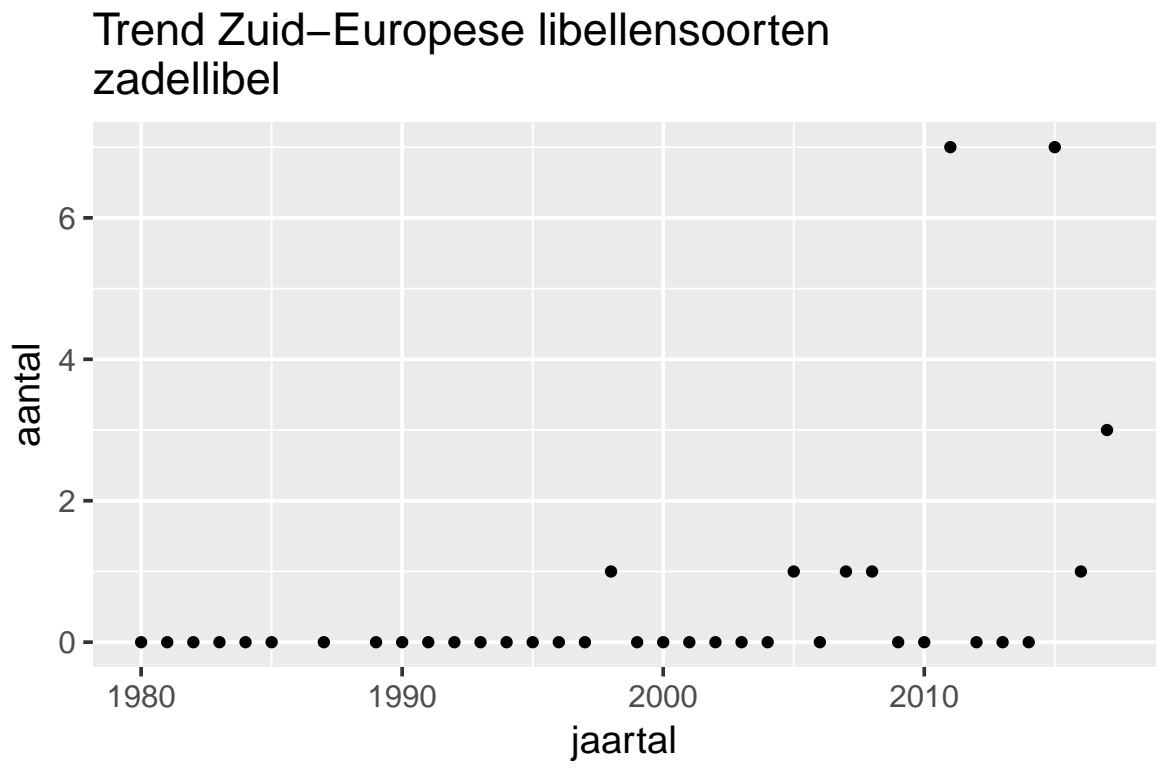

\subsubsection{Trendberekening}

Methode: Poisson

Parameterschattingen

params Estimate Std..Error statistic p.value

1 Intercept $-5.51852391 .33212183-4.142657 \quad 3.433051 \mathrm{e}-05$

2 cJaar $0.1846365 \quad 0.04091783 \quad 4.512372 \quad 6.410668 \mathrm{e}-06$

Trend Zuid-Europese libellensoorten zadellibel

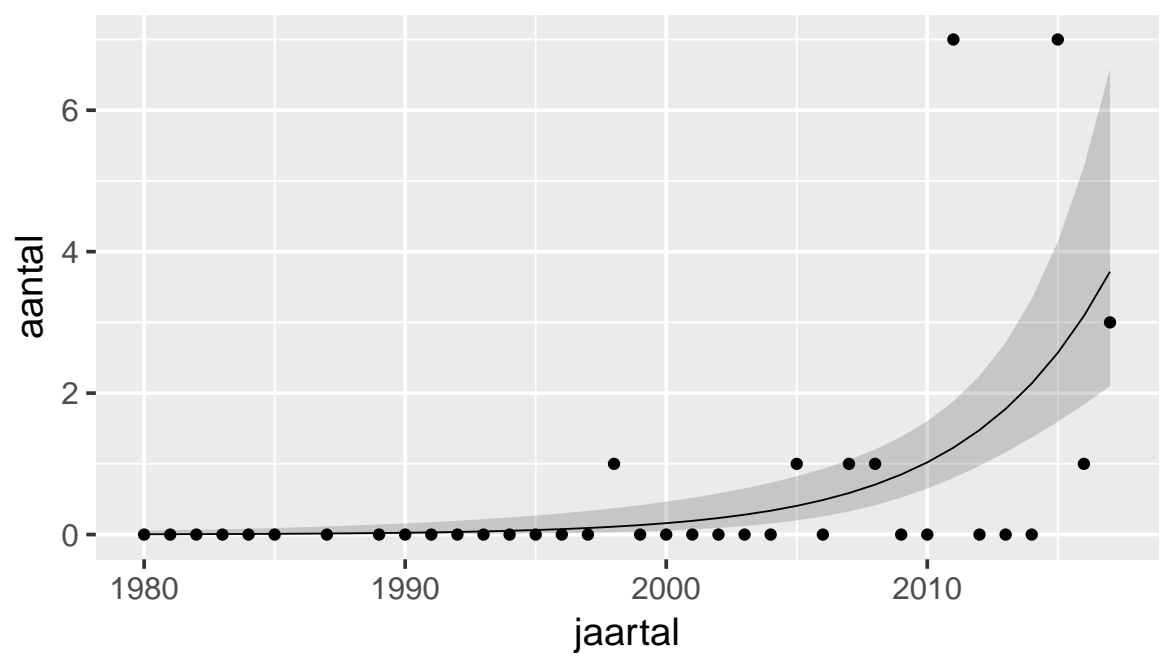

\subsubsection{Verwachting 2020}

$[3.04,13.8]$ 


\subsubsection{Conclusie}

Significante toename. 


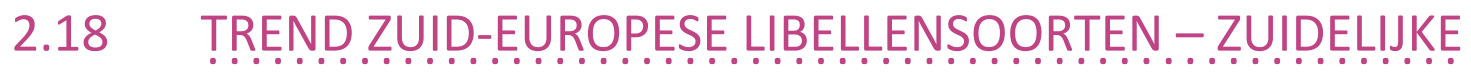
KEIZERLIBEL

\subsubsection{Ruwe data}

\begin{tabular}{rr}
\hline Jaartal & aantal \\
\hline 1980 & 0.00 \\
1981 & 0.00 \\
1982 & 0.00 \\
1983 & 0.00 \\
1984 & 1.00 \\
1985 & 0.00 \\
1987 & 0.00 \\
1989 & 0.00 \\
1990 & 0.00 \\
1991 & 0.00 \\
1992 & 0.00 \\
1993 & 0.00 \\
1994 & 0.00 \\
1995 & 0.00 \\
1996 & 0.00 \\
1997 & 0.00 \\
1998 & 0.00 \\
1999 & 4.00 \\
2000 & 3.00 \\
2001 & 0.00 \\
2002 & 1.00 \\
2003 & 5.00 \\
2004 & 2.00 \\
2005 & 12.00 \\
2006 & 9.00 \\
2007 & 5.00 \\
2008 & 15.00 \\
2009 & 10.00 \\
2010 & 23.00 \\
2011 & 24.00 \\
2012 & 23.00 \\
2013 & 40.00 \\
2014 & 48.00 \\
2015 & 73.00 \\
2016 & 71.00 \\
2017 & 105.00 \\
\hline \hline &
\end{tabular}


Trend Zuid-Europese libellensoorten zuidelijke keizerlibel

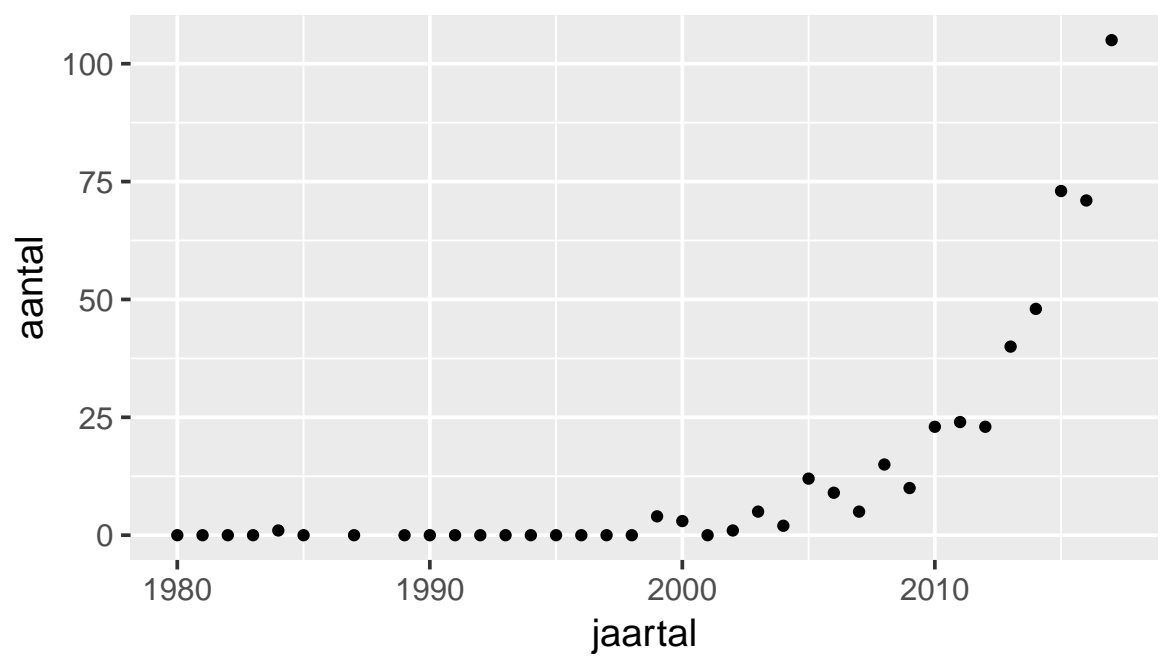

\subsubsection{Trendberekening}

Methode: Poisson

Parameterschattingen

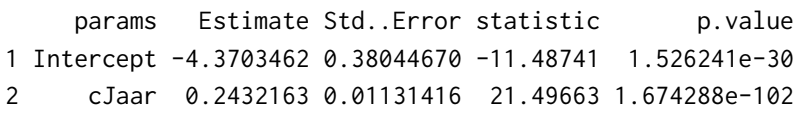

\section{Trend Zuid-Europese libellensoorten} zuidelijke keizerlibel

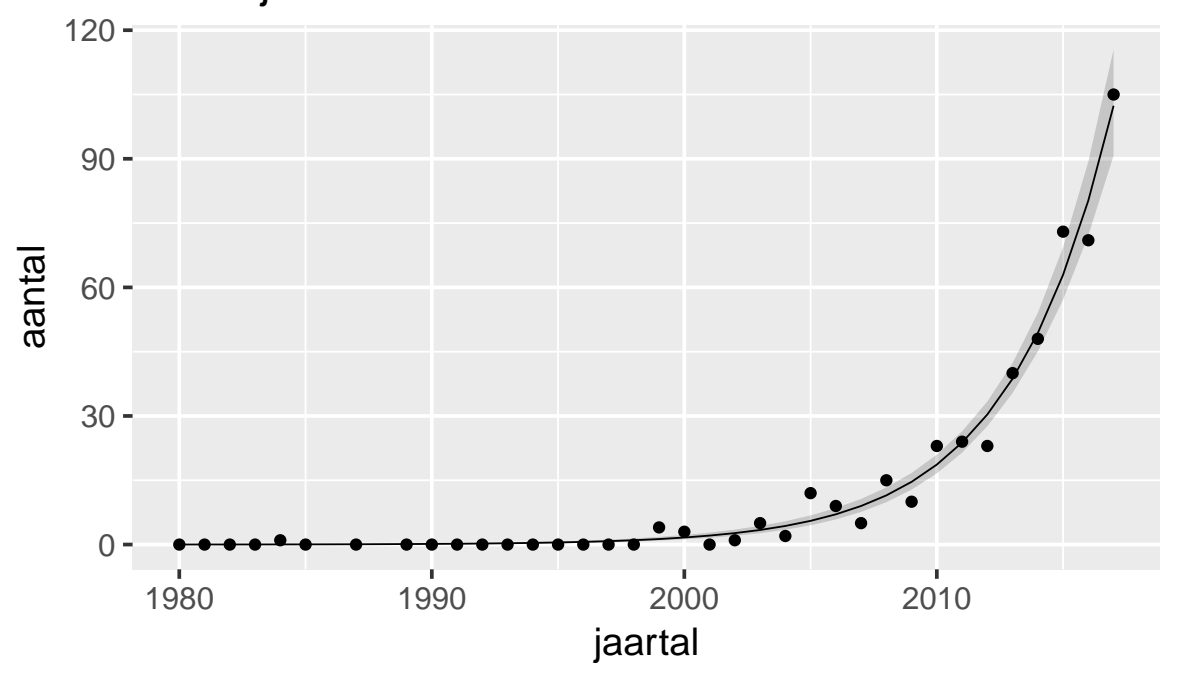

\subsubsection{Verwachting 2020}

$[179,252]$ 


\subsubsection{Conclusie}

Significante exponentiële toename. 


\subsubsection{Ruwe data}

\begin{tabular}{rr}
\hline Jaartal & aantal \\
\hline 1980 & 0.00 \\
1981 & 0.00 \\
1982 & 0.00 \\
1983 & 0.00 \\
1984 & 0.00 \\
1985 & 0.00 \\
1987 & 1.00 \\
1989 & 1.00 \\
1990 & 1.00 \\
1991 & 4.00 \\
1992 & 5.00 \\
1993 & 6.00 \\
1994 & 20.00 \\
1995 & 13.00 \\
1996 & 10.00 \\
1997 & 12.00 \\
1998 & 4.00 \\
1999 & 26.00 \\
2000 & 25.00 \\
2001 & 14.00 \\
2002 & 26.00 \\
2003 & 53.00 \\
2004 & 25.00 \\
2005 & 35.00 \\
2006 & 70.00 \\
2007 & 55.00 \\
2008 & 116.00 \\
2009 & 132.00 \\
2010 & 138.00 \\
2011 & 96.00 \\
2012 & 140.00 \\
2013 & 197.00 \\
2014 & 177.00 \\
2015 & 190.00 \\
2016 & 214.00 \\
2017 & 312.00 \\
\hline \hline &
\end{tabular}


Trend Zuid-Europese libellensoorten vuurlibel

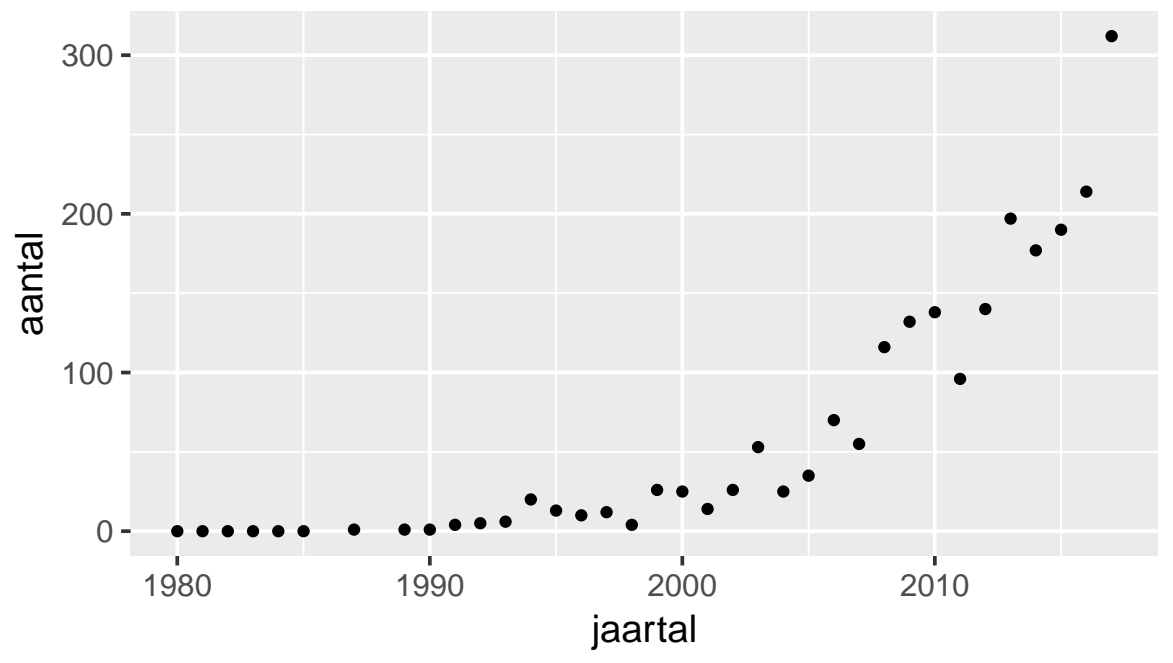

\subsubsection{Trendberekening}

Methode: Poisson smoother

Parameterschattingen

params Estimate Std..Error statistic p.value

1 Intercept $2.685921 \quad 0.09174566 \quad 29.27573 \quad 2.113173 \mathrm{e}-188$

2 s(Jaartal) $2.4057602 .725919391707 .69690 \quad 4.719052 \mathrm{e}-257$

\section{Trend Zuid-Europese libellensoorten} vuurlibel

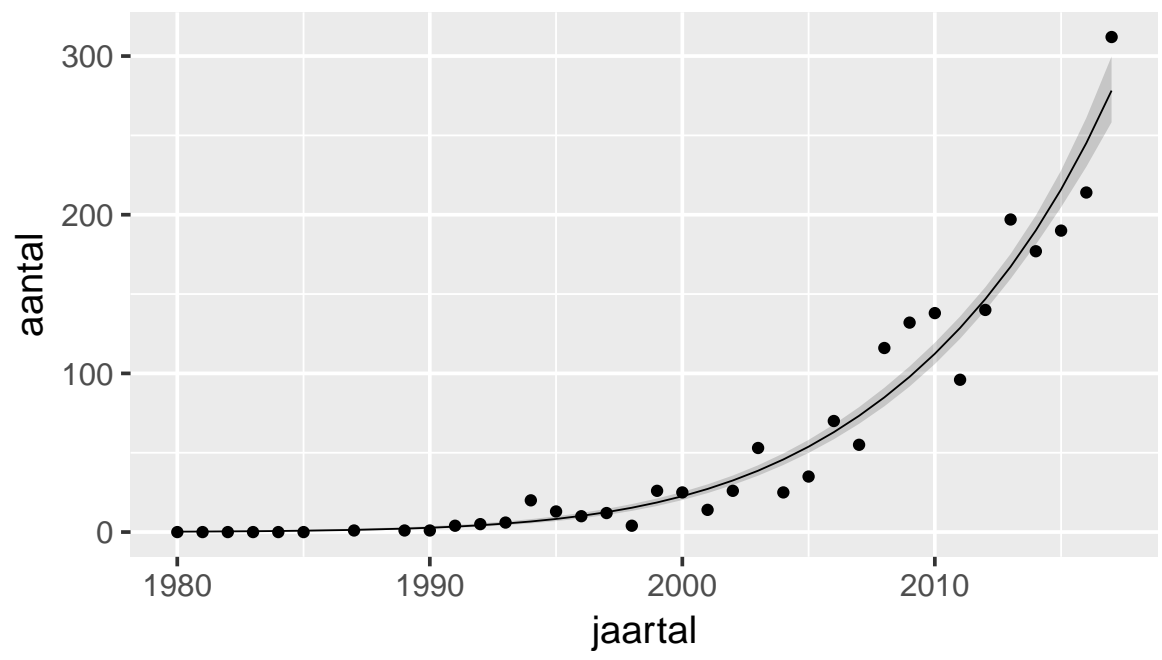

\subsubsection{Verwachting 2020}

$[362,457]$ 


\subsubsection{Conclusie}

Significante exponentiële toename. 


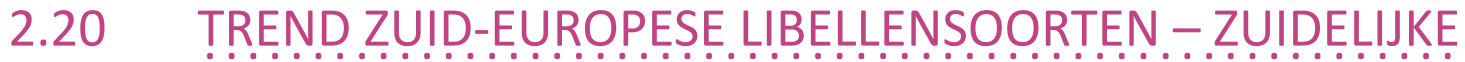
OEVERLIBEL

\subsubsection{Ruwe data}

\begin{tabular}{rr}
\hline Jaartal & aantal \\
\hline 1980 & 0.00 \\
1981 & 0.00 \\
1982 & 0.00 \\
1983 & 0.00 \\
1984 & 0.00 \\
1985 & 0.00 \\
1987 & 0.00 \\
1989 & 0.00 \\
1990 & 0.00 \\
1991 & 0.00 \\
1992 & 0.00 \\
1993 & 0.00 \\
1994 & 1.00 \\
1995 & 1.00 \\
1996 & 1.00 \\
1997 & 1.00 \\
1998 & 0.00 \\
1999 & 0.00 \\
2000 & 0.00 \\
2001 & 2.00 \\
2002 & 1.00 \\
2003 & 2.00 \\
2004 & 6.00 \\
2005 & 1.00 \\
2006 & 8.00 \\
2007 & 3.00 \\
2008 & 6.00 \\
2009 & 8.00 \\
2010 & 5.00 \\
2011 & 6.00 \\
2012 & 11.00 \\
2013 & 13.00 \\
2014 & 17.00 \\
2015 & 14.00 \\
2016 & 22.00 \\
2017 & 20.00 \\
\hline \hline & \\
\end{tabular}


Trend Zuid-Europese libellensoorten zuidelijke oeverlibel

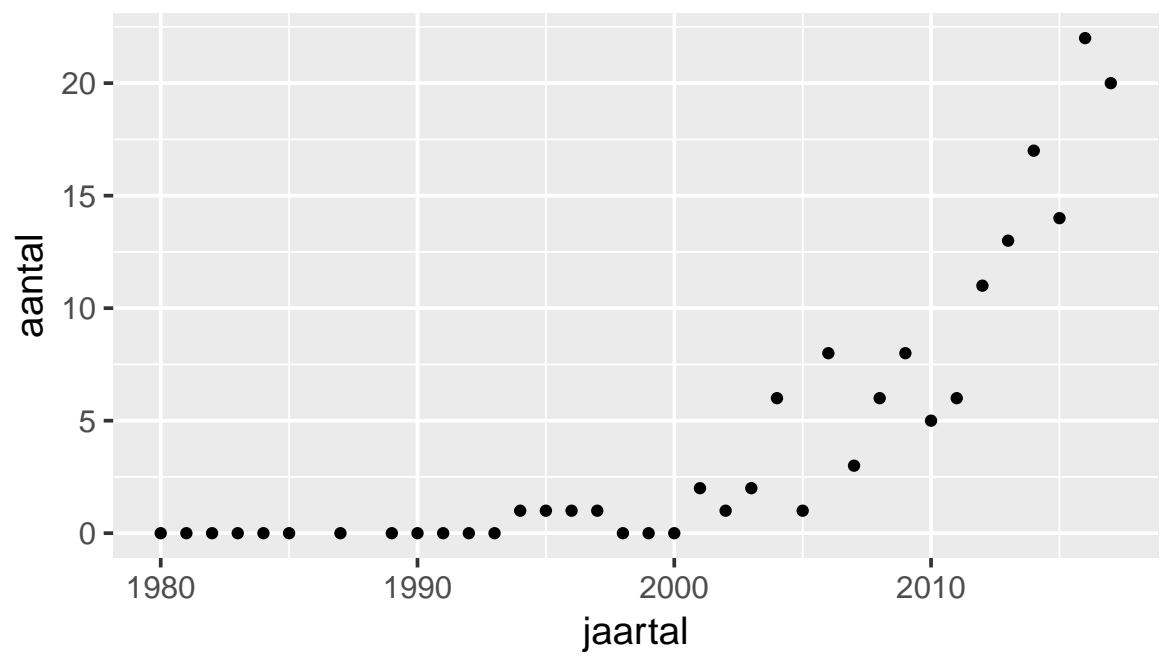

\subsubsection{Trendberekening}

Methode: Poisson smoother

Parameterschattingen

$\begin{array}{rrrrrr}\text { params } & \text { Estimate } & \text { Std..Error } & \text { statistic } & \text { p.value } \\ 1 & \text { Intercept } & -0.09951352 & 0.2813092 & -0.3537514 & 7.235252 \mathrm{e}-01 \\ 2 \mathrm{~s} \text { (Jaartal) } & 1.51191467 & 1.8159830 & 146.5550204 & 3.169479 \mathrm{e}-18\end{array}$

Trend Zuid-Europese libellensoorten zuidelijke oeverlibel

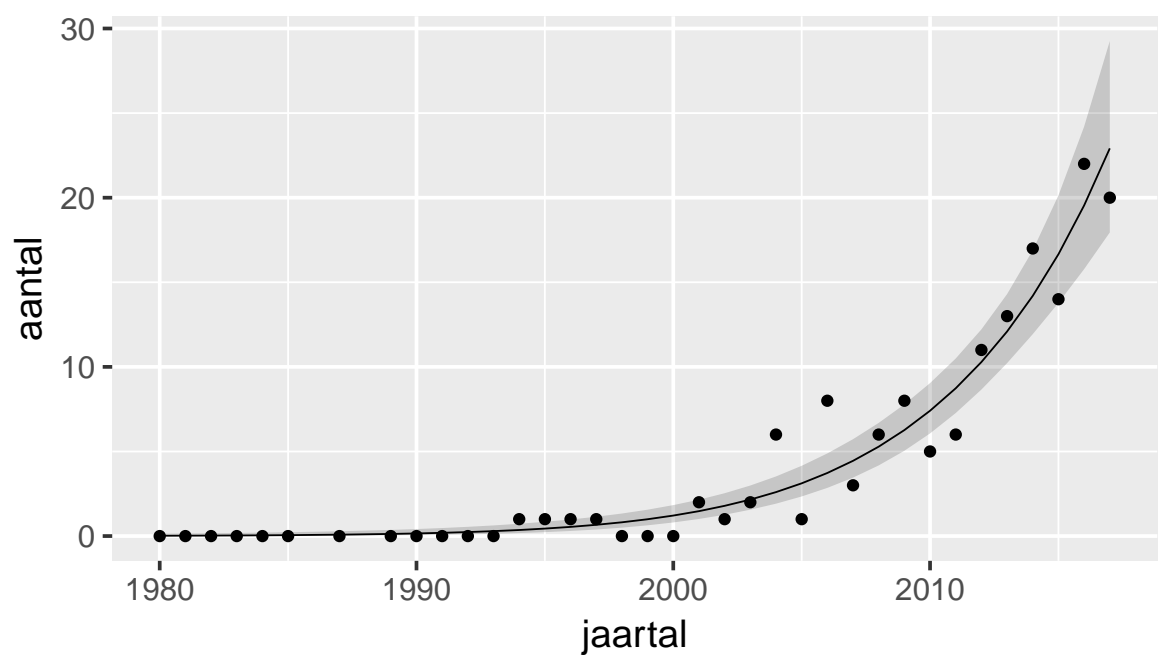

\subsubsection{Verwachting 2020}

$[25.9,52.7]$ 


\subsubsection{Conclusie}

Significante exponentiële toename. 


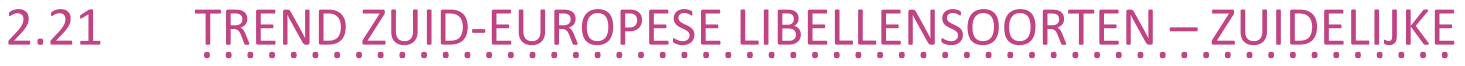
HEIDELIBEL

\subsubsection{Ruwe data}

\begin{tabular}{rr}
\hline Jaartal & aantal \\
\hline 1980 & 0.00 \\
1981 & 0.00 \\
1982 & 0.00 \\
1983 & 0.00 \\
1984 & 0.00 \\
1985 & 0.00 \\
1987 & 0.00 \\
1989 & 0.00 \\
1990 & 0.00 \\
1991 & 0.00 \\
1992 & 0.00 \\
1993 & 0.00 \\
1994 & 0.00 \\
1995 & 0.00 \\
1996 & 0.00 \\
1997 & 0.00 \\
1998 & 0.00 \\
1999 & 0.00 \\
2000 & 2.00 \\
2001 & 1.00 \\
2002 & 0.00 \\
2003 & 3.00 \\
2004 & 2.00 \\
2005 & 0.00 \\
2006 & 4.00 \\
2007 & 3.00 \\
2008 & 3.00 \\
2009 & 12.00 \\
2010 & 8.00 \\
2011 & 4.00 \\
2012 & 4.00 \\
2013 & 30.00 \\
2014 & 17.00 \\
2015 & 14.00 \\
2016 & 20.00 \\
2017 & 18.00 \\
\hline \hline & \\
\end{tabular}


Trend Zuid-Europese libellensoorten zuidelijke heidelibel

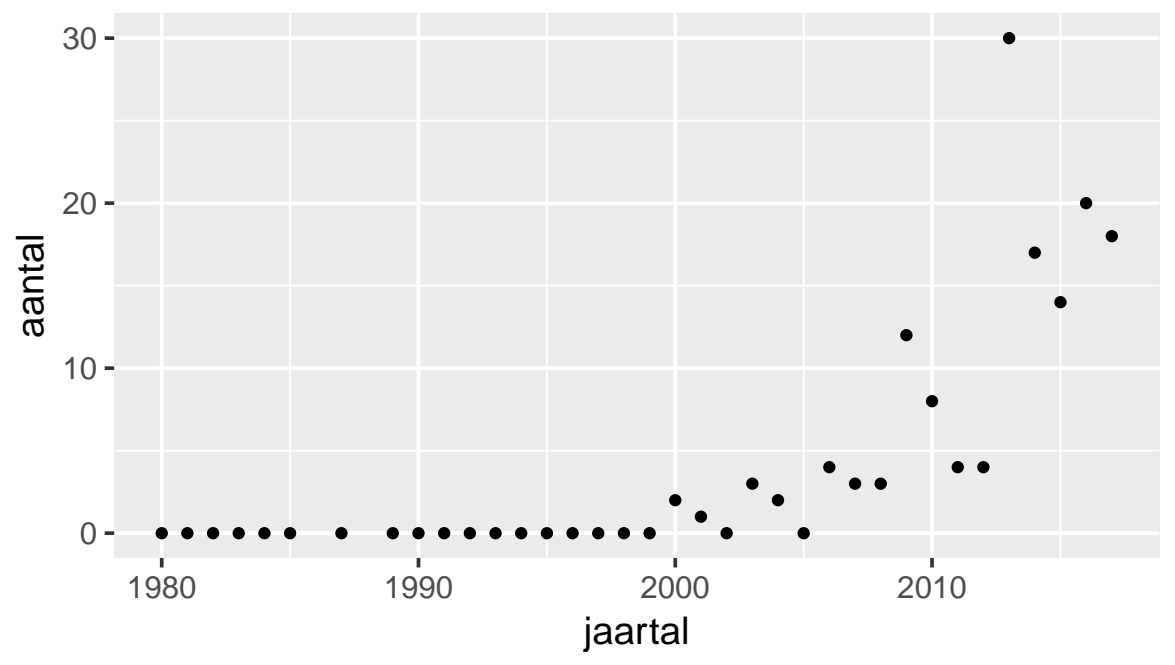

\subsubsection{Trendberekening}

Methode: Poisson smoother

Parameterschattingen

params Estimate Std..Error statistic p.value

1 Intercept $-1.578810 \quad 0.8902336 \quad-1.773479 \quad 7.614939 \mathrm{e}-02$

$2 \mathrm{~s}$ (Jaartal) $1.912815 \quad 2.151694794 .777758 \quad 1.546163 \mathrm{e}-15$

\section{Trend Zuid-Europese libellensoorten zuidelijke heidelibel}

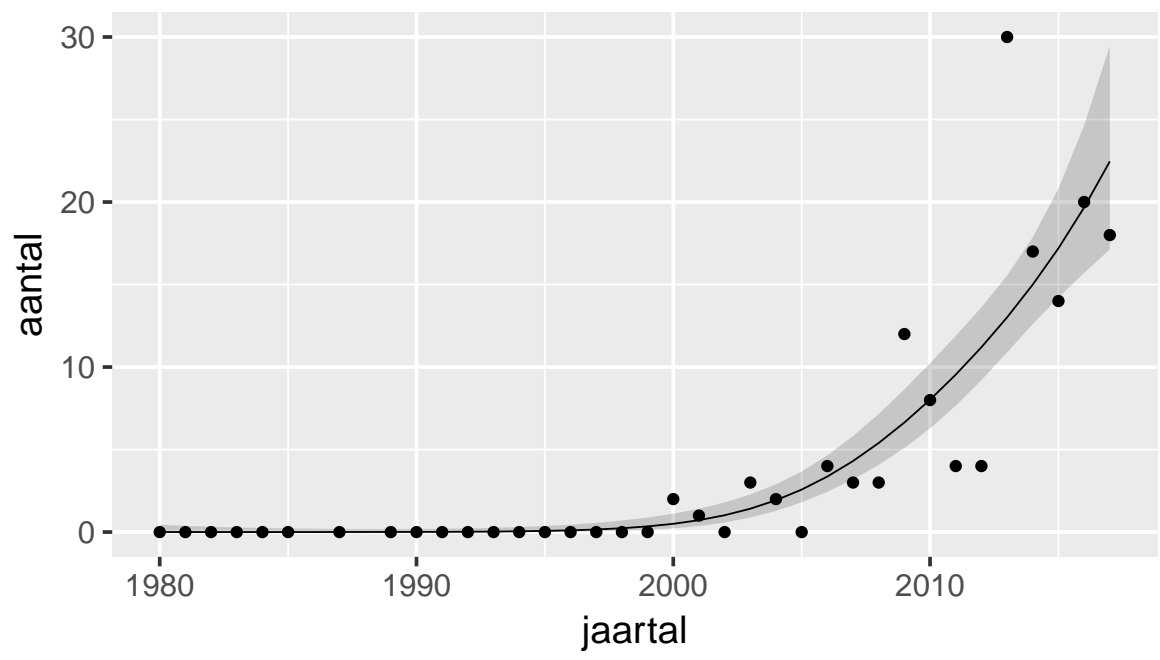

\subsubsection{Verwachting 2020}

$[21.5,52.1]$ 


\subsubsection{Conclusie}

Significante exponentiële toename. 


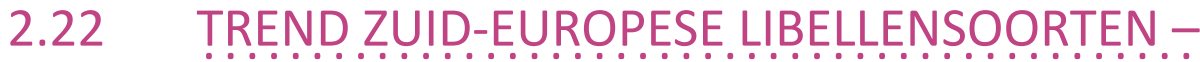
ZWERVENDE HEIDELIB!BEL

\subsubsection{Ruwe data}

\begin{tabular}{rr}
\hline Jaartal & aantal \\
\hline 1980 & 0.00 \\
1981 & 0.00 \\
1982 & 0.00 \\
1983 & 0.00 \\
1984 & 1.00 \\
1985 & 0.00 \\
1987 & 0.00 \\
1989 & 1.00 \\
1990 & 0.00 \\
1991 & 1.00 \\
1992 & 2.00 \\
1993 & 2.00 \\
1994 & 2.00 \\
1995 & 1.00 \\
1996 & 16.00 \\
1997 & 8.00 \\
1998 & 5.00 \\
1999 & 10.00 \\
2000 & 8.00 \\
2001 & 0.00 \\
2002 & 16.00 \\
2003 & 19.00 \\
2004 & 8.00 \\
2005 & 9.00 \\
2006 & 36.00 \\
2007 & 56.00 \\
2008 & 22.00 \\
2009 & 75.00 \\
2010 & 20.00 \\
2011 & 22.00 \\
2012 & 106.00 \\
2013 & 82.00 \\
2014 & 43.00 \\
2015 & 150.00 \\
2016 & 44.00 \\
2017 & 220.00 \\
\hline &
\end{tabular}


Trend Zuid-Europese libellensoorten zwervende heidelibel

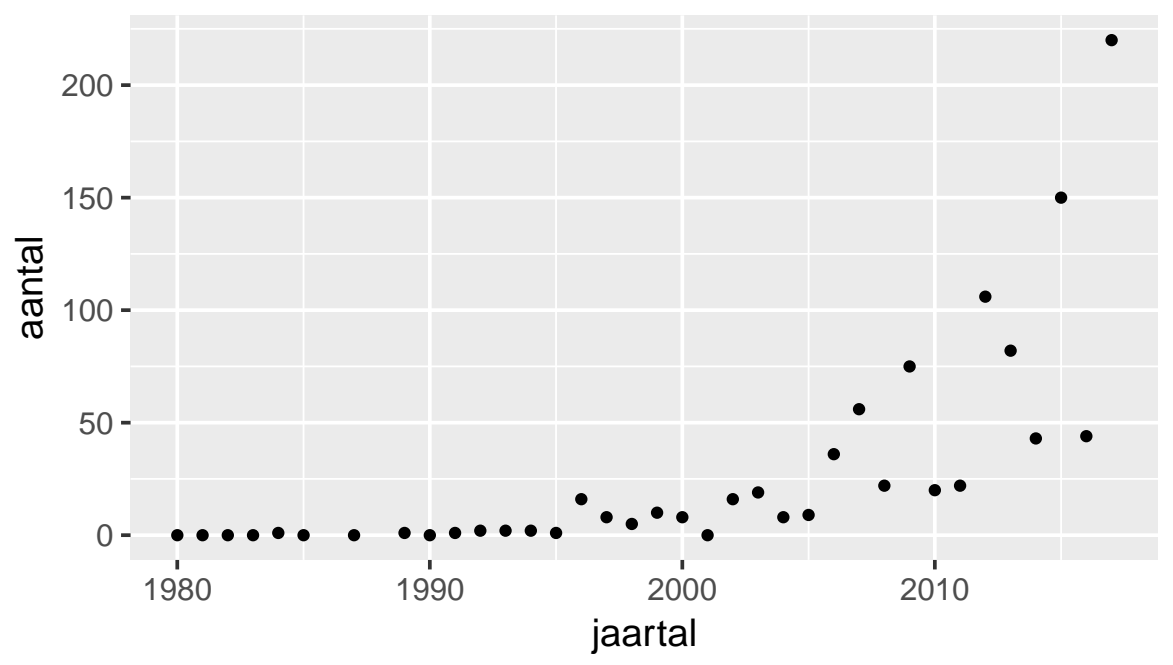

\subsubsection{Trendberekening}

Methode: Poisson smoother

Parameterschattingen

params Estimate Std..Error statistic p.value

1 Intercept $1.755172 \quad 0.1750245 \quad 10.02815 \quad 1.146446 \mathrm{e}-23$

$2 \mathrm{~s}$ (Jaartal) 2.745576 $2.9440811898 .99366 \quad 7.374493 \mathrm{e}-158$

\section{Trend Zuid-Europese libellensoorten} zwervende heidelibel

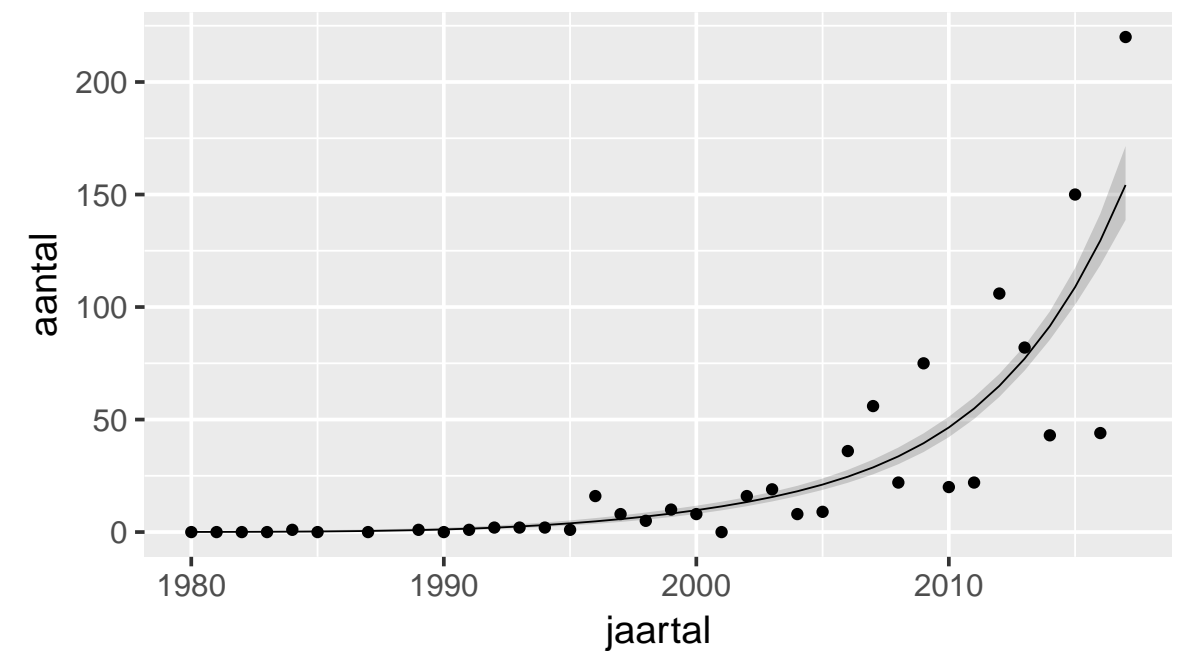

\subsubsection{Verwachting $\mathbf{2 0 2 0}$}

$[219,310]$ 


\subsubsection{Conclusie}

Significante exponentiële toename. 


\subsubsection{Ruwe data}

\begin{tabular}{rr}
\hline Jaartal & week van het jaar \\
\hline 2002 & 17.30 \\
2003 & 17.70 \\
2004 & 16.80 \\
2005 & 18.30 \\
2006 & 17.50 \\
2007 & 16.80 \\
2008 & 17.80 \\
2009 & 16.50 \\
2010 & 18.30 \\
2011 & 16.20 \\
2012 & 18.00 \\
2013 & 18.10 \\
2014 & 16.00 \\
2014 & 17.40 \\
2015 & 17.40 \\
2016 & 17.70 \\
2017 & 17.70 \\
\hline \hline
\end{tabular}

\section{Bladontwikkeling beuk bladbegin}

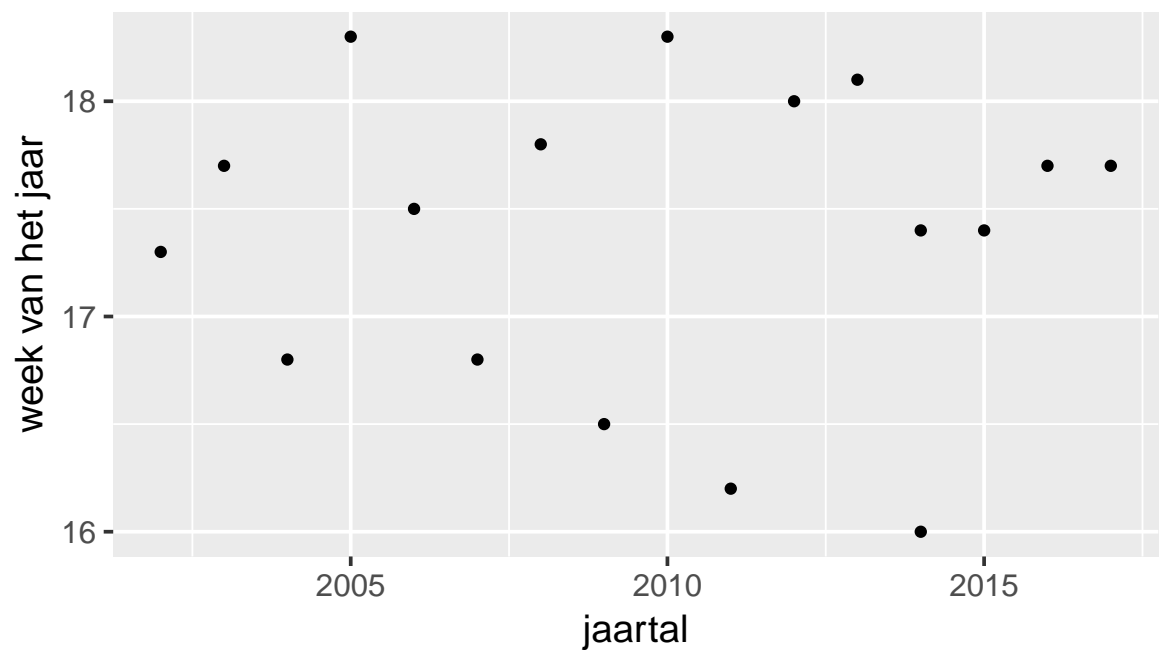

\subsubsection{Trendberekening}

Methode: Lineair

Parameterschattingen 
params Estimate Std..Error statistic p.value

1 Intercept $17.3903664080 .34434427 \quad 50.50284814 \quad 3.627699 \mathrm{e}-18$

2 cJaar $-0.0010320520 .03816359-0.027042849 .787821 \mathrm{e}-01$

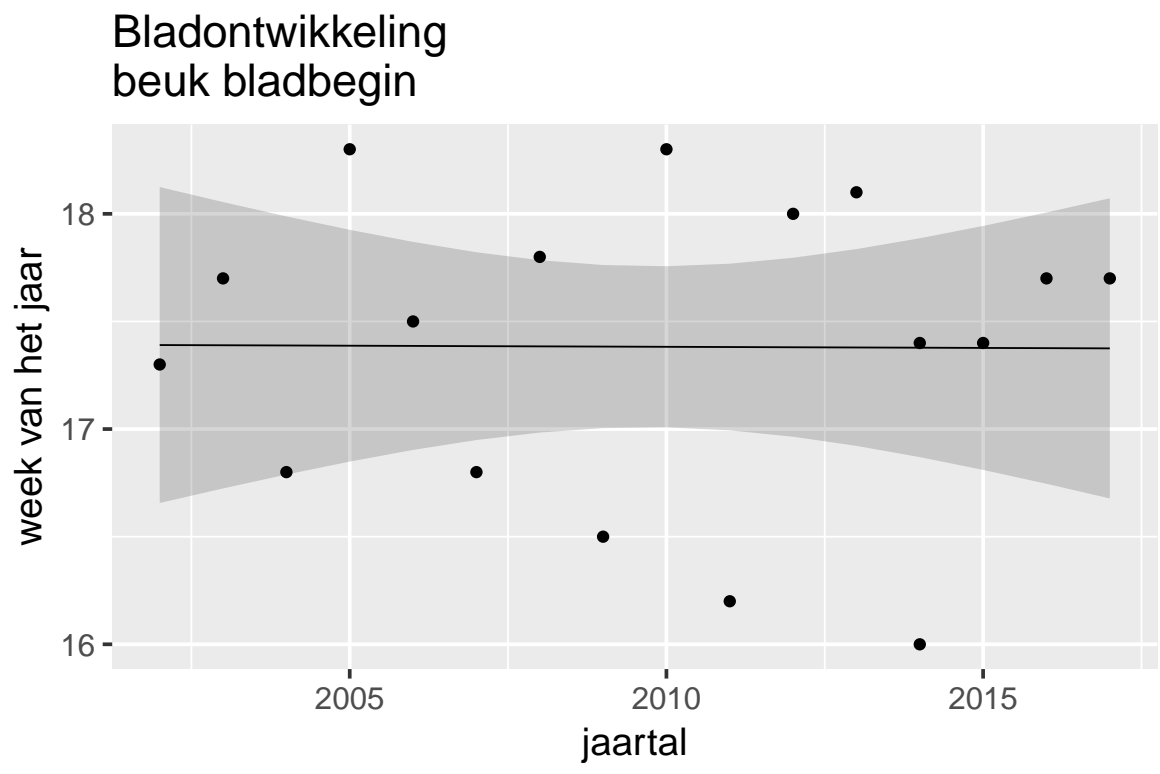

\subsubsection{Verwachting 2020}

$[15.6,19.2]$

\subsubsection{Conclusie}

Geen significante trend $(p=0.98)$. 
2.24.1 Ruwe data

\begin{tabular}{rr}
\hline Jaartal & week van het jaar \\
\hline 2002 & 20.00 \\
2003 & 18.90 \\
2004 & 18.30 \\
2005 & 19.60 \\
2006 & 18.90 \\
2007 & 17.80 \\
2008 & 18.60 \\
2009 & 17.60 \\
2010 & 19.50 \\
2011 & 17.60 \\
2012 & 19.30 \\
2013 & 19.10 \\
2014 & 17.60 \\
2014 & 18.80 \\
2015 & 18.80 \\
2016 & 19.30 \\
2017 & 19.30 \\
\hline \hline
\end{tabular}

Bladontwikkeling beuk bladvol

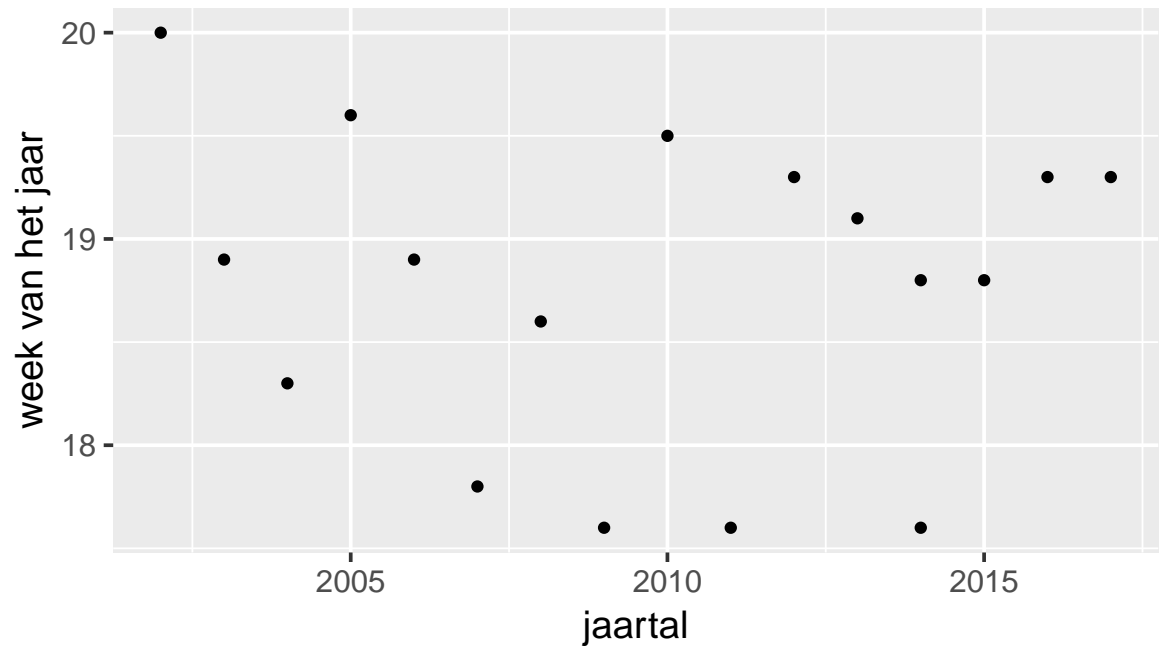

\subsubsection{Trendberekening}

Methode: Gaussian smoother

Parameterschattingen 
params Estimate Std..Error statistic p.value

1 Intercept $18.764706 \quad 0.1731834 \quad 108.35161 \quad 3.772540 \mathrm{e}-22$

$\begin{array}{llllll}2 \mathrm{~s} \text { (Jaartal) } & 1.780416 & 2.1632351 & 1.09959 & 3.436039 \mathrm{e}-01\end{array}$

\section{Bladontwikkeling beuk bladvol}

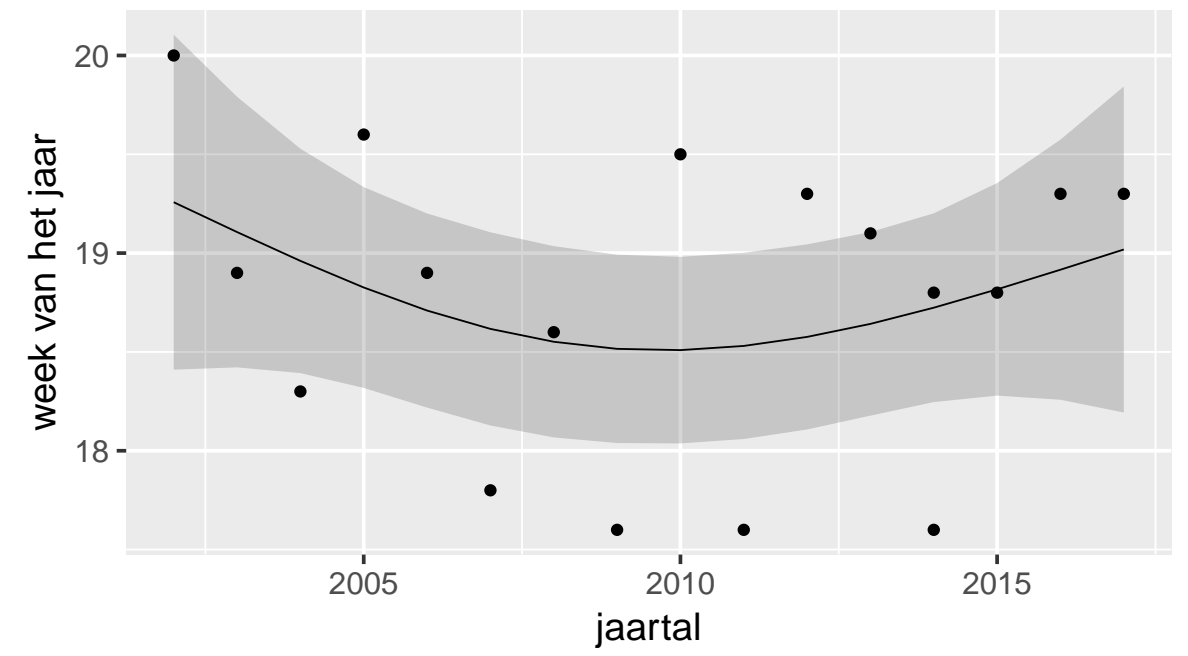

\subsubsection{Verwachting 2020}

$[17.9,20.8]$

\subsubsection{Conclusie}

Geen significante trend $(p=0.34)$. 


\subsubsection{Ruwe data}

\begin{tabular}{rr}
\hline Jaartal & week van het jaar \\
\hline 2003 & 17.50 \\
2004 & 18.10 \\
2005 & 17.80 \\
2006 & 19.50 \\
2007 & 16.20 \\
2008 & 18.00 \\
2009 & 17.10 \\
2010 & 18.40 \\
2011 & 16.70 \\
2012 & 17.00 \\
2013 & 18.80 \\
2014 & 16.30 \\
2014 & 17.60 \\
2015 & 17.60 \\
2016 & 16.90 \\
2017 & 16.90 \\
\hline \hline
\end{tabular}

\section{Bladontwikkeling} eik bladbegin

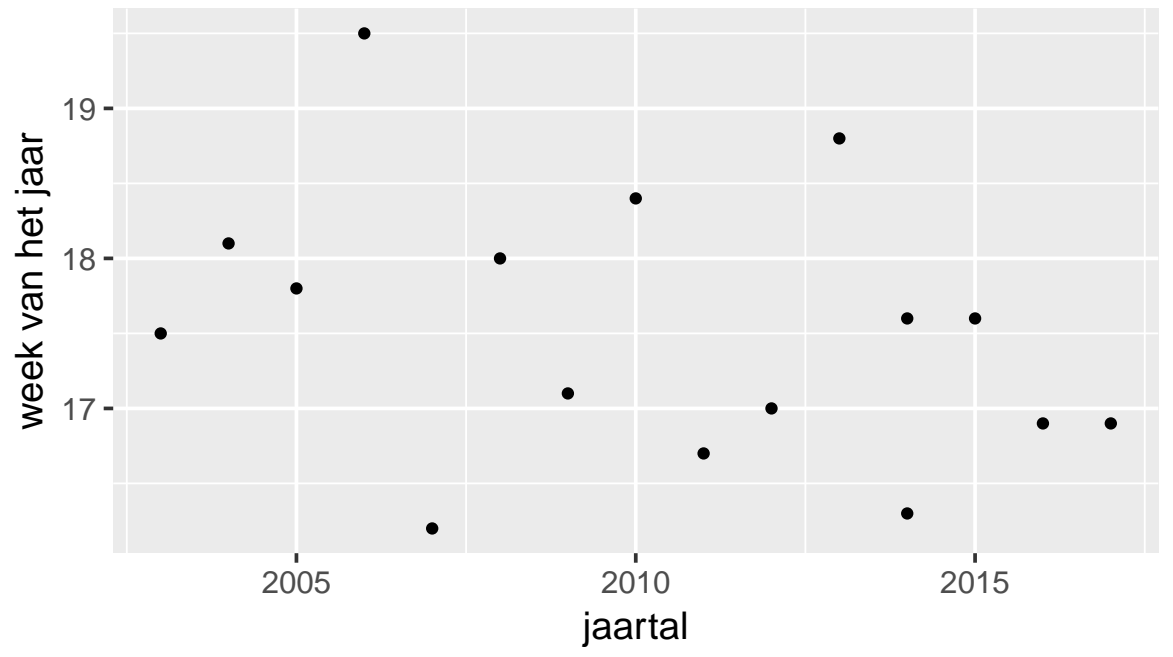

\subsubsection{Trendberekening}

Methode: Lineair

Parameterschattingen

params Estimate Std..Error statistic p.value 
1 Intercept $18.00423744 \quad 0.4313085941 .743286 \quad 4.295395 \mathrm{e}-16$

2 cJaar $-0.06610172 \quad 0.05118691 \quad-1.2913792 .174872 \mathrm{e}-01$

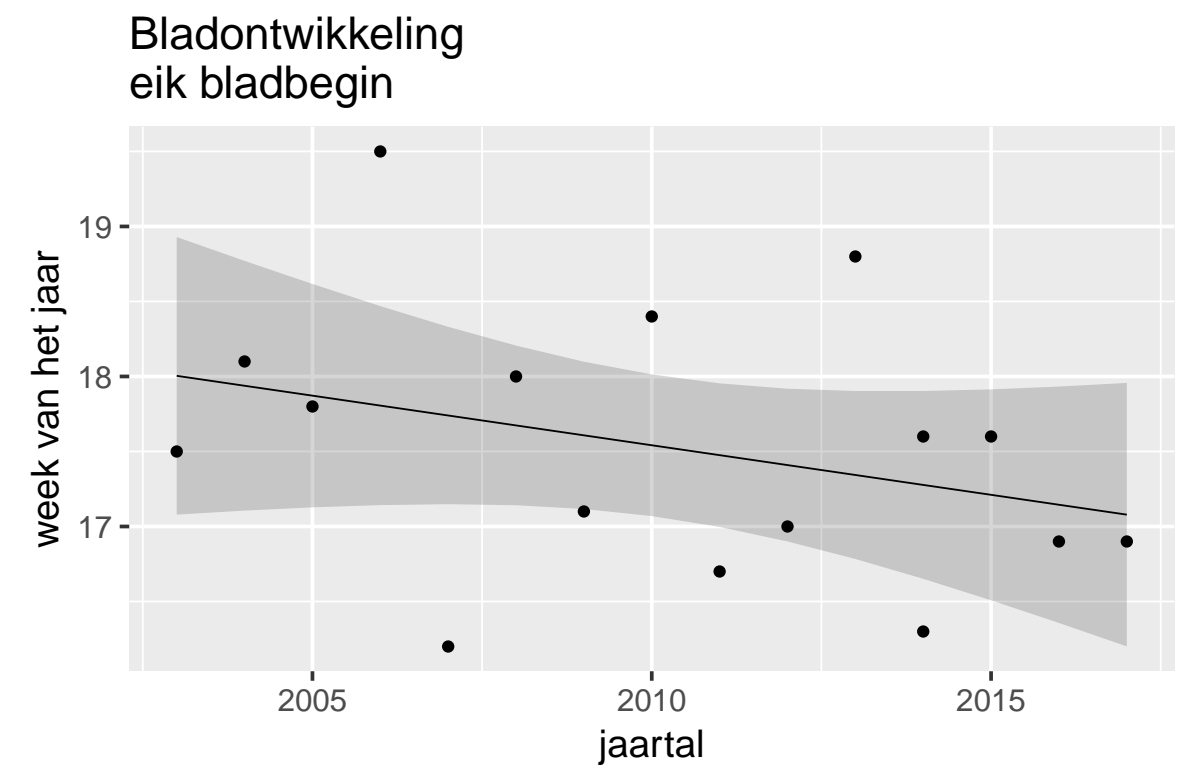

\subsubsection{Verwachting 2020}

$[14.7,19.1]$

\subsubsection{Conclusie}

Geen significante trend $(p=0.22)$. 


\subsubsection{Ruwe data}

\begin{tabular}{rr}
\hline Jaartal & week van het jaar \\
\hline 2003 & 19.40 \\
2004 & 20.40 \\
2005 & 20.80 \\
2006 & 21.00 \\
2007 & 17.80 \\
2008 & 20.00 \\
2009 & 19.90 \\
2010 & 21.80 \\
2013 & 21.40 \\
2014 & 19.00 \\
2014 & 20.00 \\
2015 & 20.00 \\
2016 & 21.10 \\
2017 & 21.10 \\
\hline \hline
\end{tabular}

Bladontwikkeling eik bladvol

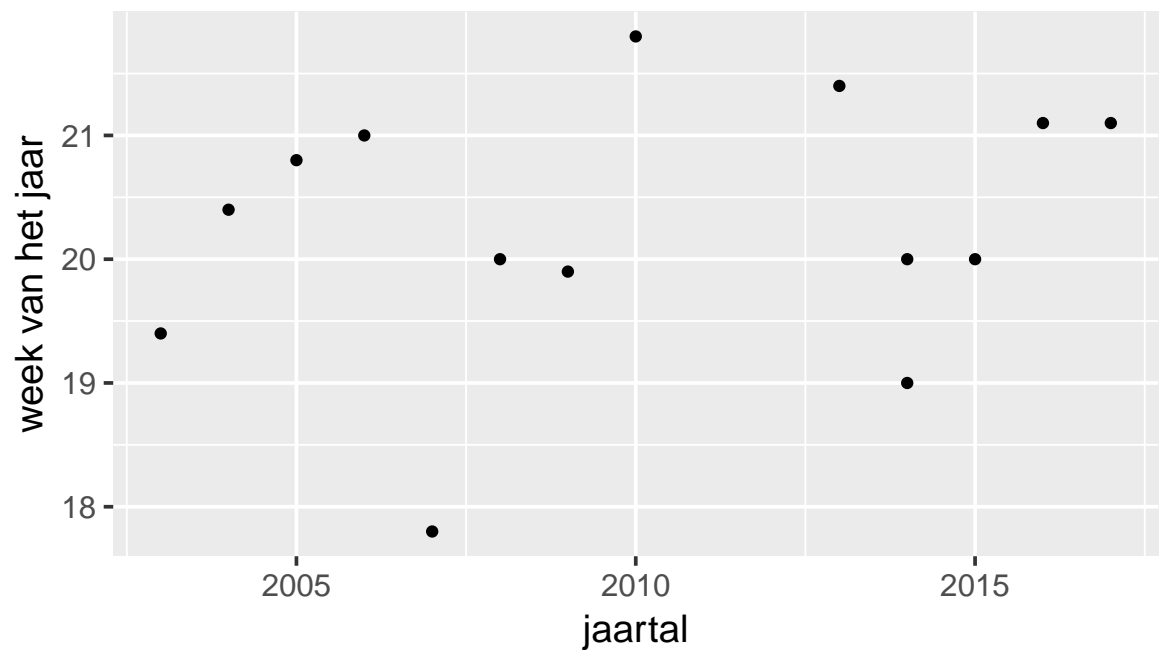

\subsubsection{Trendberekening}

Methode: Lineair

Parameterschattingen

params Estimate Std..Error statistic p.value 1 Intercept $19.906112840 .5309902237 .4886628 .337331 \mathrm{e}-14$ $2 \quad$ cJaar $0.05065068 \quad 0.06311226 \quad 0.802549 \quad 4.378417 \mathrm{e}-01$ 


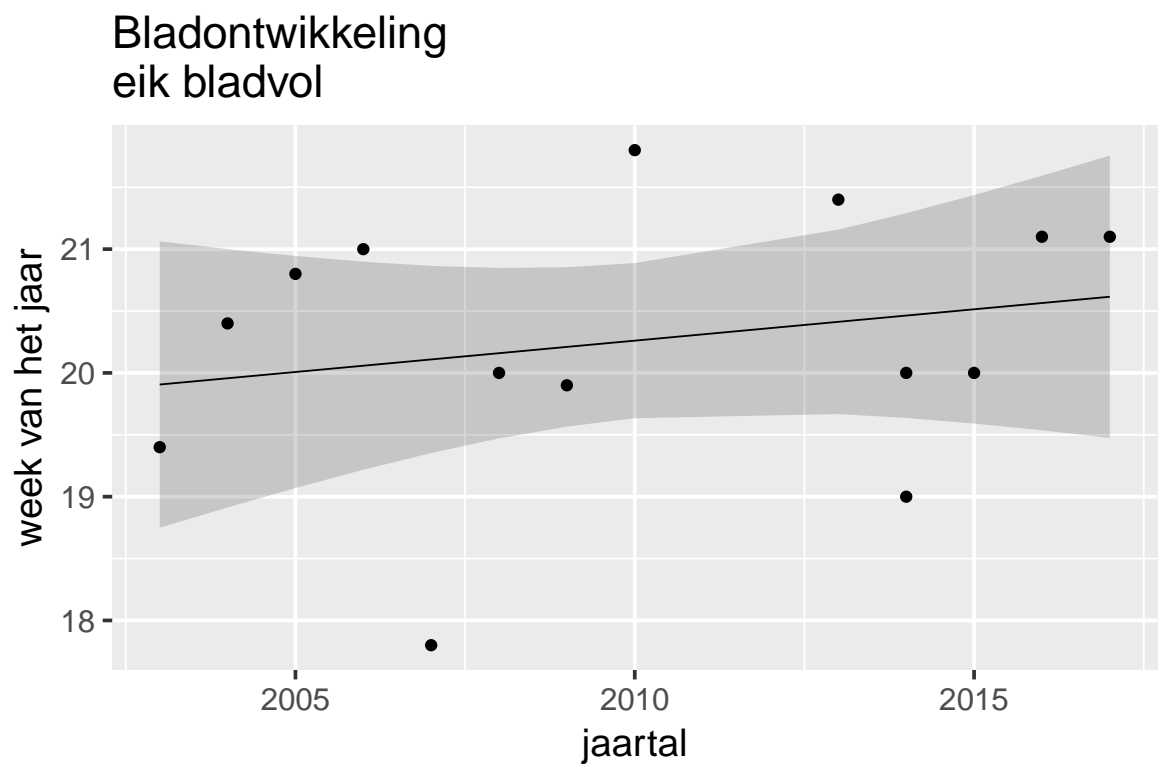

\subsubsection{Verwachting 2020}

$[18,23.6]$

\subsubsection{Conclusie}

Geen significante trend $(p=0.44)$. 


\subsubsection{Ruwe data}

\begin{tabular}{|c|c|}
\hline Jaartal & dag van het jaar \\
\hline 1974 & 95.00 \\
\hline 1975 & 117.00 \\
\hline 1976 & 109.00 \\
\hline 1977 & 122.00 \\
\hline 1978 & 113.00 \\
\hline 1979 & 104.00 \\
\hline 1980 & 122.00 \\
\hline 1981 & 99.00 \\
\hline 1982 & 109.00 \\
\hline 1983 & 114.00 \\
\hline 1984 & 114.00 \\
\hline 1985 & 107.00 \\
\hline 1986 & 122.00 \\
\hline 1987 & 107.00 \\
\hline 1988 & 109.00 \\
\hline 1989 & 99.00 \\
\hline 1990 & 91.00 \\
\hline 1991 & 100.00 \\
\hline 1992 & 102.00 \\
\hline 1993 & 109.00 \\
\hline 1994 & 112.00 \\
\hline 1995 & 112.00 \\
\hline 1996 & 111.00 \\
\hline 1997 & 92.00 \\
\hline 1998 & 112.00 \\
\hline 1999 & 95.00 \\
\hline 2000 & 99.00 \\
\hline 2001 & 121.00 \\
\hline 2002 & 91.00 \\
\hline 2003 & 103.00 \\
\hline 2004 & 104.00 \\
\hline 2005 & 93.00 \\
\hline 2006 & 113.00 \\
\hline 2007 & 102.00 \\
\hline 2008 & 112.00 \\
\hline 2009 & 99.00 \\
\hline 2010 & 102.00 \\
\hline 2011 & 91.00 \\
\hline 2012 & 94.00 \\
\hline 2013 & 113.00 \\
\hline 2014 & 92.00 \\
\hline
\end{tabular}




\begin{tabular}{rr}
2015 & 105.00 \\
2016 & 101.00 \\
2017 & 89.00 \\
\hline
\end{tabular}

Piekmoment stuifmeelproductie bij berk en grasser piek berk

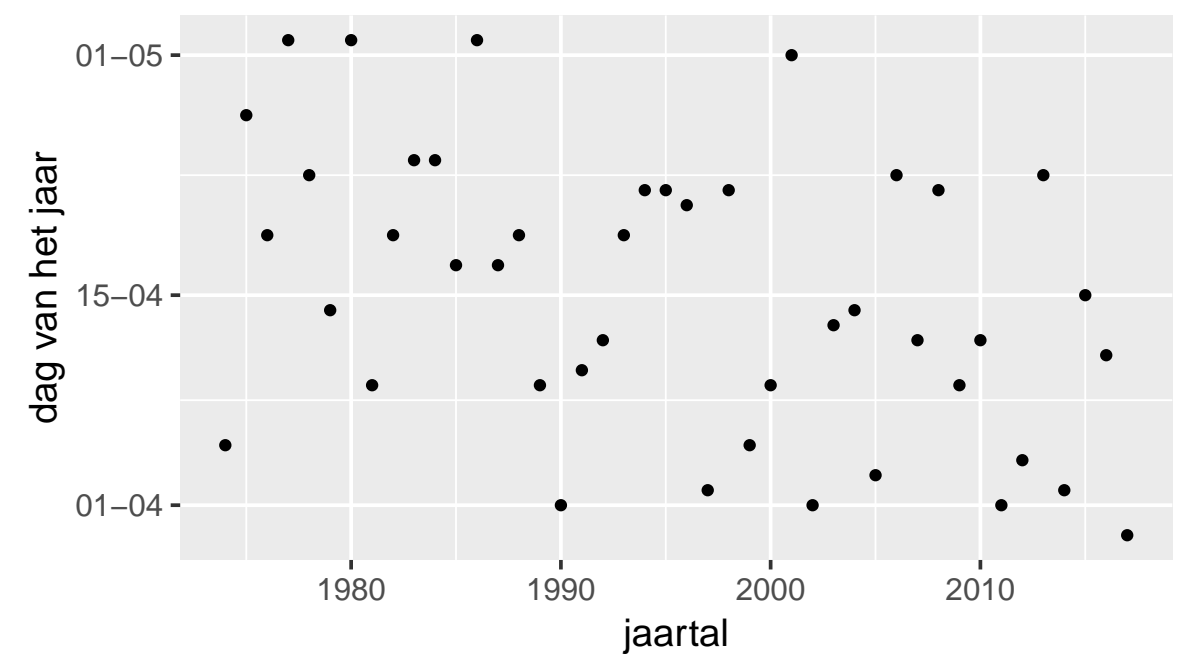

\subsubsection{Trendberekening}

Methode: Lineair

Parameterschattingen

params Estimate Std..Error statistic p.value

1 Intercept $111.7484848 \quad 2.5469334 \quad 43.875699 \quad 1.023738 \mathrm{e}-36$

2 cJaar $-0.31176890 .1019998 \quad-3.056563 \quad 3.883306 \mathrm{e}-03$

Piekmoment stuifmeelproductie bij berk en grasser piek berk

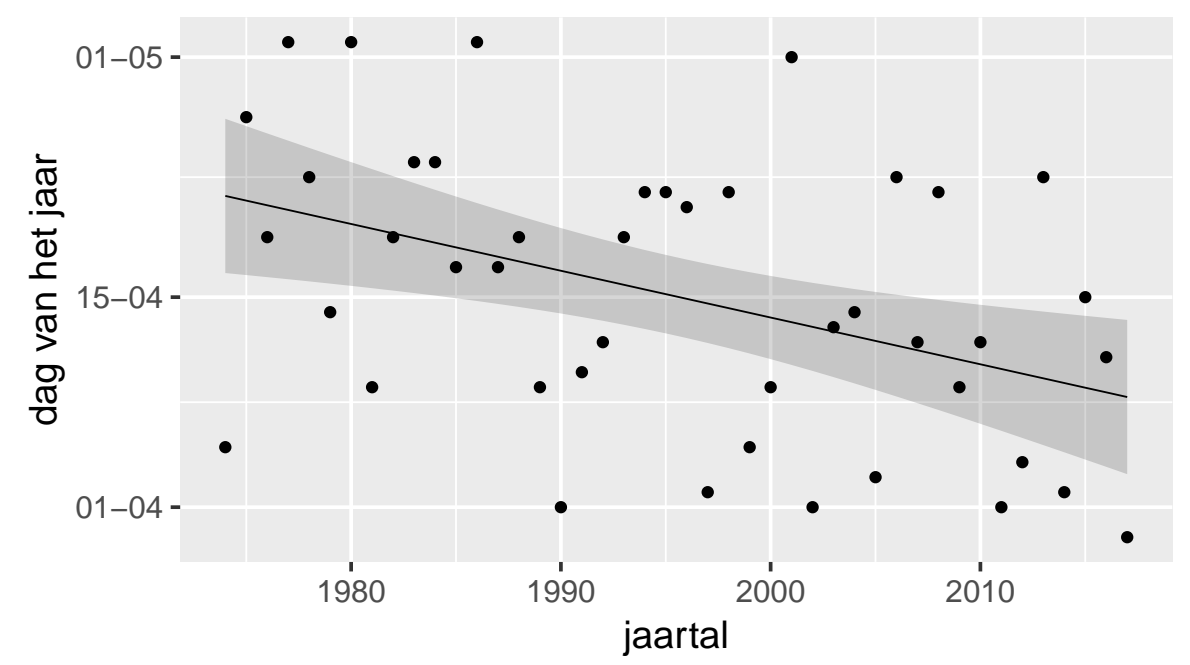

\subsubsection{Verwachting 2020}




\subsubsection{Conclusie}

Significante afname. 


\subsubsection{Ruwe data}

\begin{tabular}{rr}
\hline Jaartal & dag van het jaar \\
\hline 1974 & 163.00 \\
1975 & 163.00 \\
1976 & 160.00 \\
1977 & 174.00 \\
1978 & 164.00 \\
1979 & 160.00 \\
1980 & 165.00 \\
1981 & 164.00 \\
1982 & 156.00 \\
1983 & 169.00 \\
1984 & 177.00 \\
1985 & 153.00 \\
1986 & 165.00 \\
1987 & 171.00 \\
1988 & 165.00 \\
1989 & 162.00 \\
1990 & 192.00 \\
1991 & 186.00 \\
1992 & 158.00 \\
1993 & 155.00 \\
1994 & 173.00 \\
1995 & 170.00 \\
1996 & 159.00 \\
1997 & 160.00 \\
1998 & 149.00 \\
1999 & 152.00 \\
2000 & 160.00 \\
2001 & 155.00 \\
2002 & 164.00 \\
2003 & 157.00 \\
2004 & 160.00 \\
2005 & 159.00 \\
2006 & 162.00 \\
2007 & 143.00 \\
2008 & 160.00 \\
2009 & 149.00 \\
2010 & 165.00 \\
2011 & 152.00 \\
2012 & 150.00 \\
2013 & 169.00 \\
2014 & 157.00
\end{tabular}




\begin{tabular}{ll}
2015 & 174.00 \\
2016 & 157.00 \\
2017 & 152.00 \\
\hline
\end{tabular}

Piekmoment stuifmeelproductie bij berk en grasser piek grassen

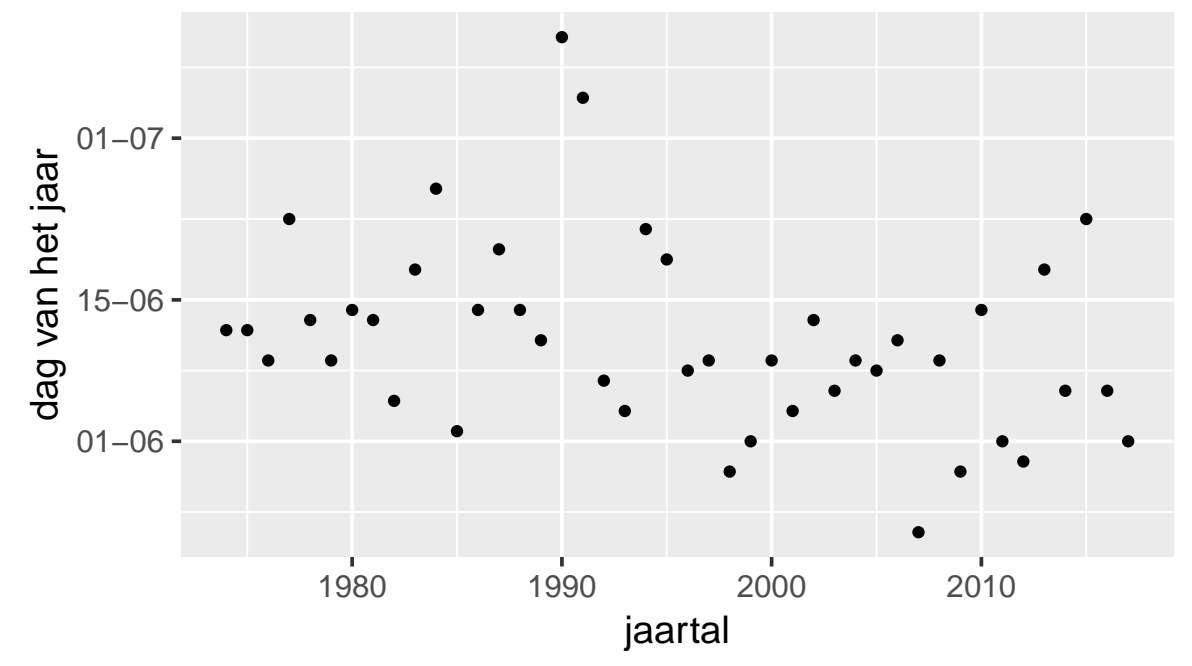

\subsubsection{Trendberekening}

Methode: Lineair

Parameterschattingen

params Estimate Std..Error statistic p.value

1 Intercept $167.3424242 \quad 2.6919036 \quad 62.165088 \quad 5.632038 \mathrm{e}-43$

2 cJaar $-0.2463707 \quad 0.1078056 \quad-2.285324 \quad 2.740774 \mathrm{e}-02$

Piekmoment stuifmeelproductie bij berk en grasser piek grassen

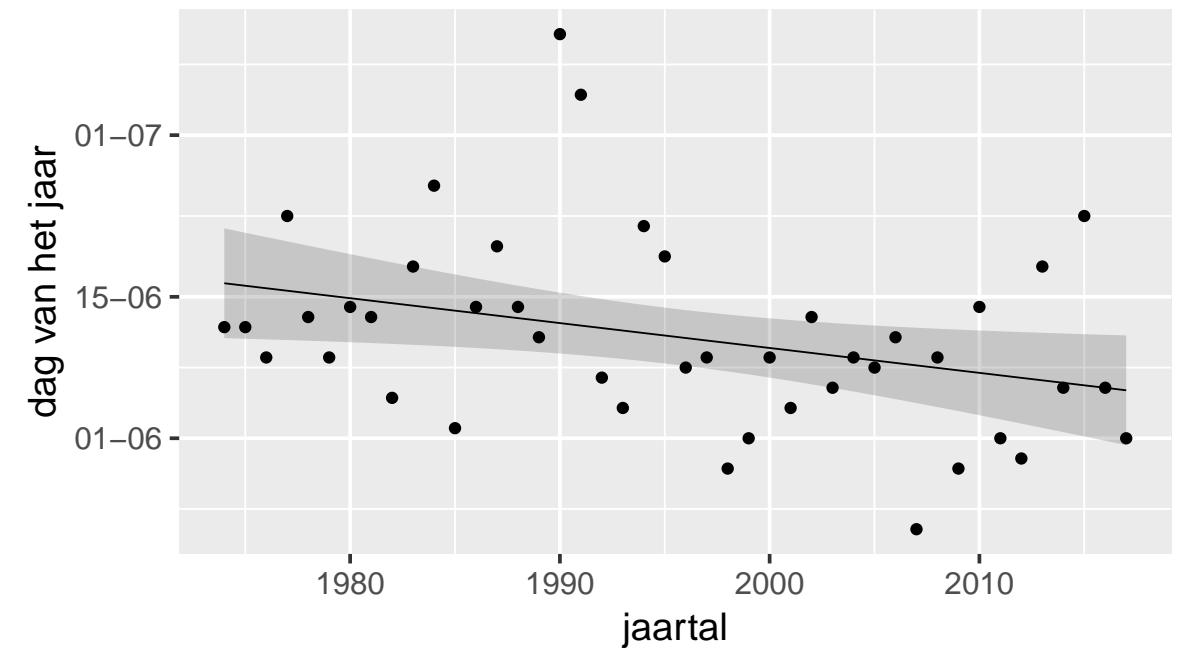

\subsubsection{Verwachting 2020}




\subsubsection{Conclusie}

Significante afname. 

AANDEEL UITHEEMSSE PLANTEN

\subsubsection{Ruwe data}

\begin{tabular}{rrr}
\hline Jaartal & Aandeel & Totaal \\
\hline 1972 & 5.55 & 140 \\
1973 & 6.43 & 133 \\
1974 & 6.13 & 137 \\
1975 & 6.26 & 140 \\
1976 & 5.79 & 137 \\
1977 & 5.99 & 137 \\
1978 & 7.32 & 139 \\
1979 & 8.06 & 143 \\
1980 & 8.10 & 141 \\
1981 & 8.18 & 150 \\
1982 & 8.69 & 152 \\
1983 & 9.85 & 146 \\
1984 & 9.96 & 157 \\
1985 & 11.36 & 156 \\
1986 & 11.07 & 155 \\
1987 & 11.44 & 160 \\
1988 & 11.45 & 159 \\
1989 & 10.94 & 151 \\
1990 & 14.06 & 175 \\
1991 & 12.29 & 167 \\
1992 & 11.95 & 164 \\
1993 & 12.39 & 164 \\
1994 & 12.82 & 163 \\
1995 & 11.18 & 159 \\
1996 & 10.95 & 154 \\
1997 & 12.52 & 163 \\
1998 & 13.12 & 159 \\
1999 & 13.09 & 156 \\
2000 & 12.22 & 152 \\
2001 & 12.62 & 154 \\
2002 & 13.49 & 154 \\
2003 & 13.73 & 158 \\
2004 & 13.22 & 164 \\
2005 & 14.48 & 161 \\
2006 & 15.26 & 165 \\
2007 & 15.75 & 160 \\
2008 & 15.61 & 159 \\
2009 & 16.37 & 164 \\
2010 & 14.83 & 157 \\
2011 & 16.05 & 167 \\
2012 & 17.41 & 169
\end{tabular}




\begin{tabular}{lll}
2013 & 17.23 & 175 \\
2014 & 15.42 & 165 \\
2015 & 11.20 & 144 \\
2016 & 14.40 & 162 \\
2017 & 13.94 & 157 \\
\hline
\end{tabular}

Bedreiging door uitheemse plantensoorten aandeel uitheemse planten

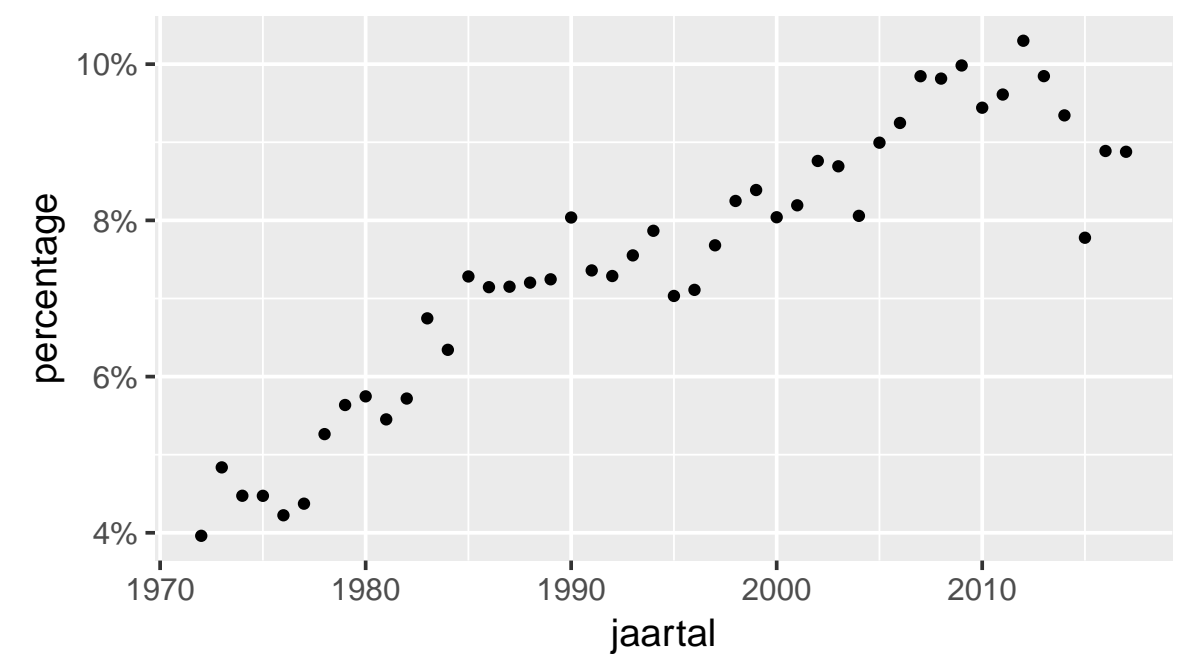

\subsubsection{Trendberekening}

Methode: Binomial

Parameterschattingen

params Estimate Std..Error statistic p.value

1 Intercept $-2.925814380 .099750594-29.331298 \quad 4.139019 \mathrm{e}-189$

2 cJaar $0.01734083 \quad 0.003481835 \quad 4.980371 \quad 6.346260 \mathrm{e}-07$

Bedreiging door uitheemse plantensoorten aandeel uitheemse planten

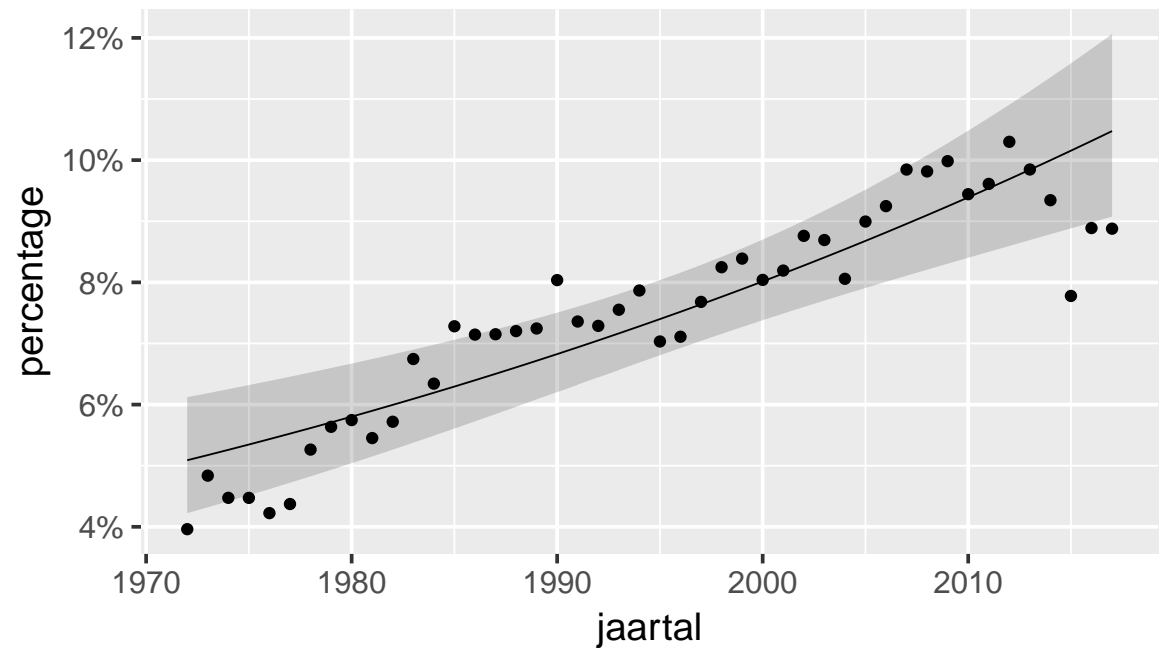


2.29.3 Verwachting $\mathbf{2 0 2 0}$

$[9.37,12.8]$

2.29.4 Conclusie

Significante toename. 


\subsubsection{Ruwe data}

\begin{tabular}{rr}
\hline Jaartal & opp in ha \\
\hline 1994 & 33.23 \\
1996 & 33.77 \\
1999 & 33.95 \\
2001 & 34.23 \\
2002 & 34.50 \\
2003 & 35.28 \\
2004 & 35.50 \\
2005 & 35.71 \\
2006 & 35.63 \\
2007 & 35.48 \\
2008 & 35.60 \\
2009 & 35.84 \\
2010 & 35.83 \\
2011 & 35.84 \\
2012 & 35.66 \\
2013 & 35.57 \\
2014 & 35.47 \\
2015 & 35.43 \\
2016 & 35.51 \\
2017 & 35.52 \\
\hline \hline
\end{tabular}

Ontsnippering planologisch groengebied versnipperingsgraad

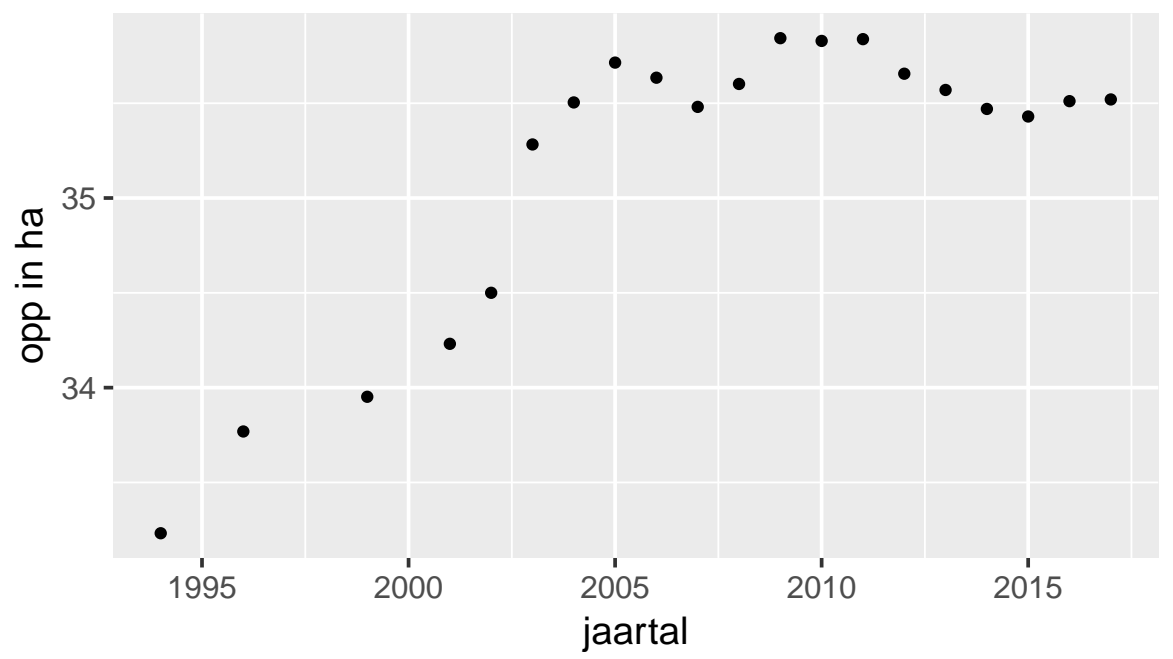




\subsubsection{Trendberekening}

Methode: Kwadratisch

Parameterschattingen

params Estimate Std..Error statistic p.value 1 Intercept $33.0101407810 .188475467 \quad 175.142905 \quad 3.976834 \mathrm{e}-29$

2 cJaar $0.312428083 \quad 0.033151451 \quad 9.424266 \quad 3.665922 \mathrm{e}-08$

3 cJaar2 $-0.009030899 \quad 0.001322553-6.8283852 .935643$ e-06

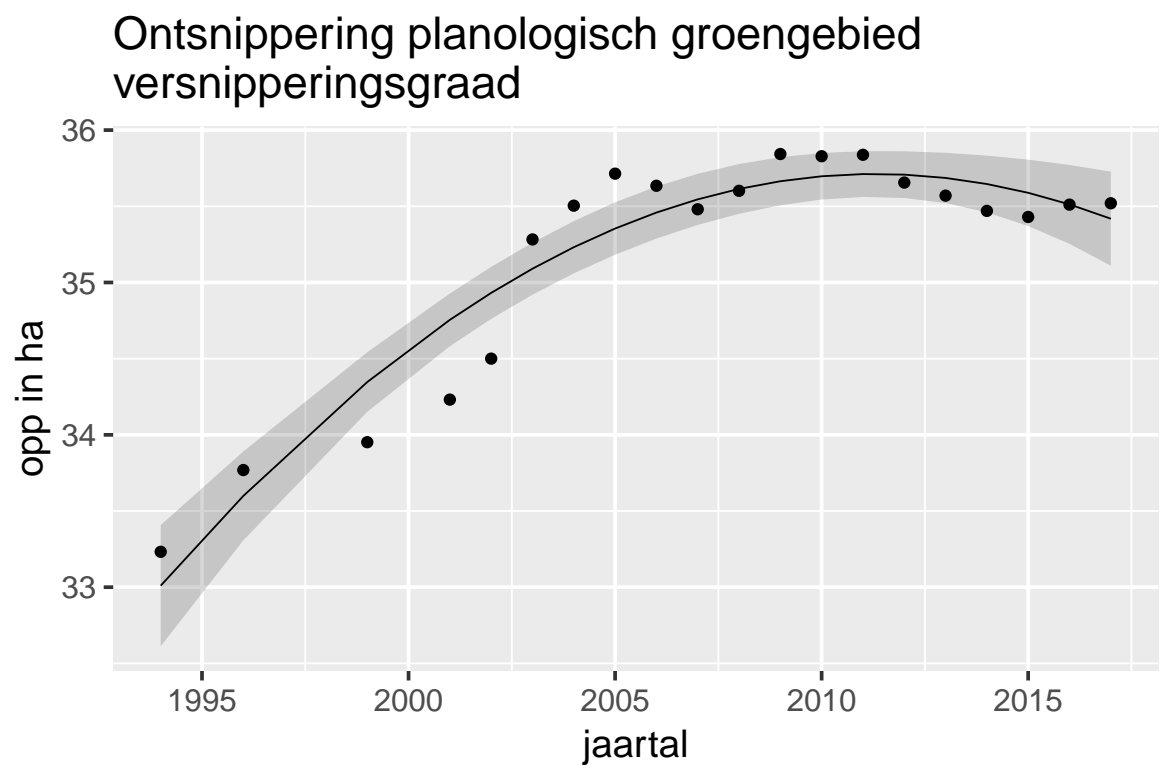

\subsubsection{Verwachting 2020}

$[34.3,35.8]$

\subsubsection{Conclusie}

Significante trend. Afname sinds 2011. 

BOS

\subsubsection{Ruwe data}

\begin{tabular}{rr}
\hline Jaartal & opp in ha \\
\hline 1999 & 1100.00 \\
2000 & 1173.00 \\
2001 & 1481.00 \\
2002 & 1384.00 \\
2003 & 1396.00 \\
2004 & 1372.00 \\
2005 & 1900.00 \\
2006 & 2000.00 \\
2007 & 2000.00 \\
2008 & 2300.00 \\
2009 & 2300.00 \\
2010 & 2200.00 \\
2011 & 2100.00 \\
2012 & 2400.00 \\
2013 & 2500.00 \\
2014 & 3100.00 \\
2015 & 3200.00 \\
2016 & 3200.00 \\
2017 & 3200.00 \\
\hline \hline
\end{tabular}

Oppervlakte extra planologisch groengebied bos

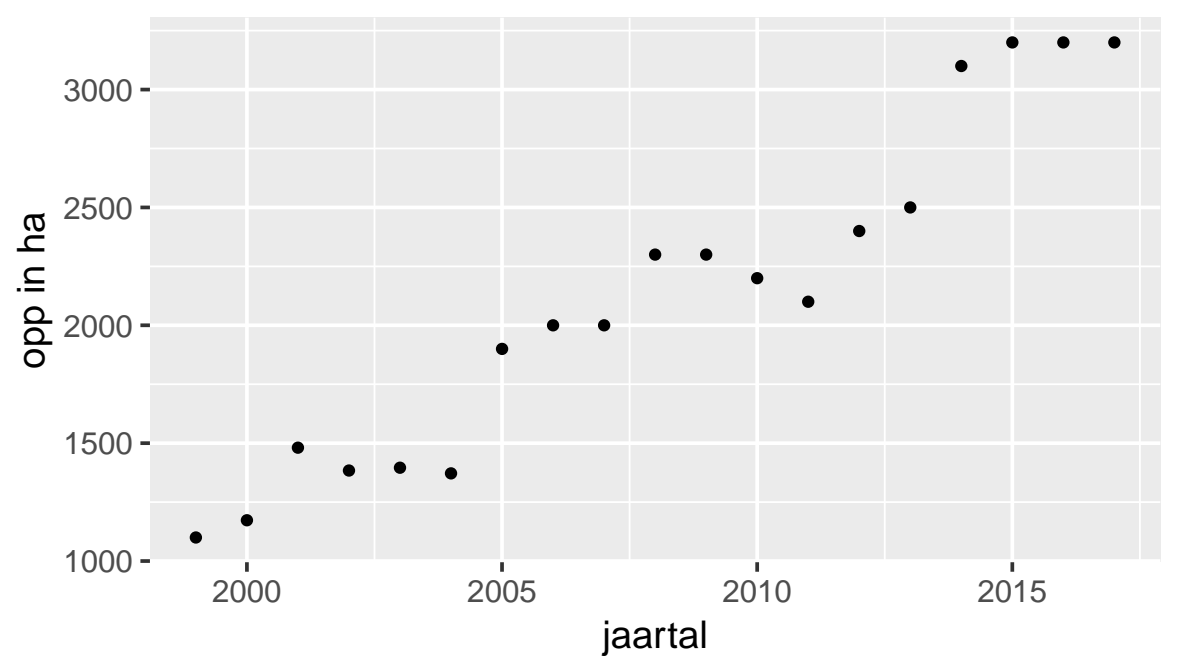




\subsubsection{Trendberekening}

Methode: Lineair

\section{Parameterschattingen}

params Estimate Std..Error statistic p.value 1 Intercept $1041.7316 \quad 82.875585 \quad 12.56982 \quad 4.932599 \mathrm{e}-10$

2 cJaar $119.9596 \quad 7.866202 \quad 15.25001 \quad 2.381132 \mathrm{e}-11$

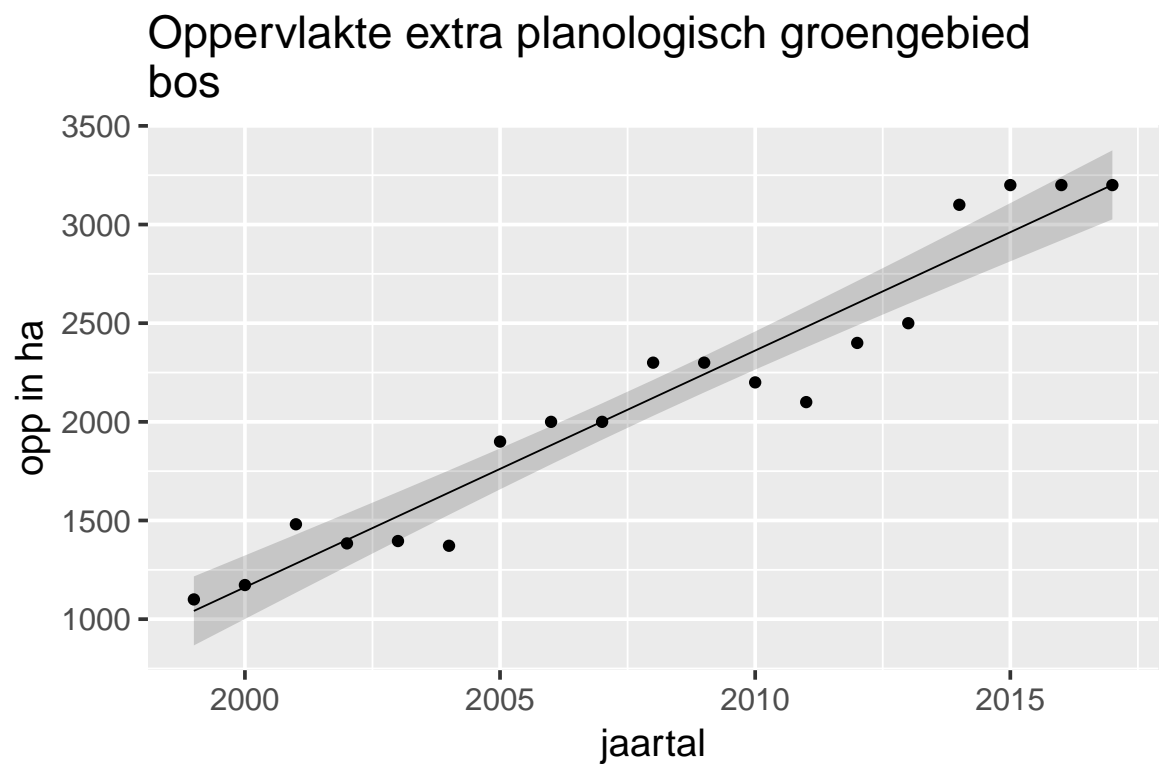

\subsubsection{Verwachting 2020}

$[3110,4010]$

\subsubsection{Conclusie}

Significante toename. 

NATUUUR EN RESERYAATT.

\subsubsection{Ruwe data}

\begin{tabular}{rr}
\hline Jaartal & opp in ha \\
\hline 1999 & 4797.00 \\
2000 & 6411.00 \\
2001 & 8641.00 \\
2002 & 8717.00 \\
2003 & 8587.00 \\
2004 & 10760.00 \\
2005 & 11500.00 \\
2006 & 11500.00 \\
2007 & 11500.00 \\
2008 & 12300.00 \\
2009 & 13500.00 \\
2010 & 14600.00 \\
2011 & 15500.00 \\
2012 & 15600.00 \\
2013 & 16400.00 \\
2014 & 16000.00 \\
2015 & 16800.00 \\
2016 & 16900.00 \\
2017 & 16600.00 \\
\hline \hline
\end{tabular}

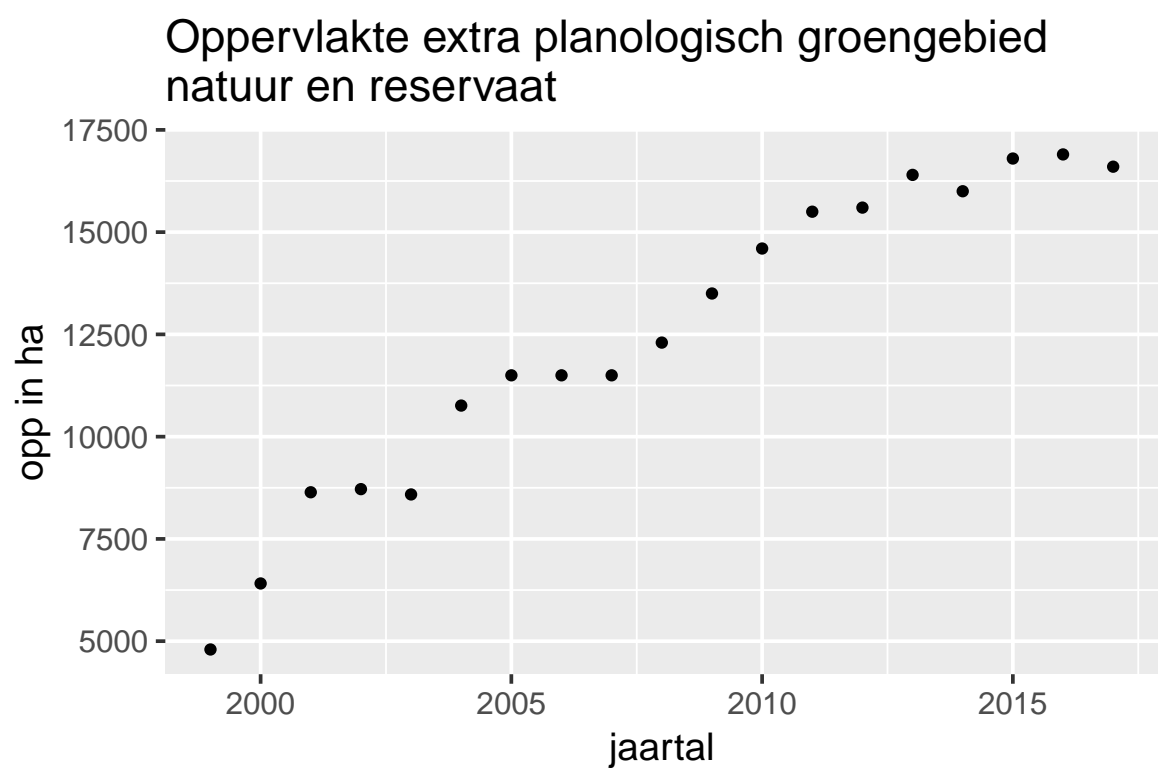




\subsubsection{Trendberekening}

Methode: Kwadratisch

Parameterschattingen

params Estimate Std..Error statistic p.value 1 Intercept $5422.15789381 .045455 \quad 14.229691 .680069 \mathrm{e}-10$

$2 \quad$ cJaar $1070.41125 \quad 98.143136 \quad 10.90663 \quad 8.105226 \mathrm{e}-09$

$3 \quad$ cJaar2 $-23.44634 \quad 5.262537 \quad-4.45533 \quad 3.987545 \mathrm{e}-04$

\section{Oppervlakte extra planologisch groengebied natuur en reservaat}

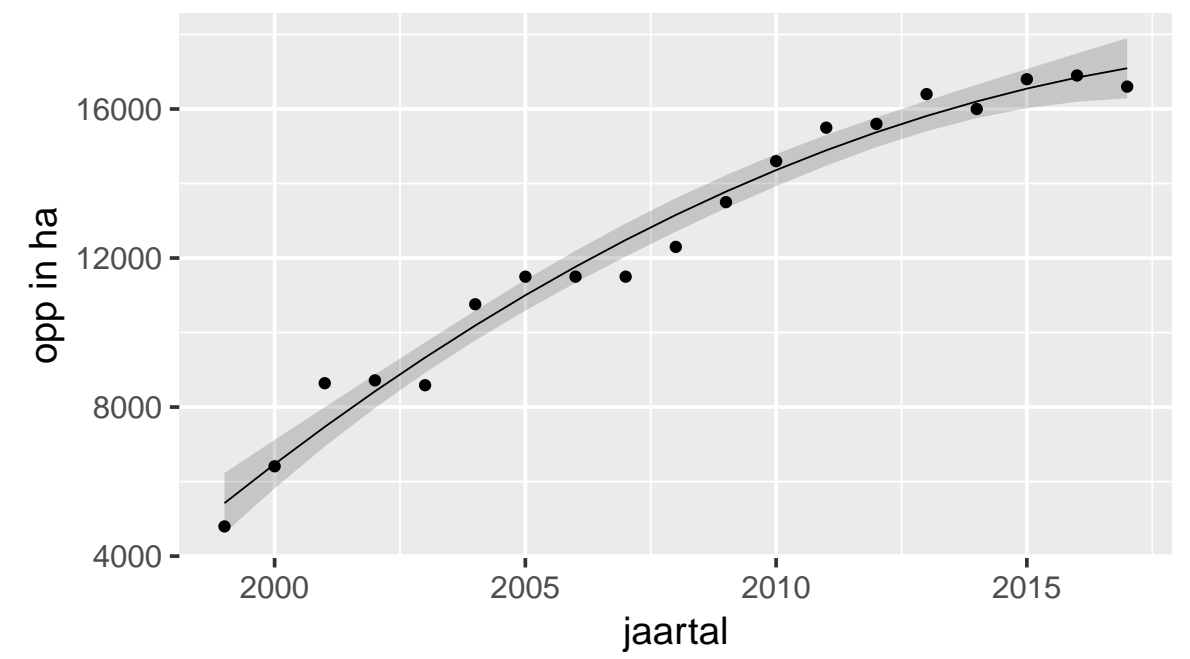

\subsubsection{Verwachting 2020}

$[15600,19500]$

\subsubsection{Conclusie}

Significante toename. 

OVERIG GRQPQEN

\subsubsection{Ruwe data}

\begin{tabular}{rr}
\hline Jaartal & opp in ha \\
\hline 1999 & -102.00 \\
2000 & -545.00 \\
2001 & -518.00 \\
2002 & 210.00 \\
2003 & 189.00 \\
2004 & 147.00 \\
2005 & -700.00 \\
2006 & -1000.00 \\
2007 & -1000.00 \\
2008 & -1100.00 \\
2009 & -1200.00 \\
2010 & -1200.00 \\
2011 & -1000.00 \\
2012 & -900.00 \\
2013 & -1500.00 \\
2014 & -1200.00 \\
2015 & -1100.00 \\
2016 & -800.00 \\
2017 & -400.00 \\
\hline \hline
\end{tabular}

\section{Oppervlakte extra planologisch groengebied} overig groen

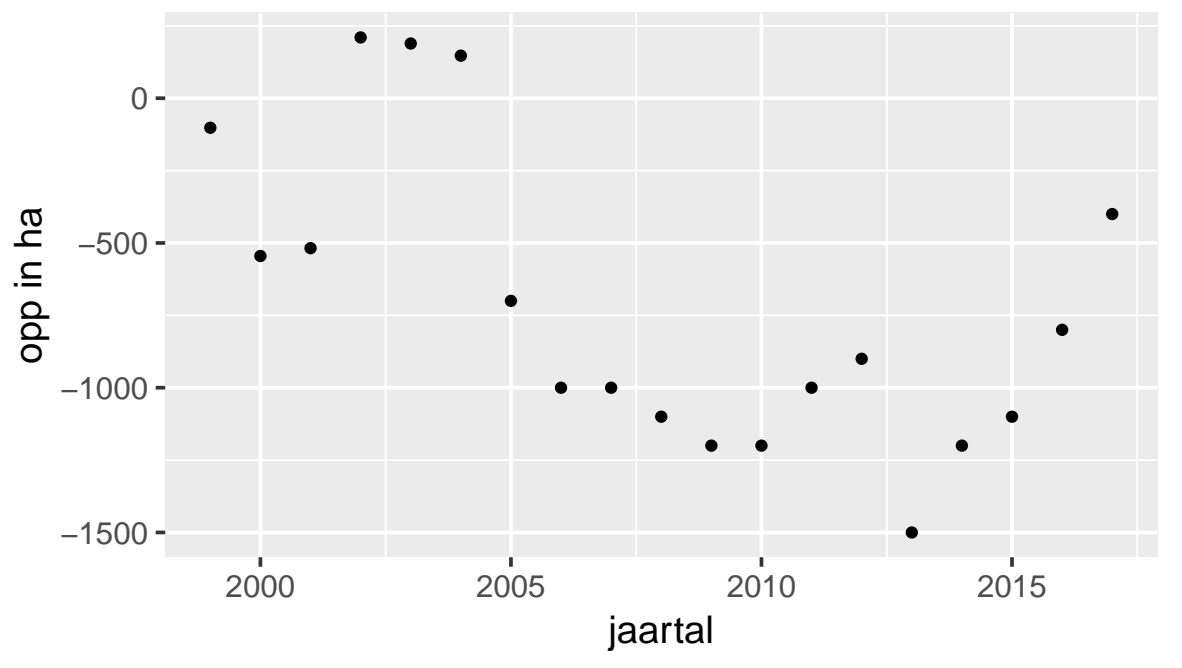




\subsubsection{Trendberekening}

Methode: Derdemacht

\section{Parameterschattingen}

params Estimate Std..Error statistic p.value 1 Intercept $-292.637731235 .7093385-1.2415190 .23347803$

$2 \quad$ cJaar $152.045530 \quad 116.5616441 \quad 1.304422 \quad 0.21175042$

$3 \quad$ cJaar2 $-40.979246 \quad 15.2926003 \quad-2.679678 \quad 0.01714284$

$\begin{array}{llllll}4 & \text { cJaar3 } & 1.787441 & 0.5578015 & 3.204439 & 0.00590989\end{array}$

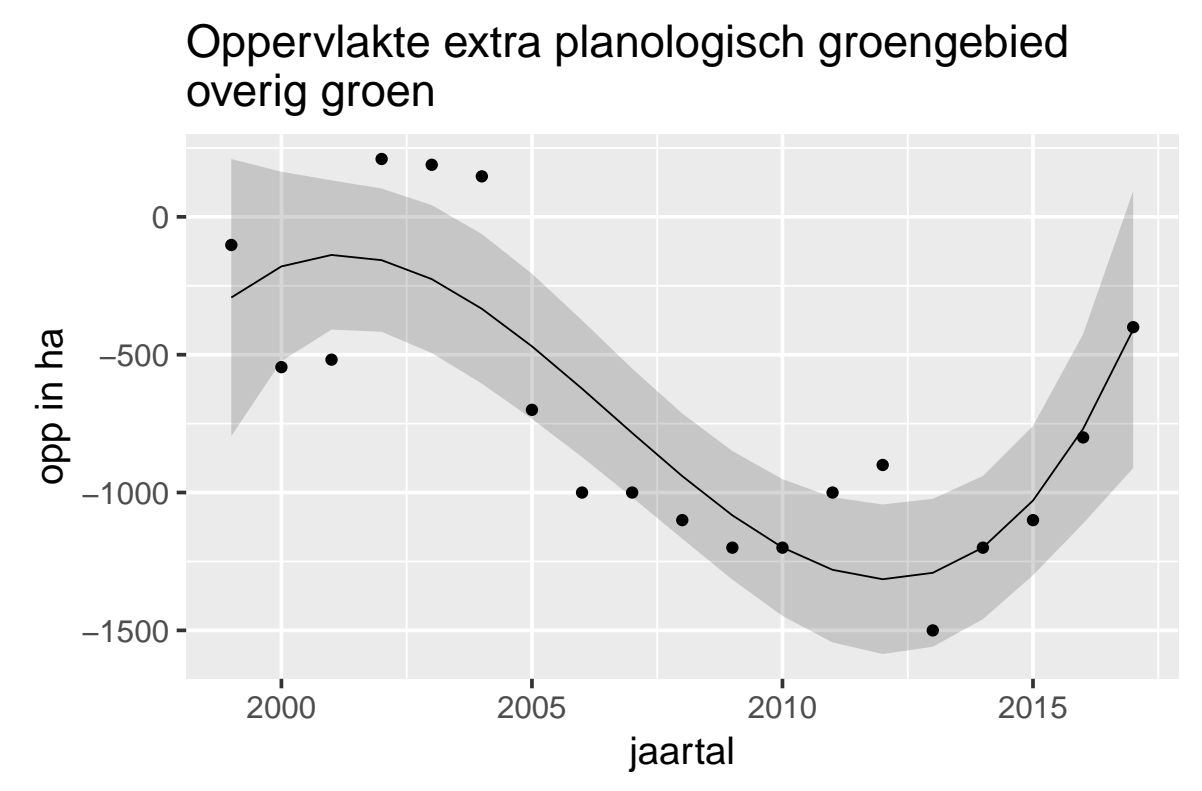

\subsubsection{Verwachting 2020}

$[-242,3010]$

\subsubsection{Conclusie}

Significante trend. Stijging tot 2001, afname tot 2012, sindsdien terug een stijging. 


\subsubsection{Ruwe data}

\begin{tabular}{rr}
\hline Jaartal & opp in ha \\
\hline 2002 & 87.00 \\
2003 & 87.00 \\
2004 & 275.00 \\
2005 & 664.00 \\
2006 & 664.00 \\
2007 & 1071.00 \\
2008 & 1071.00 \\
2009 & 1204.00 \\
2010 & 1885.00 \\
2011 & 3093.00 \\
2012 & 3093.00 \\
2013 & 3790.00 \\
2015 & 4441.00 \\
2016 & 5769.00 \\
2017 & 6092.00 \\
\hline \hline
\end{tabular}

Oppervlakte gerealiseerde natuurinrichtingsproject $€$ totale oppervlakte uitgevoerde projecten

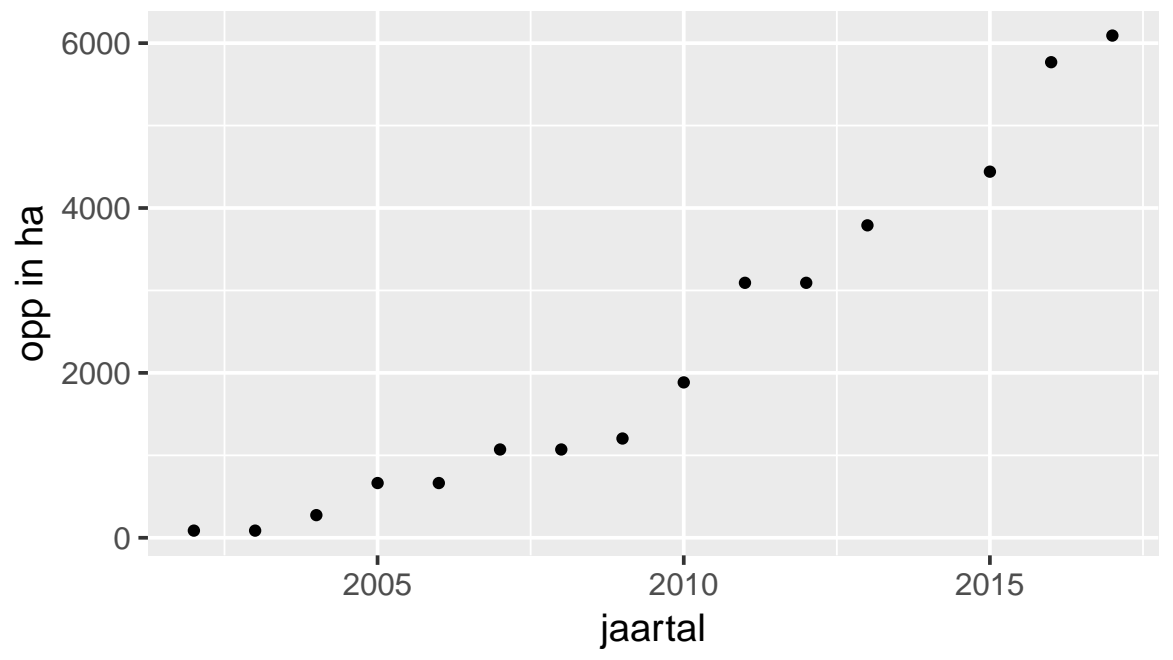

\subsubsection{Trendberekening}

Methode: Kwadratisch

Parameterschattingen 
params Estimate Std..Error statistic p.value 1 Intercept $50.55793186 .851310 \quad 0.2705784 \quad 7.913130 \mathrm{e}-01$

2 cJaar $69.65357 \quad 57.857628 \quad 1.2038788 \quad 2.518469 \mathrm{e}-01$

3 cJaar2 $22.81482 \quad 3.708604 \quad 6.1518621 \quad 4.932372 \mathrm{e}-05$

\section{Oppervlakte gerealiseerde natuurinrichtingsproject $€$ totale oppervlakte uitgevoerde projecten}

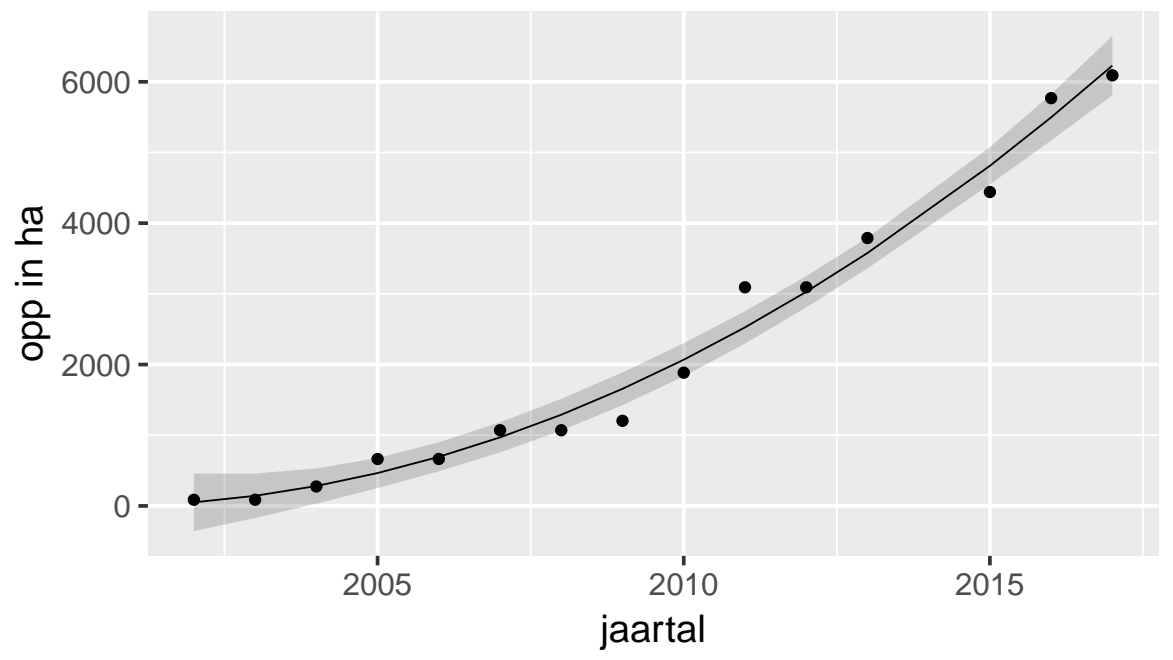

\subsubsection{Verwachting 2020}

$[7670,9720]$

\subsubsection{Conclusie}

Significante kwadratische toename. 


\subsubsection{Ruwe data}

\begin{tabular}{rr}
\hline Jaartal & opp in ha \\
\hline 2008 & 21725.00 \\
2009 & 22025.00 \\
2010 & 22408.00 \\
2011 & 22748.00 \\
2012 & 23167.00 \\
2013 & 22794.00 \\
2014 & 21136.00 \\
2015 & 20695.00 \\
2016 & 17965.00 \\
2017 & 15834.00 \\
\hline \hline
\end{tabular}

\section{Oppervlakte bosbeheerplan} beperkt bosbeheerplan

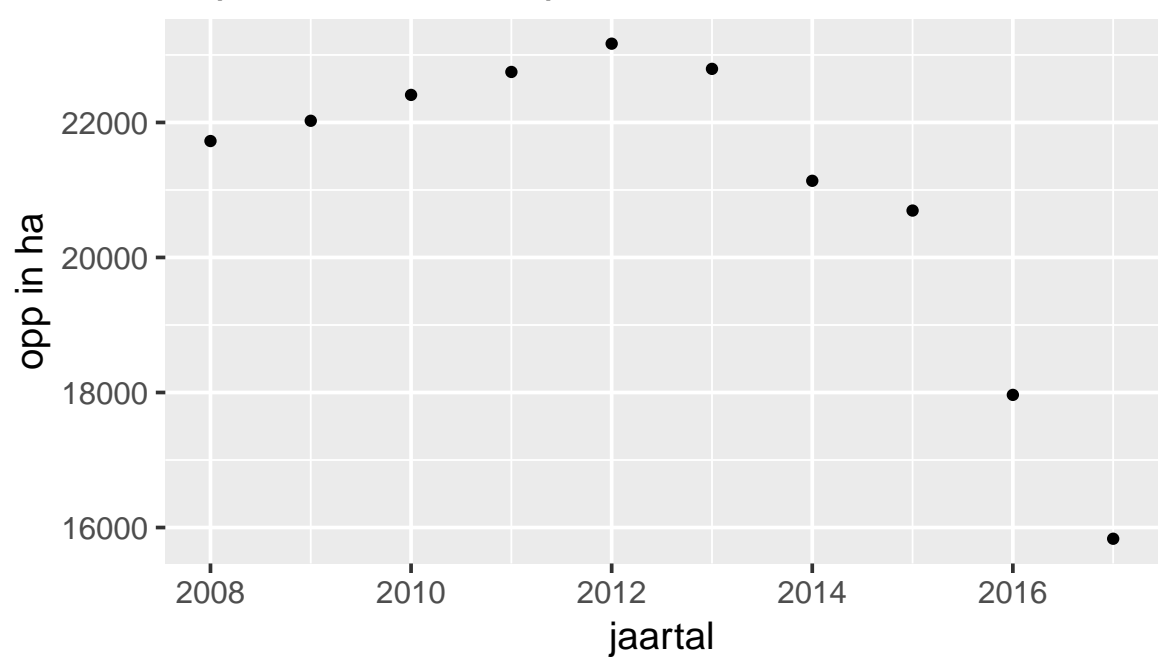

\subsubsection{Trendberekening}

Methode: Derdemacht

Parameterschattingen

params Estimate Std..Error statistic p.value 1 Intercept $21598.186014346 .18323562 .389462581 .139936 \mathrm{e}-09$

2 cJaar $556.625874 \quad 352.387423 \quad 1.57958496 \quad 1.652822 \mathrm{e}-01$

3 cJaar2 $\quad-1.991259 \quad 94.124116 \quad-0.02115567 \quad 9.838075 \mathrm{e}-01$

4 cJaar3 $-14.797786 \quad 6.862882-2.15620584 \quad 7.446572 \mathrm{e}-02$ 


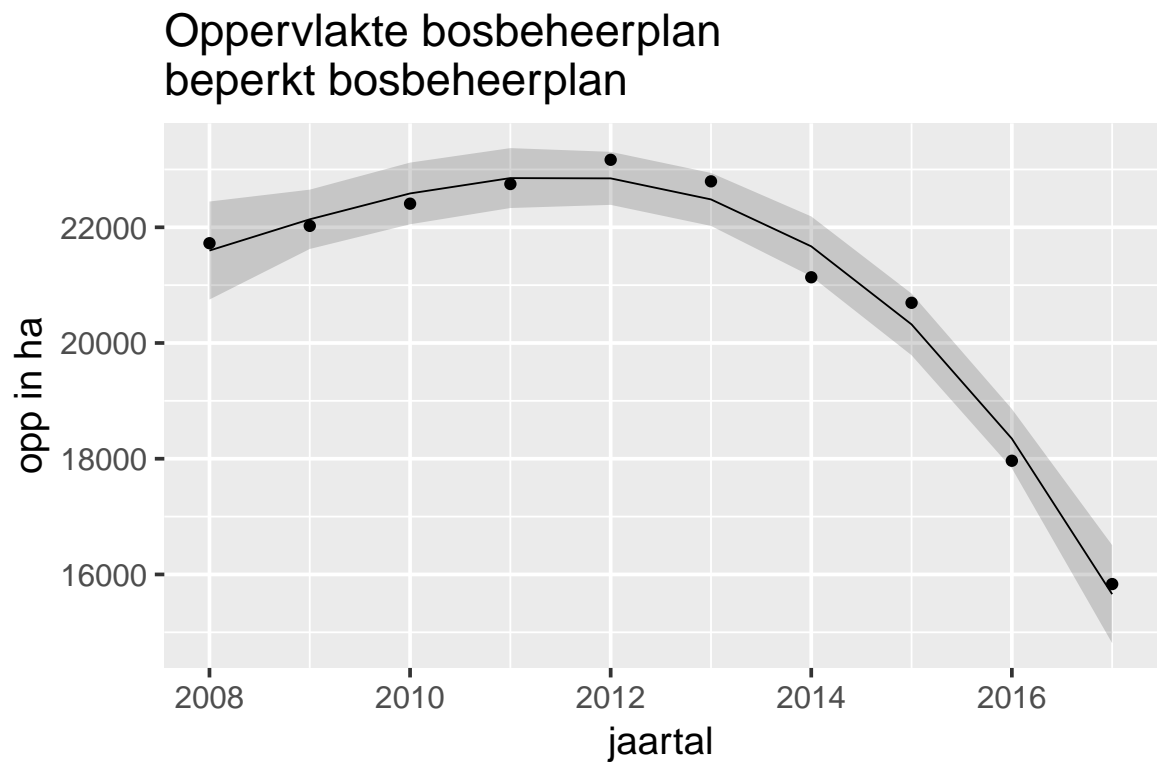

\subsubsection{Verwachting 2020}

$[-3310,8150]$

\subsubsection{Conclusie}

Significante trend. Afname sinds 2011. 


\subsubsection{Ruwe data}

\begin{tabular}{rr}
\hline Jaartal & opp in ha \\
\hline 2008 & 13827.00 \\
2009 & 16022.00 \\
2010 & 18941.00 \\
2011 & 24119.00 \\
2012 & 26623.00 \\
2013 & 28484.00 \\
2014 & 36147.00 \\
2015 & 38445.00 \\
2016 & 39106.00 \\
2017 & 39478.00 \\
\hline \hline
\end{tabular}

\section{Oppervlakte bosbeheerplan} uitgebreid bosbeheerplan

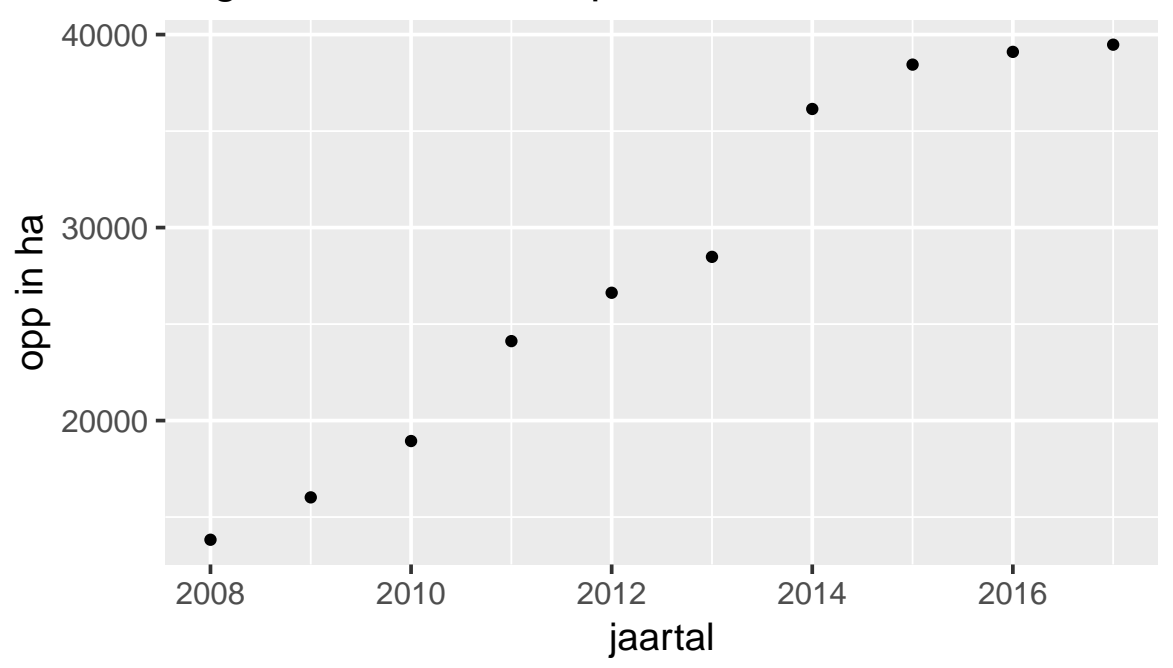

\subsubsection{Trendberekening}

Methode: Derdemacht

Parameterschattingen

params Estimate Std..Error statistic p.value 1 Intercept $14009.381821236 .07022 \quad 11.333807 \quad 2.824724 \mathrm{e}-05$

2 cJaar $1273.46465 \quad 1258.22269 \quad 1.012114 \quad 3.505442 \mathrm{e}-01$

3 cJaar2 $740.74242 \quad 336.07640 \quad 2.204089 \quad 6.970841 \mathrm{e}-02$

$4 \quad$ cJaar3 $\quad-62.87374 \quad 24.50437 \quad-2.565817 \quad 4.257399 \mathrm{e}-02$ 


\section{Oppervlakte bosbeheerplan uitgebreid bosbeheerplan}

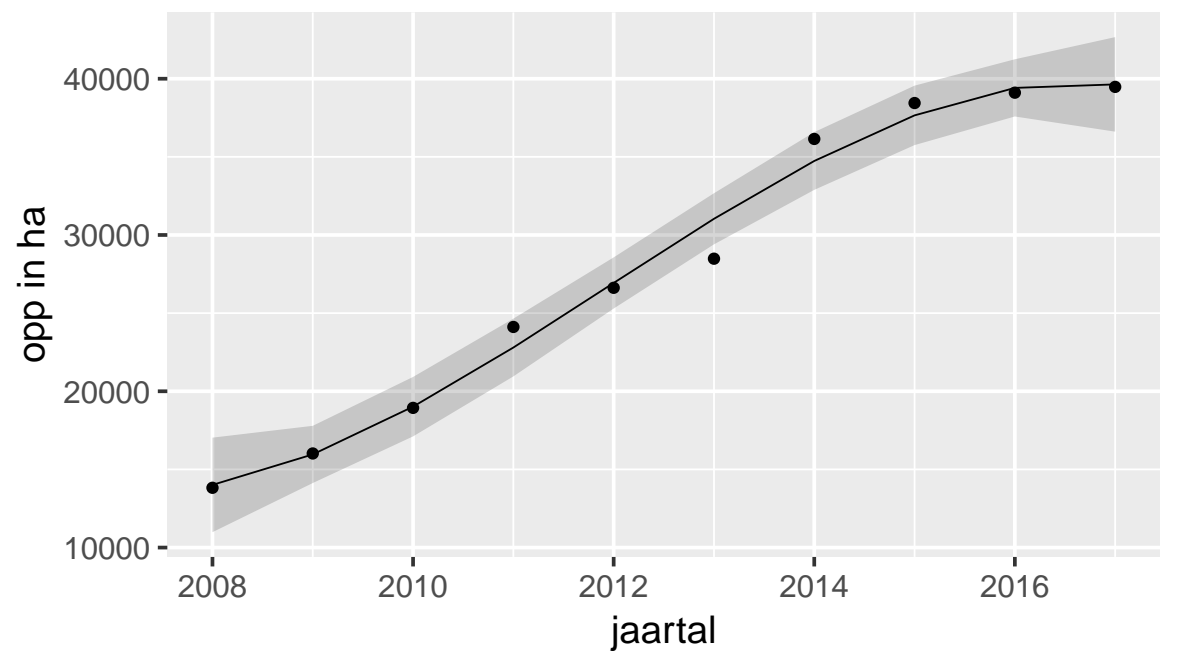

\subsubsection{Verwachting 2020}

$[6860,47800]$

\subsubsection{Conclusie}

Significante toename. 

BEHEER

\subsubsection{Ruwe data}

\begin{tabular}{rr}
\hline Jaartal & opp in m2 \\
\hline 2000 & 1362.00 \\
2001 & 1597.00 \\
2002 & 1722.00 \\
2003 & 1789.00 \\
2004 & 2173.00 \\
2005 & 1414.00 \\
2006 & 1749.00 \\
2007 & 1745.00 \\
2008 & 1557.00 \\
2009 & 1368.00 \\
2010 & 1179.00 \\
2011 & 515.00 \\
2012 & 304.00 \\
2013 & 316.00 \\
2014 & 316.00 \\
2015 & 300.00 \\
2016 & 331.00 \\
2017 & 381.81 \\
\hline \hline
\end{tabular}

Oppervlakte beheerovereenkomsten botanisch beheer

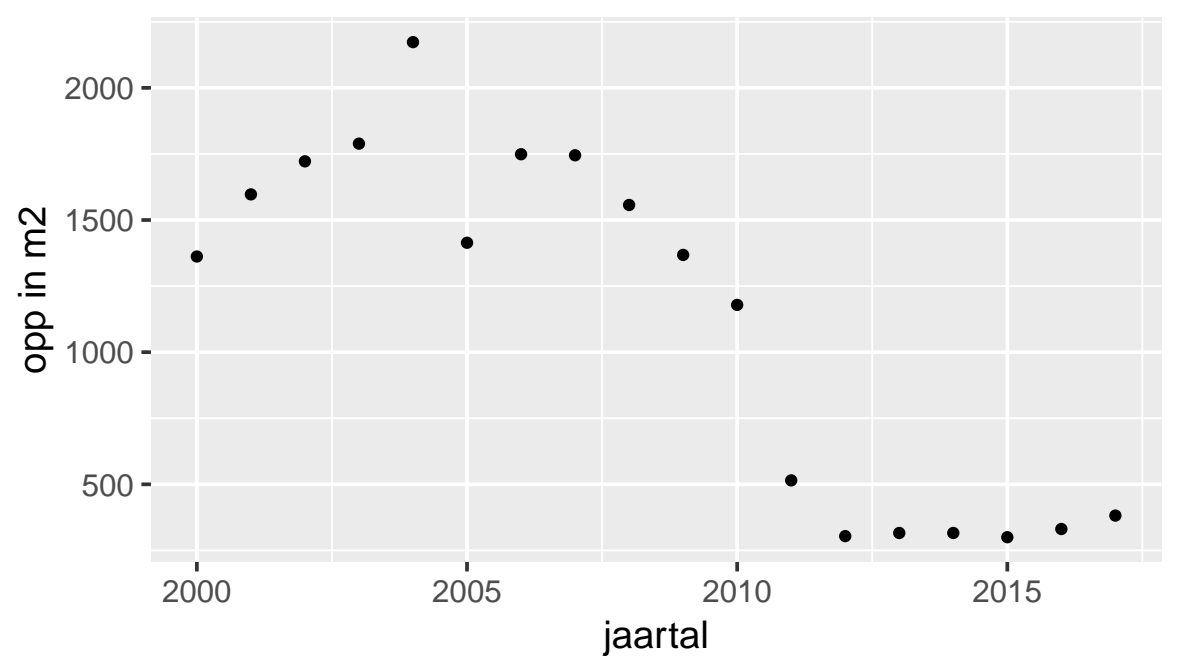

\subsubsection{Trendberekening}

Methode: Derdemacht 


\section{Parameterschattingen}

params Estimate Std..Error statistic p.value

1 Intercept $1274.362807 \quad 155.2895849 \quad 8.2063641 .016837 \mathrm{e}-06$

2 cJaar $381.141021 \quad 81.4424136 \quad 4.679884 \quad 3.544294 \mathrm{e}-04$

$3 \quad$ cJaar2 $-63.845913 \quad 11.3248484-5.637684 \quad 6.123595 \mathrm{e}-05$

$\begin{array}{llllll}4 & \text { cJaar3 } & 2.256852 & 0.4373539 & 5.160243 & 1.447489 \mathrm{e}-04\end{array}$

\section{Oppervlakte beheerovereenkomsten}

botanisch beheer

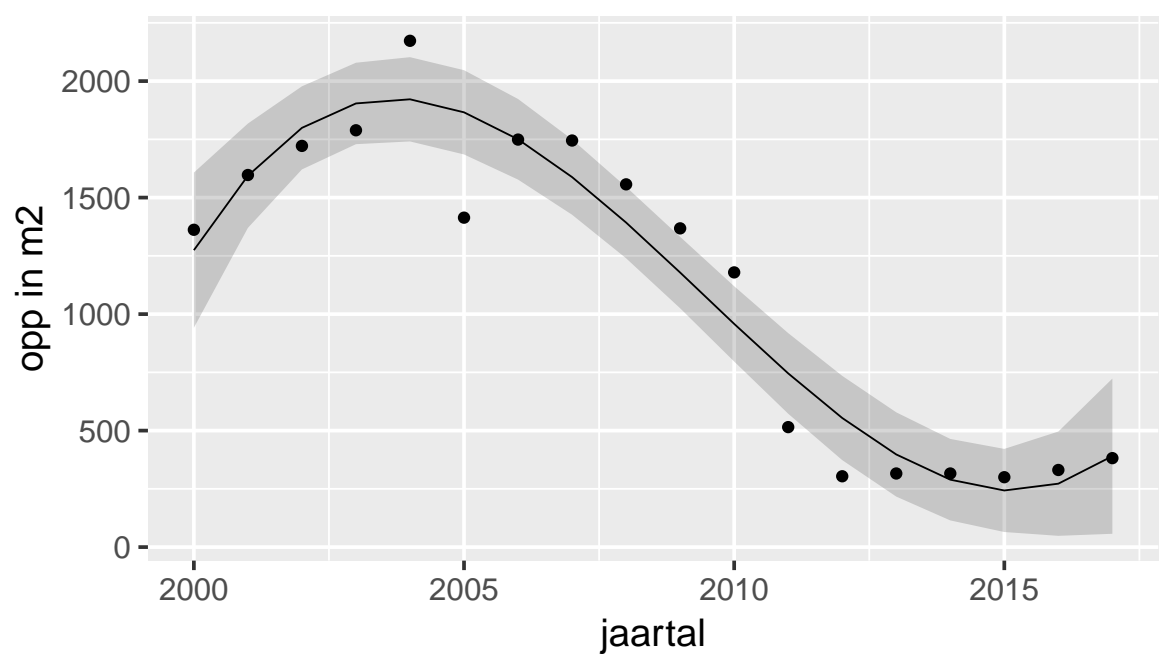

\subsubsection{Verwachting 2020}

$[290,2540]$

\subsubsection{Conclusie}

Significante trend. Stijging tot 2004 , afname tot 2015 , sindsdien terug een stijging. 


\subsubsection{Ruwe data}

\begin{tabular}{rr}
\hline Jaartal & opp in m2 \\
\hline 2000 & 35.00 \\
2001 & 87.00 \\
2002 & 204.00 \\
2003 & 306.00 \\
2004 & 376.00 \\
2005 & 496.00 \\
2006 & 1313.00 \\
2007 & 1236.00 \\
2008 & 1304.00 \\
2009 & 1372.00 \\
2010 & 1441.00 \\
2011 & 1445.00 \\
2012 & 1192.00 \\
2013 & 1173.00 \\
2014 & 1173.00 \\
2015 & 1263.00 \\
2016 & 1385.00 \\
2017 & 1539.15 \\
\hline \hline
\end{tabular}

Oppervlakte beheerovereenkomsten perceelranden

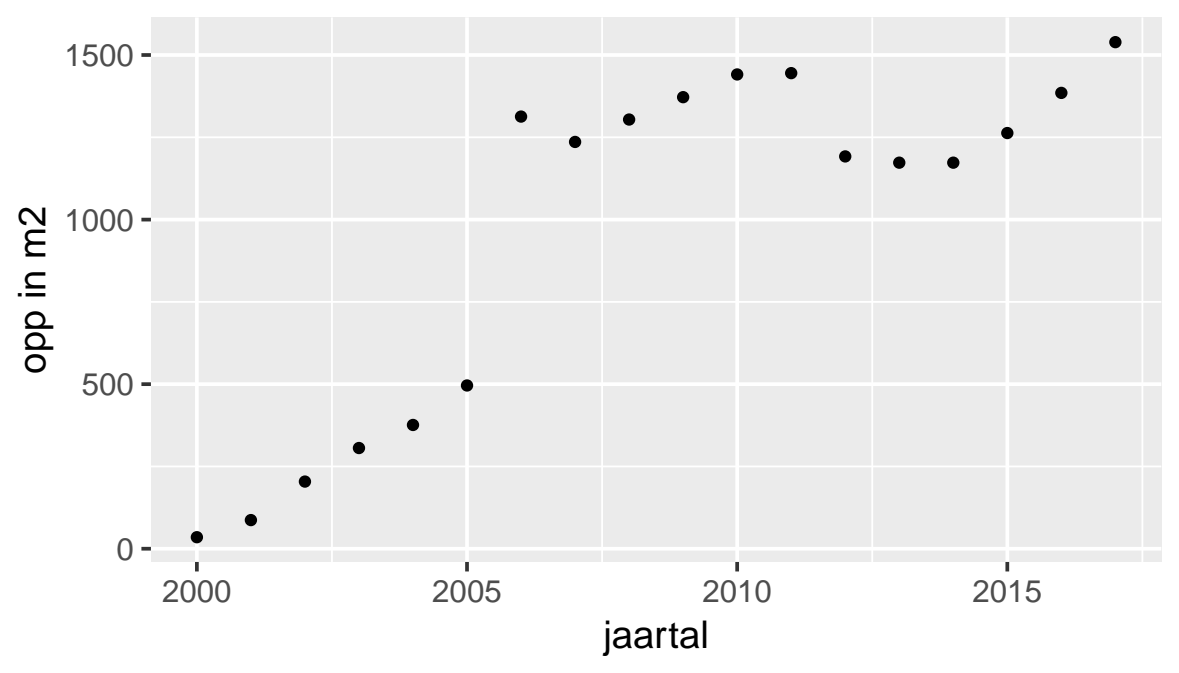

\subsubsection{Trendberekening}

Methode: Kwadratisch 


\section{Parameterschattingen}

params Estimate Std..Error statistic p.value

1 Intercept $-137.431576 \quad 136.549116 \quad-1.006463 \quad 0.3301538094$

$\begin{array}{llllll}\text { cJaar } 228.280210 & 37.247778 & 6.128693 & 0.0000193027\end{array}$

$\begin{array}{lllll}\text { cJaar2 } & -8.466641 \quad 2.114395 & -4.004285 & 0.0011492574\end{array}$

Oppervlakte beheerovereenkomsten

perceelranden

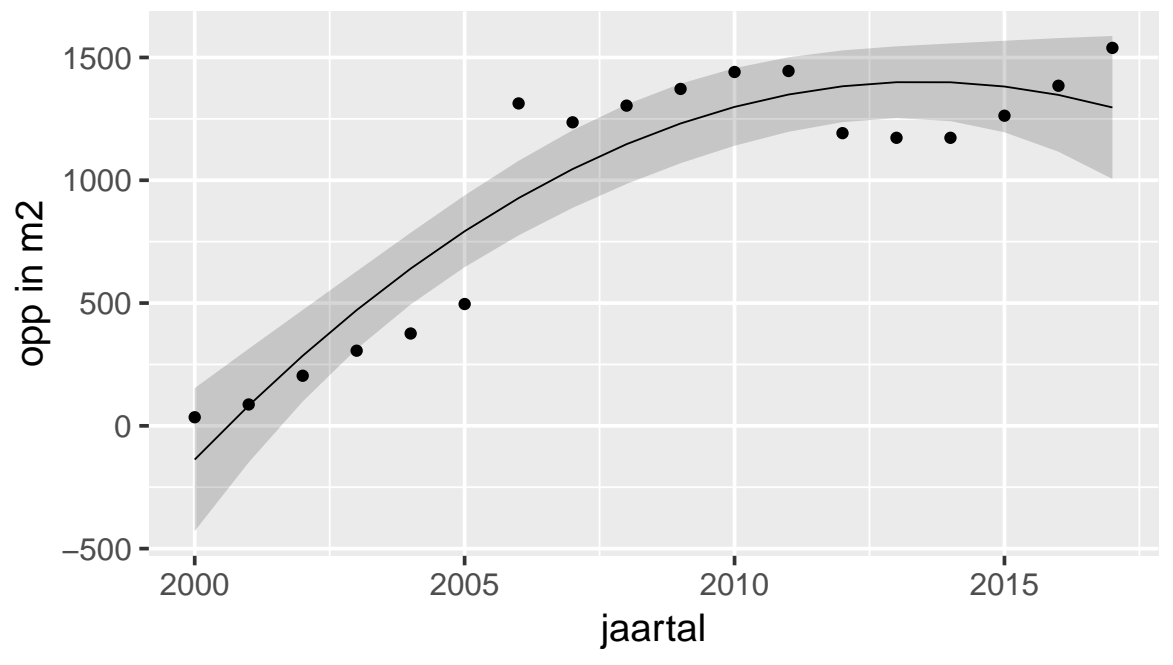

\subsubsection{Verwachting 2020}

$[331,1750]$

\subsubsection{Conclusie}

Significante trend. Afname sinds 2013. 


\subsubsection{Ruwe data}

\begin{tabular}{rr}
\hline Jaartal & opp in m2 \\
\hline 2000 & 152.00 \\
2001 & 236.00 \\
2002 & 426.00 \\
2003 & 501.00 \\
2004 & 630.00 \\
2005 & 786.00 \\
2006 & 730.00 \\
2007 & 560.00 \\
2008 & 559.00 \\
2009 & 558.00 \\
2010 & 557.00 \\
2011 & 964.00 \\
2012 & 2188.00 \\
2013 & 1296.00 \\
2014 & 1296.00 \\
2015 & 1723.00 \\
2016 & 2560.00 \\
2017 & 3110.97 \\
\hline \hline
\end{tabular}

Oppervlakte beheerovereenkomsten soortbescherming

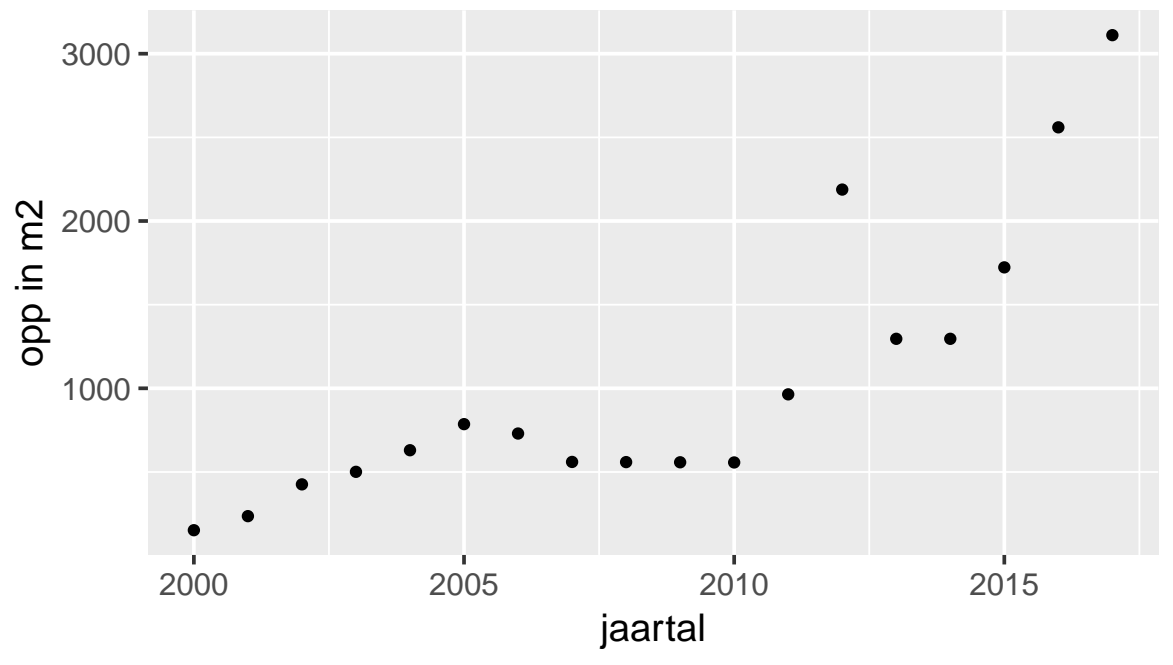

\subsubsection{Trendberekening}

Methode: Derdemacht 


\section{Parameterschattingen}

params Estimate Std..Error statistic p.value

1 Intercept $131.868307258 .0320531 \quad 0.511054 \quad 0.61727730$

$\begin{array}{lllll}\text { cJaar } 199.097729 & 135.3262243 & 1.471243 & 0.16334385\end{array}$

cJaar2 $-28.450796 \quad 18.8175781 \quad-1.511927 \quad 0.15279368$

$\begin{array}{lllll}\text { cJaar3 } & 1.571278 & 0.7267154 & 2.162165 & 0.04840679\end{array}$

Oppervlakte beheerovereenkomsten

soortbescherming

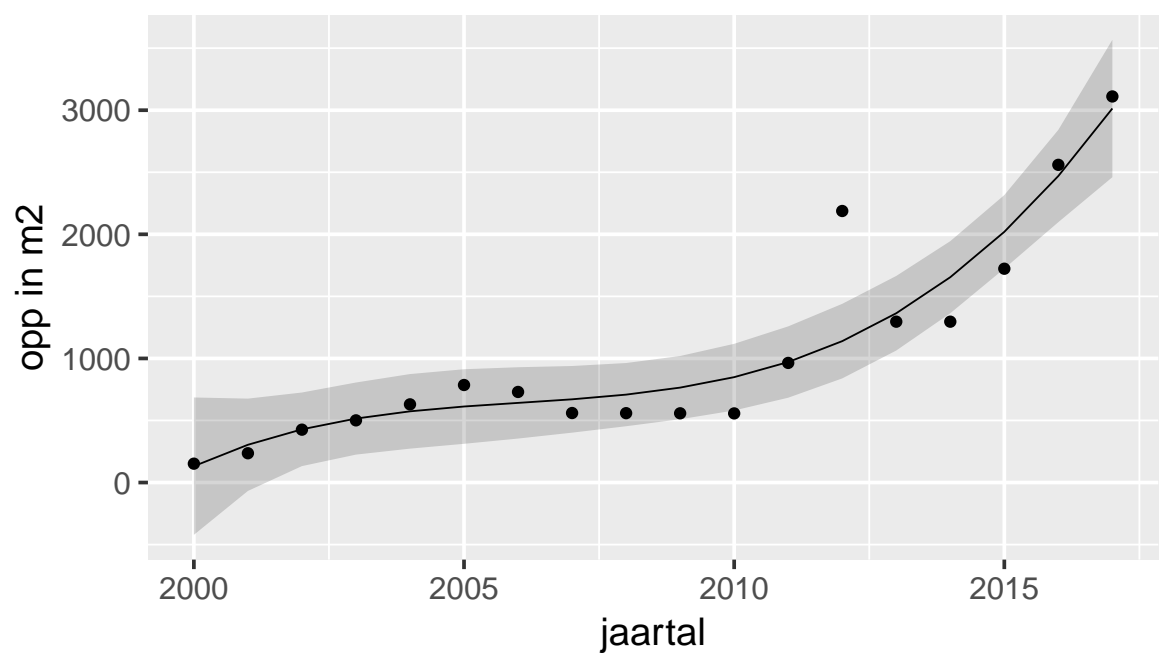

\subsubsection{Verwachting 2020}

$[3440,7170]$

\subsubsection{Conclusie}

Significante toename. 


\subsubsection{Ruwe data}

\begin{tabular}{rr}
\hline Jaartal & aantal \\
\hline 1994 & 34744.00 \\
1995 & 37622.00 \\
1996 & 77719.00 \\
1997 & 80960.00 \\
1998 & 86847.00 \\
1999 & 93136.00 \\
2000 & 101524.00 \\
2001 & 108280.00 \\
2002 & 110236.00 \\
2003 & 115830.00 \\
2004 & 157679.00 \\
2005 & 166747.00 \\
2006 & 172185.00 \\
2007 & 181121.00 \\
2008 & 136097.00 \\
2009 & 195746.00 \\
2010 & 198333.00 \\
2011 & 197347.00 \\
2012 & 199399.00 \\
2013 & 211124.00 \\
2014 & 228468.00 \\
2015 & 240987.00 \\
2016 & 247992.00 \\
2017 & 255500.00 \\
\hline \hline
\end{tabular}

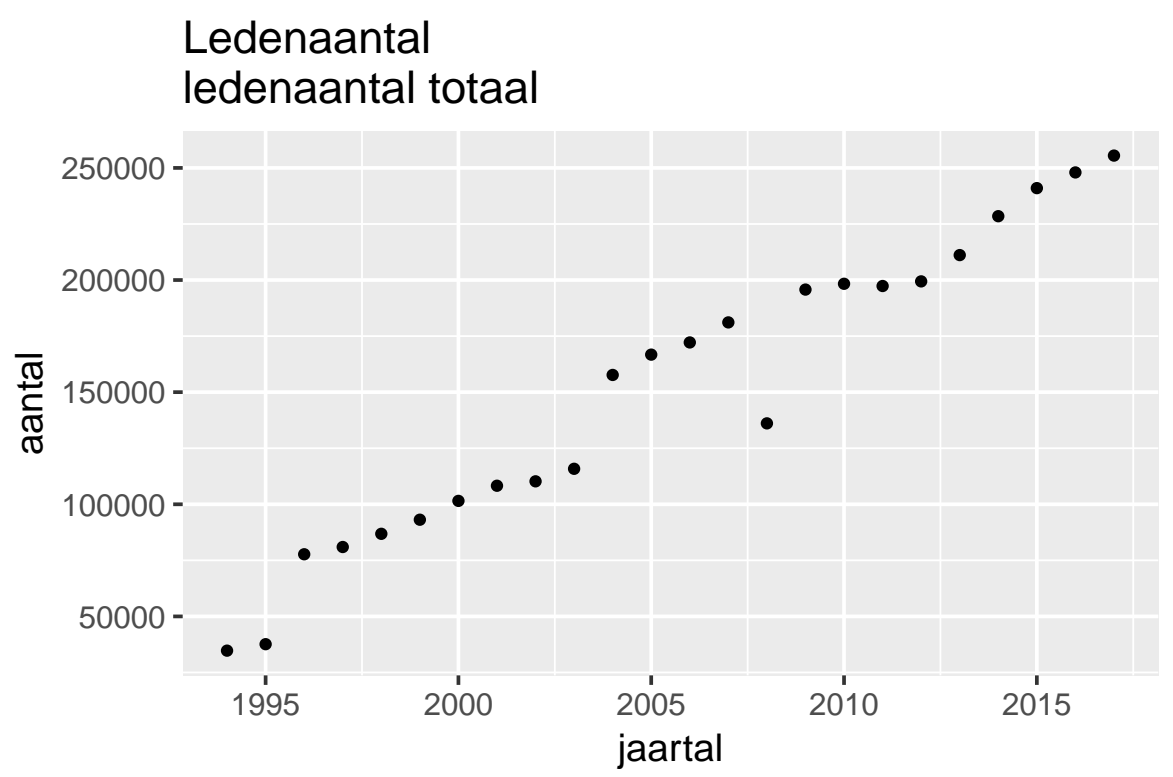




\subsubsection{Trendberekening}

Methode: Lineair

Parameterschattingen

params Estimate Std..Error statistic p.value 1 Intercept $46530.997 \quad 5427.4794 \quad 8.573224 \quad 1.836482 \mathrm{e}-08$

2 cJaar $9126.373 \quad 404.353322 .570297 \quad 1.049653 \mathrm{e}-16$

Ledenaantal

ledenaantal totaal

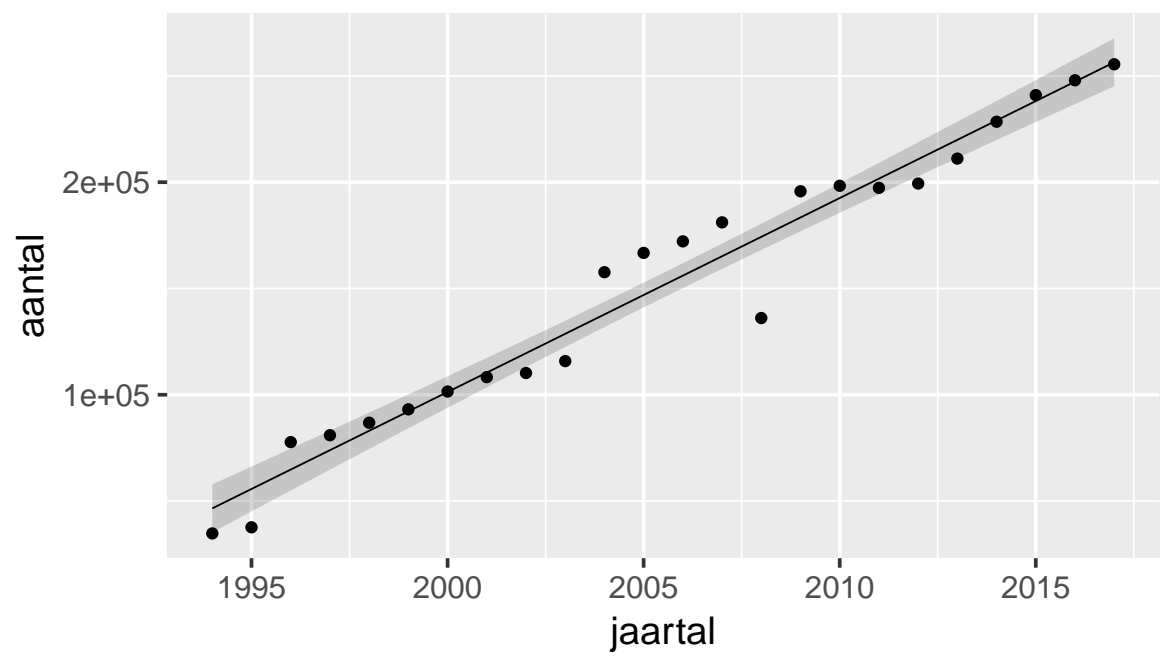

2.40.3 Verwachting 2020

[252000,315000]

\subsubsection{Conclusie}

Significante toename. 
